\author{
FEDERAL RESERVE BANK OF SAN FRANCISCO \\ WORKING PAPER SERIES
}

\title{
Does Medicare Part D Save Lives?
}

\author{
Abe Dunn \\ Bureau of Economic Analysis \\ Adam Hale Shapiro \\ Federal Reserve Bank of San Francisco
}

September 2015

Working Paper 2015-04

http://www.frbsf.org/economic-research/publications/working-papers/wp2015-04.pdf

\section{Suggested citation:}

Dunn, Abe, Adam H. Shapiro 2015. "Does Medicare Part D Save Lives?” Federal Reserve Bank of San Francisco Working Paper 2015-04.

http://www.frbsf.org/economic-research/publications/working-papers/wp2015-04.pdf

The views in this paper are solely the responsibility of the authors and should not be interpreted as reflecting the views of the Bureau of Economic Analysis, the Federal Reserve Bank of San Francisco or the Board of Governors of the Federal Reserve System. 


\title{
Does Medicare Part D Save Lives?*
}

\author{
Abe Dunn ${ }^{\dagger}$ and Adam Hale Shapiro
}

September 15, 2015

\begin{abstract}
We examine the impact of Medicare Part D on mortality for the population over the age of 65 . We identify the effects of the reform using variation in drug coverage across counties before the reform was implemented. Studying mortality rates immediately before and after the reform, we find that cardiovascular-related mortality drops significantly in those counties most affected by Part D. Estimates suggest that up to 26,000 more individuals were alive in mid-2007 because of the Part D implementation in 2006.
\end{abstract}

*We thank Ben Bridgman, Marika Cabral, Jeff Clemens, Mary Daly, Ted Frech, Matthew Grennan, Alice Henriques, Erzo F.P. Luttmer, Christopher Ruhm, Louise Sheiner, Jonathan Skinner, Dick Startz, as well as seminar participants at the Federal Reserve Bank of San Francisco, UC Santa Barbara, and the Federal Reserve System Applied Micro conference for useful comments and suggestions. We would also like to express our thanks to Ahmed Kablan for useful discussions regarding the properties of prescription drug treatments and their effects on mortality. The views expressed in this paper are solely those of the authors and do not necessarily reflect the views of the Bureau of Economic Analysis, the Federal Reserve Bank of San Francisco, or the Board of Governors of the Federal Reserve System.

${ }^{\dagger}$ Corresponding Author: Bureau of Economic Analysis, abe.dunn@bea.gov

${ }^{\ddagger}$ Federal Reserve Bank of San Francisco, adam.shapiro@sf.frb.org 
With the aim of reducing the burden of drug expenditures for the elderly, Congress passed the Medicare Modernization Act of 2003, which introduced Medicare Part D in January 2006. The reform led to a substantial expansion in prescription drug insurance coverage. Part D now covers 39 million individuals, and has cost the U.S. government a cumulative $\$ 353$ billion. $^{1}$ At the time of its inception, Medicare Part D represented the largest expansion of an entitlement program since the implementation of Medicare. Despite the enormous size of the program, there exists little evidence of any benefits of Medicare Part D in terms of health outcomes.

This study presents new evidence on the impact of Medicare Part D, and more broadly, the effect of prescription drug coverage expansion on mortality. There are several reasons to believe that the reform may have had an impact on mortality. Nearly half of drug expenditures are spent on treatments to prevent cardiovascular-related deaths. These drugs include some of the most innovative and effective treatments for preventing heart disease, the leading cause of death in the United States. Second, the Act improved the affordability of prescription drugs. The financial incentives from expanding drug insurance may be particularly important, since before the reform prescription drugs accounted for around 42 percent of out-of-pocket spending, even though drugs accounted for just 18 percent of total medical expenditures. In addition, numerous studies have shown that financial incentives encourage the chronically ill to start treatment and also improve adherence to medications (Eaddy et al. (2012), Solomon et al.(2009) and Cutler and Everett (2010)).

By contrast, Medicare Part D may have had only a limited effect on mortality, if, for instance, those individuals in need of prescription drugs had already purchased prescription drug insurance before the reform. That is, the impact on mortality of prescription drug coverage expansion is likely to be less than under random assignment. Overall, it remains unclear whether Medicare Part D had any impact on the mortality rate of elderly individuals.

Our identification strategy relies on geographic differences in insurance coverage across U.S. counties before the reform's implementation. Using the Medicare Current Beneficiary Survey (MCBS), we estimate demographically adjusted rates of prescription drug coverage for age $65+$ Medicare enrollees across counties before the implementation of Part D. We find that those areas with lower levels of coverage before the reform experienced greater drug insurance expansion as a result of Part D. ${ }^{2}$ This information is combined with county-

\footnotetext{
${ }^{1}$ Source: Congressional Budget Office, 2014.

${ }^{2}$ We also show that pre-reform levels of drug insurance are strongly and negatively related to the observed increase in drug coverage post-reform, providing the basis for the identification strategy applied
} 
level mortality data obtained from the Centers for Disease Control and Prevention (CDC) for the years 2000 to 2010. We then examine whether those areas most impacted by the reform have a larger reduction in mortality post reform.

While this type of geographic variation has been employed in other studies, ${ }^{3}$ there are a few additional factors introduced in this study that are critical for identifying the effects on mortality. First, it is important to analyze the effects of mortality by disease category. We focus on measuring the effects of mortality on two categories: (1) cardiovascular-related conditions (e.g., heart disease, stroke, and heart attacks) and (2) all other conditions (e.g., cancers and pneumonia). We find strong persistence in the disease-specific cause of death within counties over time, implying county-disease fixed effects are important for accounting for the health across these populations.

Second, it is essential to consider how the reform affects the population's health in future periods. If drug insurance expansion is successful it will improve the survival of those who would have died without the reform - that is, those with relatively poor health. This implies that in subsequent periods the population of individuals living with a serious chronic health condition will increase, which may affect mortality rates in future years. This effect is likely to be more pronounced for chronic conditions and especially in those counties where Part D had a stronger impact on mortality. Considering this type of dynamic effect, which we call "delayed mortality," is crucial when studying health care and mortality in the United States since chronic conditions cause seven out of ten deaths each year. ${ }^{4}$

We present two alternative strategies for measuring the impact of the reform, which both address the delayed mortality issue. One approach is to focus on the immediate impact of the reform just after implementation. Since this is the population that is initially affected by the reform, it is most comparable to the health of the population prior to the reform. Specifically, we focus on the mortality effects for those dying immediately following the reform from July 1, 2006, and June 30, 2007. ${ }^{5}$ The second approach measures the effect on mortality for the entire post-period of our sample from 2006 to 2010, but includes controls designed to remove the effects of delayed mortality. That is, we estimate a model which

in this paper.

${ }^{3}$ This approach is similar to Finkelstein (2007) looking at the effects of the 1965 introduction of Medicare and Dunn and Shapiro (2015) looking at the effects of Massachusetts insurance reform.

${ }^{4}$ They also account for 75 percent of health care costs. These statistics are from the Centers of Disease Control and Prevention (http://www.cdc.gov/chronicdisease/overview/).

${ }^{5}$ Ketcham and Simon (2008) use large monthly pharmaceutical data that highlight the timing of Part D effects. It appears most of the impact on out-of-pocket cost and utilization occurred by early to mid-2006. 
accounts for dynamic effects of the reform.

Across a range of estimates, we find that the probability of a cardiovascular-related mortality drops significantly, while mortality rates for noncardiovascular causes of death remain statistically unchanged. Estimates suggest that between 7,000 and 26,000 more individuals were alive in mid-2007 because of the Part D implementation in 2006. We conduct numerous robustness checks to confirm the reduction in cardiovascular-related mortality is statistically significant. For example, weighting by population, including county-specific trends or county disease-specific trends produces similar results. Furthermore, the estimates provide evidence of a delayed mortality effect. Specifically, estimates using the dynamic model show that those counties which experienced larger declines in mortality due to the reform had larger rebounds in mortality the subsequent year.

We also find evidence that Part D caused a decline in cardiovascular mortality over and above its impact on the near elderly (i.e., ages 55 to 64) in the same county. Despite this evidence, we do not use the near elderly in our main analysis because they are not an appropriate control group. In particular, we find that Part D had a significant, albeit smaller, impact on the cardiovascular mortality rate of the near elderly. Indeed, around 17 percent of Medicare enrollees are below the age of 65 and are relatively unhealthy as they must be disabled, have end stage renal disease, or Amyotropic Lateral Sclerosis (ALS) to qualify for Medicare. We show that the reduction in mortality for the near elderly is concentrated in those counties with a higher share of medicare individuals below 65. Importantly, our results imply that an analysis that uses the near elderly as a control group to measure the implied effects of Part D will understate the true effects of the reform.

To better understand the total value of the Part D expansion, we measure the effects of Part D on prescription drug expenditures using the MCBS data. As expected, those areas predicted to be most affected by the reform had the largest increase in drug expenditures. We find that the increase in spending occurs in 2006, corresponding with patterns found in other work. Overall, the reforms are associated with a 28 percent reduction in out-of-pocket cost sharing and a 10 percent increase in drug expenditures. Across several estimates, we find that the predicted changes in response to the reform imply a price elasticity of demand between -0.2 and -0.4, which corresponds roughly to other estimates in the literature (e.g., Newhouse (1993) and Chandra et al. (2010)).

The growth in expenditures caused by the reform are compared to the monetized benefit of lives saved with the aim to better understand the overall value of the reform. Based on a $\$ 200,000$ monetary value of a life-year, ${ }^{6}$ we find that the additional value of life-years gained

\footnotetext{
${ }^{6}$ This is the amount applied in Eggleston et al. (2011).
} 
is between $\$ 1.5$ and $\$ 4.8$ billion, which greatly exceeds the additional out-of-pocket costs for cardiovascular-related drugs of $\$ 800$ million. In fact, for most of our key specifications, the total benefit exceeds the total estimated additional spending on cardiovascular drugs from the program of $\$ 3.5$ billion. ${ }^{7}$ When the financial risk protection of the program is also considered (see Engelhardt and Gruber (2011)) it is likely that the benefits of the program greatly outweighed the deadweight loss of the reform across all scenarios. ${ }^{8}$

Although this study assesses solely prescription drug expansion, it is related to a broader literature discussing the link between health insurance and health outcomes. The wellknown RAND study, a randomized trial of health insurance coverage across the population (Newhouse (1993)), found that insurance generosity had only a limited impact on health. More recently, a randomized experiment in Oregon found no statistically significant relationship between Medicaid coverage and measured physical outcomes after two years (Baicker et al. (2013)). By contrast, Card, Dobkin and Maestas (2009) apply regression discontinuity analysis and find lower mortality rates and higher service utilization for Medicare patients admitted to emergency departments, relative to individuals under age $65 .{ }^{9}$ Our study shows that a subset of health insurance, specifically prescription drug coverage, has had clear positive effects on health outcomes, mainly stemming from the improved health for those with cardiovascular-related diseases. It is important to emphasize that this paper measures the estimated lives saved by the Part D program due to insurance expansion. Prior to the expansion, one may expect that those with the highest need for prescription drugs would have purchased insurance, if possible. For this reason, we expect the expansion effect to understate the full effect on mortality relative to randomized assignment.

\footnotetext{
${ }^{7}$ Even if he monetary value of a life-year is set at $\$ 100,000$, the value of life-years gained from the reform matches or exceed the additional out-of-pocket costs on cardiovascular drugs caused by the reform.

${ }^{8}$ Engelhardt and Gruber (2011) measure the value of financial risk protection from the Part D program and find that it roughly equals the deadweight loss of financing Part D. Their cost-benefit analysis did not consider the potential health benefits of the Part D program.

${ }^{9} \mathrm{An}$ examination of the introduction of Medicare in 1965 shows no effect of Medicare expansion on mortality (Finkelstein and McKnight (2008).
} 


\section{Background on Medicare Part D and Drug Spend- ing}

Medicare was established in 1965 and provides insurance coverage to those age 65 and older, as well as certain disabled populations. Although the program covered most medical care expenditures, such as hospital and doctor office expenditures, it did not cover prescription drug costs. In 1965 this was not viewed as a serious omission, since prescription drugs accounted for only a small fraction of total expenditures. However, in subsequent years numerous breakthroughs in the pharmaceutical sector led to innovative treatments that greatly increased expenditures on prescription drugs. Just before the reform, the total average per capita expenditures on prescription drugs for the $65+$ population was $\$ 1,743$ per year in 2004-05 (about 18 percent of total medical expenditures).

With the aim of reducing the burden of drug expenditures for the elderly, Congress passed the Medicare Modernization Act of 2003, which introduced Medicare Part D in January 2006 and led to a substantial expansion in prescription drug coverage. Unlike traditional fee-for-service Medicare that is administered by the federal government, Medicare Part D coverage is offered through private-sector insurers that are under contract with the government. Individuals can obtain insurance through three distinct alternatives. One option is to purchase a stand-alone Medicare Prescription Drug Plan (PDP), that offers prescription-drug benefits. Another option is to purchase a private Medicare Advantage plan, an alternative to traditional fee-for-service Medicare, that provides all the benefits associated with fee-for-service Medicare but often includes additional benefits, such as prescription drug coverage. The third option is to retain their existing drug coverage that they received through their current employer, as long as the plan's benefits are comparable to the generosity of a standard Part D plan or better. ${ }^{10}$

Indeed, the passage of Medicare Part D had a large effect on the number of people with drug insurance coverage. Using measures constructed in this paper, in 2004 around 67 percent of the elderly Medicare population had drug coverage, but that percentage grew to more than 90 percent by 2007. However, connecting the measure of drug insurance expansion to changes in mortality rates is challenging, as illustrated in Figure 1. Figure 1 shows the trend in mortality rates for the $65+$ population for both cardiovascular and noncardiovascular causes, along with the fraction of the population with drug insurance.

\footnotetext{
${ }^{10}$ In 2006, a standard Part D plan included no coverage for the first $\$ 250$ in drug costs for each year. The plan covered 75 percent of the cost for the next $\$ 2,250,0$ percent of the drug expenditures for the next $\$ 3,600$, and 95 percent of drug spending above $\$ 5,100$.
} 
The graph illustrates two points. First, there appears to be no obvious effect of drug insurance coverage on either category of mortality at the national level. ${ }^{11}$ Second, the mortality rate for cardiovascular-related conditions is falling over the entire time period, even prior to Part D implementation. The increased use of prescription drugs to treat cardiovascular-related conditions is likely a contributing factor to this decline. ${ }^{12}$

Figure 1: Mortality and Drug Coverage Over the Reform Period

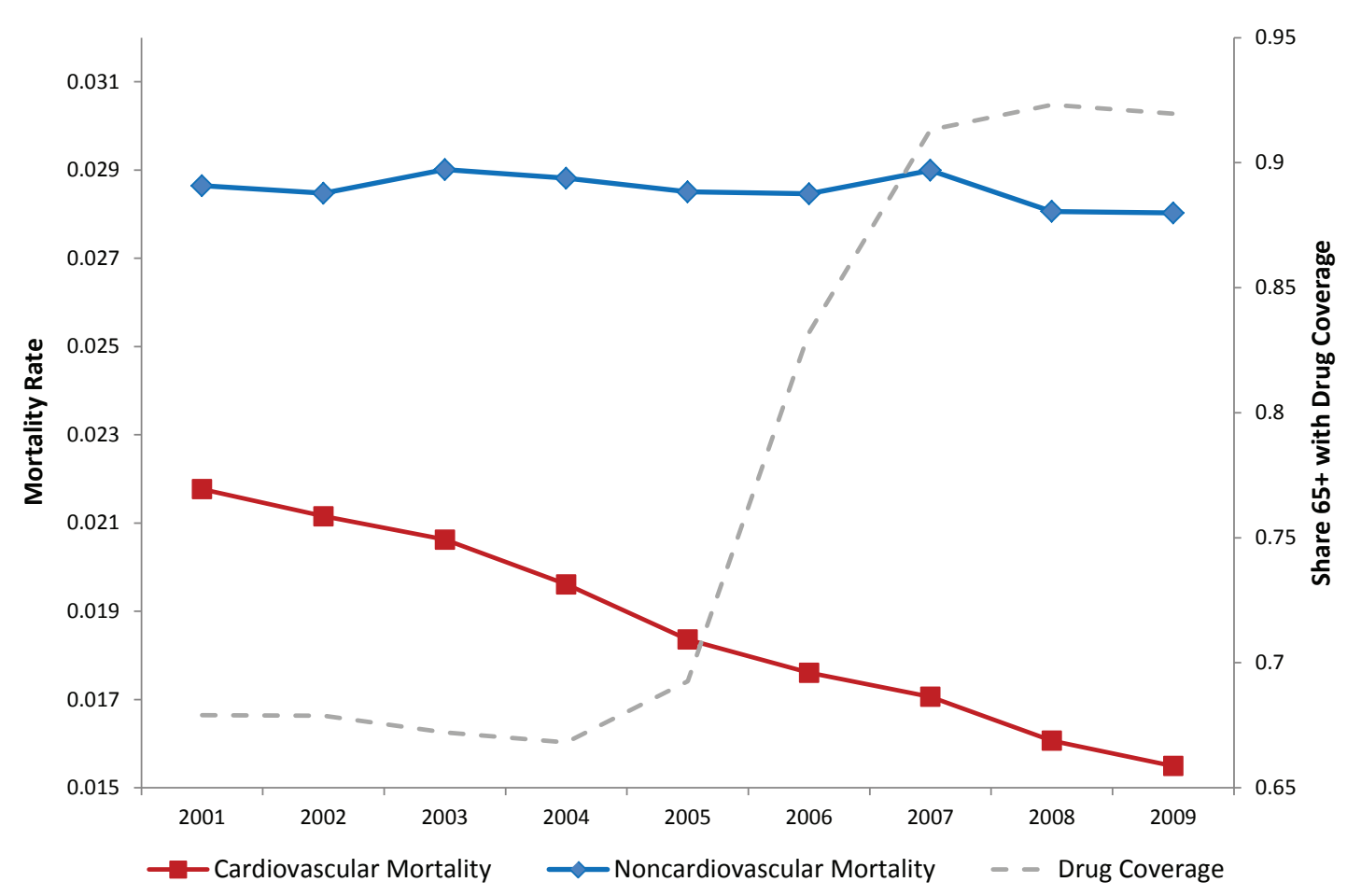

Notes: Authors' calculations based on CDC and MCBS data.

While the trend of falling cardiovascular-related deaths occurred both before and after the reform, this entire period is also marked by a continued rise in the use of cardiovascular drugs. Figure 2 divides cardiovascular-related drug use into the number of prescription drug purchases for the $65+$ population by drug category, with the bottom three shades accounting for the major cardiovascular drug categories. These three therapeutic classes of drugs are particularly effective at treating cardiovascular illnesses and preventing

\footnotetext{
${ }^{11}$ About 1.8 million individuals over the age of 65 die each year, so it may be challenging to identify the thousands of individuals who lived due to Part D reform using national aggregate mortality statistics.

${ }^{12}$ Cutler (2004) argues that roughly one-third of the decline in cardiovascular-related mortality may be attributable to innovative prescription drugs that control hypertension and high cholesterol. The growth in anticholesterol drug use is particularly rapid in the early 2000s (see Dunn (2012)).
} 
cardiovascular-related deaths. The largest category is antihyperlipidemic agents, which is a category of drugs used to treat high cholesterol, one of the leading causes of heart disease. In numerous clinical trials, anticholesterol drugs have proven effective at reducing cardiovascular deaths (LaRosa et al. (1999) and Law et al. (2003)) and this category of drugs underwent substantial expansion and innovation in the preceding decade (Dunn (2012)). The second category of cardiovascular agents includes a variety of antihypertensive drugs used to treat high blood pressure, such as oral diuretics, calcium channel blockers, beta-blockers, angiotensin-converting enzyme (ACE) inhibitors, and angiotension-receptor antagonists, all of which have been shown to substantially reduce the risk of mortality, stroke and heart attacks (Cutler et al. (2007)). The smallest of these three categories, based on expenditures, is the coagulation modifiers. Coagulation modifiers include a variety of drugs that are used to prevent clots from forming in blood vessels and to prevent strokes. Like other categories of drugs, these have also been proven highly effective in reducing cardiovascular-related mortalities (Antithrombotic Trialists' Collaboration (2002)). Combined, these three drug categories account for 48 percent of expenditures for individuals 65 and older over the 2003-09 period, and they account for an even greater share of pharmacy purchases, around 53 percent. ${ }^{13}$

Most of these types of cardiovascular drugs have been shown to have an immediate impact on an individual's health. The timing of the benefits of drugs used to treat hypertension is well documented. For instance, two well-known clinical trials performed in the 1960s by the Veterans Administration Cooperate Study Group (VACG (1967, 1970)) found strong evidence that hypertension drugs are effective within a small time frame. One trial consisted of 143 male hypertensive patients with very high diastolic blood pressure, averaging between 115 and $129 \mathrm{~mm} \mathrm{Hg}$. Over the course of the trial period, there were no deaths in the treated group and four deaths in the placebo group. Three of these four deaths occurred within the first six months of the trial period. The second VACG trial examined hypertensive males with less severe diastolic blood pressure - between 90 and $114 \mathrm{~mm} \mathrm{Hg}$. Drug treatment was shown to reduce the risk of death from 55 percent to 18 percent over a five-year period, with effects beginning in the first year of treatment.

More recent clinical trials of drugs used to treat hypertension have been conducted on older patients, as well as patients with isolated systolic hypertension. For instance, a trial by the SHEP Cooperate Research Group (SHEP (1991)) examined the effect of a

\footnotetext{
${ }^{13}$ Estimates obtained from Medical Care Expenditure Panel Survey data. The same drug categories were not reported consistently in the years prior to 2003, so only post-2003 prescription drug purchases are shown in Figure 2.
} 
low-dosage of chlorthalidone on individuals over the age of 60 . The trial found that the incidence of total stroke (i.e., fatal and nonfatal) was reduced by 36 percent over five years, with large effects within 18 months of treatment (see Figure 2 of the study on page 3259). Results from the Swedish Trial in Old Patients with Hypertension (Dahlof et al. (1991)), focused on older individuals (ages 70 to 84) with hypertension. The study found that drug treatment reduced the risk of death within one year of treatment.

Results from clinical trials on statins began being reported in the early 1990s. The Cholesterol Treatment Trialists' (CTT) Collaboration summed up many of these trials in a meta-analysis based on individual patient data. The study showed efficacy across a broad range of patients (CTT Collaborators (2005)). In particular, there was a large reduction in fatal coronary heart disease and nonfatal myocardial infarction in the first year of treatment. Certain studies show large immediate impacts on mortality for sicker individuals. For instance, a study by the Blood Pressure Lowering Treatment Trialists' Collaboration (BPLTT Collaboration 2003) examined the impact of atorvastatin on patients with lowerthan-average cholesterol, but who had hypertension. The study showed that the risk of fatal coronary heart disease or non-fatal myocardial infarction fell significantly in the first year of follow-up. A later meta-analysis by the CTT (CTT Collaborators 2008) showed similarly strong effects on mortality for patients with and without diabetes within one year of treatment. More recent meta-analyses have shown that statins may reduce major cardiovascular events for patients without any cardiovascular disease (CTT Collaborators 2010, 2012).

The noncardiovascular expenditures are likely to have a relatively small impact on mortality. Cancers, which are the second leading cause of death for the over 65 age group, accounted for less than 3 percent of total drug expenditures around the time of the reform. In addition, much of expenditures on prescription drugs that are not for the treatment of cardiovascular related conditions are for musculoskeletal conditions, digestive conditions, or mental health, which have less of an immediate impact on mortality.

From Figure 1 we do not observe any sharp changes in mortality rates, despite the substantial evidence that Part D increased prescription drug utilization (i.e., Lichtenberg and Sun (2007), Ketcham and Simon (2008), Khan and Kaestner (2009), and Duggan and Scott-Morton (2010)). To identify the effects of Part D on mortality, this paper exploits geographic differences in drug insurance coverage before the reform. Prior to the reform, drug insurance coverage across geographic markets was influenced by several factors, such as the availability of Medicare Advantage plans, which frequently offered drug coverage. Drug coverage was also influenced by the eligibility requirements for Medicaid 
Figure 2: Prescription Drug Purchases Over the Reform Period

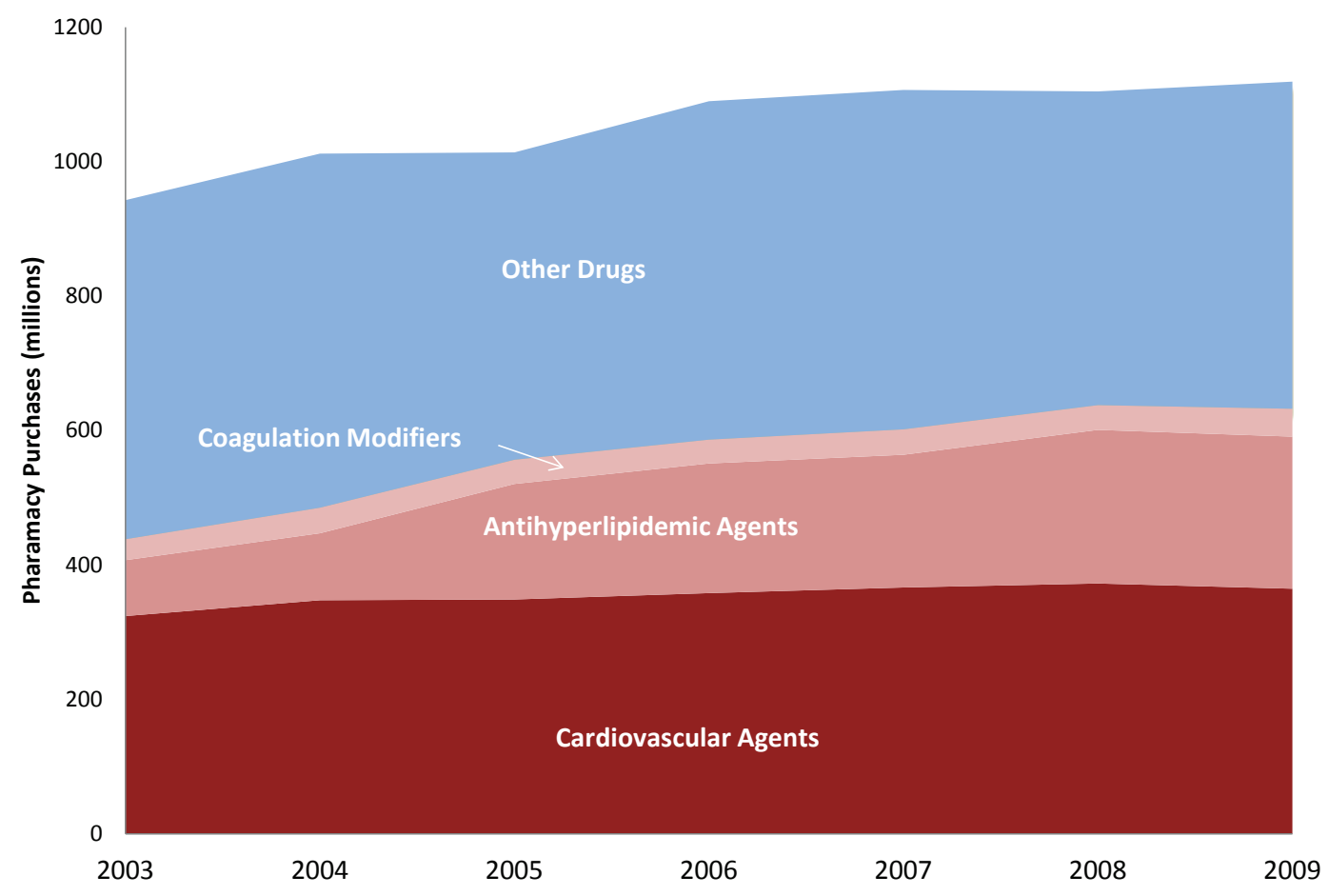

Notes: Authors' calculations based on data from the Medical Expenditure Panel Survey.

in the state, the prevalence of employers offering prescription drug coverage to retirees, and other socioeconomic factors. As we show later, those areas that had lower levels of drug coverage before the reform are also the areas that had higher levels of drug utilization expansion.

The MCBS dataset used to estimate drug coverage in Figure 1 is not large enough to investigate the precise month that Part D had an effect on prescription drug utilization, since some purchases of Part D plans occurred later in 2006. However, two papers in the literature provide strong evidence of the timing of Part D's impact on utilization. Ketcham and Simon (2008), use a large database of pharmacy claims, covering about 31 percent of the nation's prescriptions and covering 80 percent of U.S. counties, and find that most of the expansion in prescription drug utilization occurred quite rapidly in the first few months of 2006. Similar timing is observed by Lichtenberg and Sun (2007) using distinct pharmacy claims data from Walgreens. Although the MCBS data in our paper cannot be used to look at monthly changes, we are able to examine annual changes in prescirption drug purchases. 
Consistent with these papers, we find drug expenditures increased significantly in 2006 in those counties most impacted by Part D. We also find that this higher level of spending persisted for years after the reform. Therefore, considering mid-2006 to mid-2007 as the initial 12 months that Part D would have an impact on mortality seems appropriate.

An alternative strategy for identifying the effects of reform on mortality is to see how mortality rates of individuals aged 65 and over have changed relative to a younger but comparable population, the population aged 55-64. Indeed, we also explore differential effects of Part D on this population in our analysis as additional proof of identification. However, a major issue with this approach is that around 7 percent of the 55-64 population qualifies for Medicare based on their disabilities, but this insurance information is not available in the mortality data. This population is relatively unhealthy, accounting for around 18 percent of total medical expenditures for the 55-64 age category, and the reported rate of cardiovascular conditions in this population is actually much more prevalent than in the 65-69 age range. ${ }^{14}$ In fact, the annual mortality rate for the 55-64 age category enrolled in Medicare is about 3 percent compared to less than 1 percent for the general population in that age range. In addition, Part D had a substantial impact on prescription drug coverage for the under 65 Medicare population, increasing the share of the under 65 Medicare enrollees with drug coverage from around 70 percent to 90 percent. Therefore, the introduction of Part D will likely have a disproportionate effect on the mortality of the Medicare subpopulation in the 55-64 age range, potentially leading to an underestimation of the total mortality effect. ${ }^{15}$ We provide evidence that comparing to the 55-64 population could substantially understate the effects of Part D, due to the Medicare eligible population in this age range.

\footnotetext{
${ }^{14}$ For instance, 11 percent of the 55-64 population have atherosclerosis, while just 7 percent of the $65-69$ population have this condition. Hypertension and diabetes are also more prevalent in the 55-64 Medicare population. This estimate is obtained from the MCBS data for the years 2001-2009.

${ }^{15}$ Moreover, there may be spillover effects, since the increase in the use of prescription drugs by the elderly could lead to increased use for other populations through a number of mechanisms. These could be either social effects of peers, effects through the prescribing patterns of physicians, or the impact of expanding the private insurance market on bargaining for the non-Medicare commercial market (see Lakdawalla and Yin (2014)).
} 


\section{Drug Insurance Coverage Expansion and Expected Effects on Mortality}

Assessing the impact of drug insurance expansion on mortality includes a number of empirical challenges. To highlight these challenges and also help motivate our empirical approach, we begin by discussing the hypothetical effects of an insurance expansion on mortality rates.

Figure 3 shows a hypothetical effect of drug insurance expansion on mortality. On the $\mathrm{X}$-axis of the figure is a timeline and the $\mathrm{Y}$-axis includes the two main mortality rates studied in this paper, cardiovascular-related mortality and noncardiovascular-related mortality. We normalize the mortality rate for both categories to 4 percent before the reform. The annual mortality rate is measured over a one-year period and represents the share of the population that dies in the following year, which is calculated based on a ratio of the number of deaths in the following year divided by the total population. For example, the mortality rate in period $t$ captures the share of the population at time $t-1$ that dies over the following year. The timeline includes the pre-Part D period when mortality rates are constant, as well as the point of drug insurance expansion at time period $t-1$.

Panel A shows the impact on the mortality rate under the assumption that prescription drugs have a large beneficial health effect on cardiovascular-related illnesses. Here there is a permanent decline in the level of cardiovascular mortality rate, and no impact on the noncardiovascular mortality rate. Panel A, however, ignores the fact that those saved by the reform are likely in poor health status - that is, they are on the margin of dying. This poses two additional likely effects of the Medicare Part D health reform.

First, those individuals saved by the reform likely have numerous comorbidities. Once saved, these individuals are more likely to die of an alternative cause. In other words, different disease categories are competing risks. Second, those individuals saved by the reform likely have more severe forms of cardiovascular or noncardiovascular disease, and therefore represent a sicker population. Thus, the periods after the reform will appear to have a less healthy population, which increases the proportion of those dying from any disease. Similar types of "harvesting" effects have been documented by researchers studying the impact of weather and air quality on mortality (e.g., Lee (1981), Hajat et al. (2002), Schwartz (2001), and Deschenes and Moretti (2009)), but to our knowledge, this phenomenon has not been studied in the context of Medicare Part D.

These two additional effects are included in Panel B. The competing-risks effect causes the mortality rate for noncardiovascular deaths to increase-once being saved, the indi- 
vidual is more likely to die of something other then cardiovascular disease. ${ }^{16}$ The delayedmortality effect causes both cardiovascular- and noncardiovascular-related mortality to increase in later periods. This reflects the fact that those (likely sicker) individuals saved from a cardiovascular-related death in period $t$ enter the population of period $t+1$, raising the mortality rate for any cause. ${ }^{17}$

The magnitude of these effects will depend on the health of the population that survives due to reform. Interestingly, we should expect that the health of the population in the post-reform periods will be quite distinct from the population in the pre-reform period, precisely when the effect on mortality is larger. Therefore, one might expect this secondary effect to be strongest in those areas where Part D has the greatest impact.

\section{Figure 3: Hypothetical Effects of Drug Insurance Expansion}

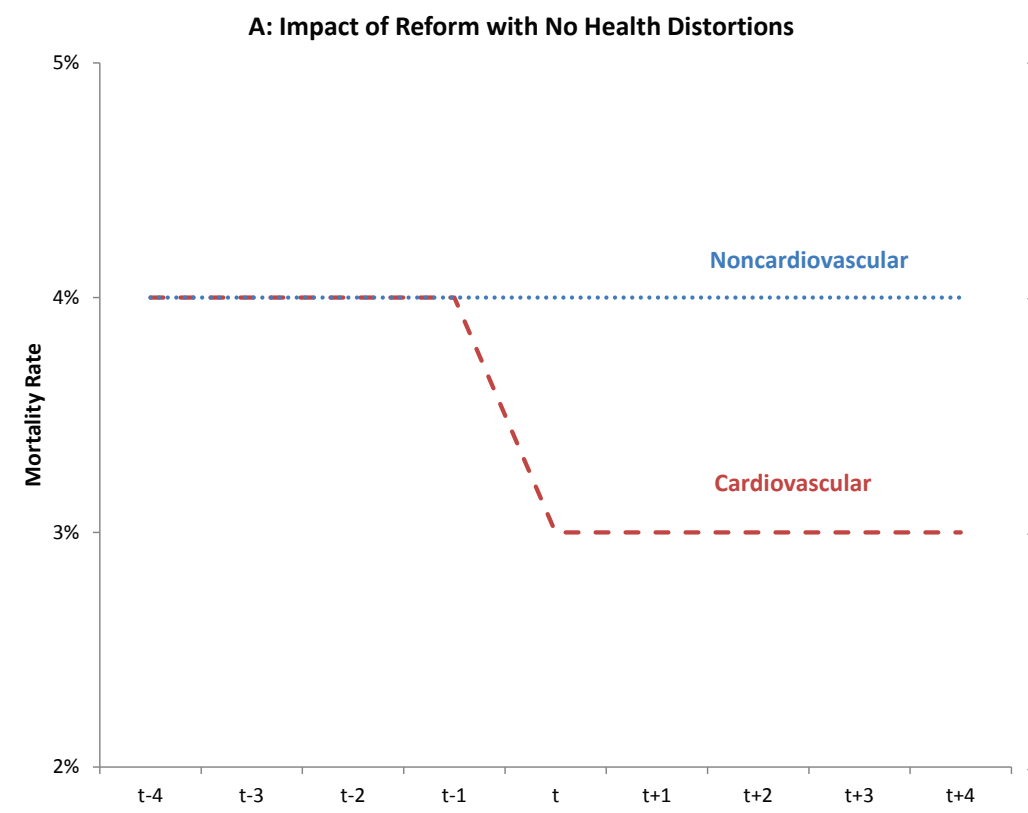

B: Impact of Reform with Delayed Mortality and Competing-Risk Effects

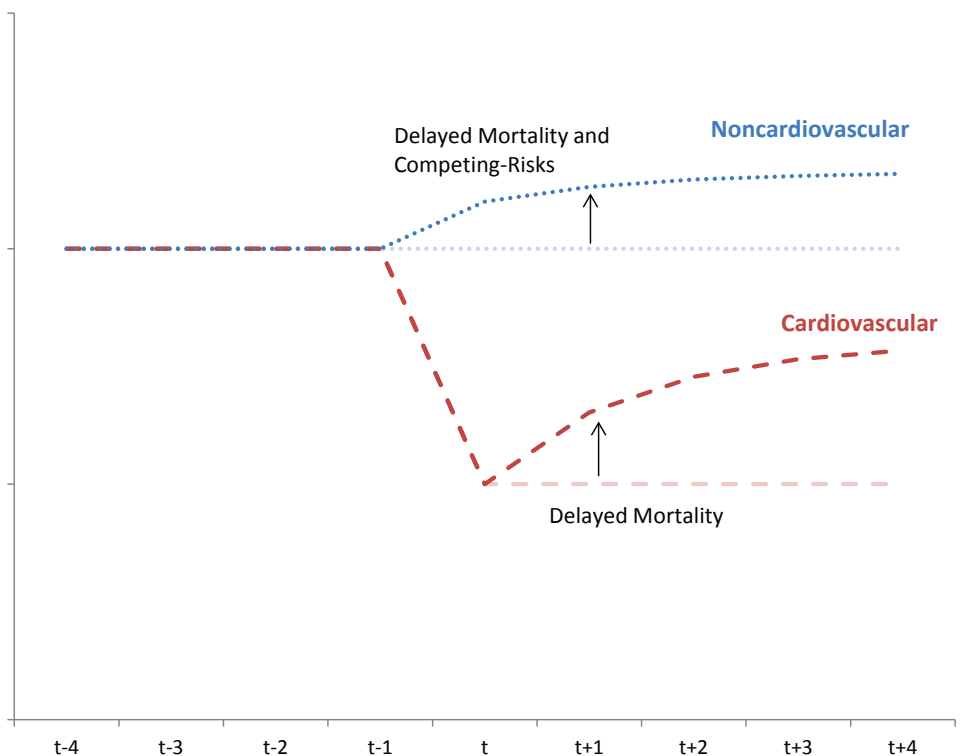

\footnotetext{
${ }^{16}$ This illustrative figure is based on a simulation that posits:

$\operatorname{Pr}($ dying from a noncardio disease in $\mathrm{t} \mid$ "saved" by reform in $\mathrm{t})=20 \%$.

${ }^{17}$ This illustrative figure is based on a simulation that posits:

$\operatorname{Pr}($ dying from any disease in $\mathrm{t}+1 \mid$ "saved" by reform in $\mathrm{t})=50 \%$

$\operatorname{Pr}($ dying ......................... $\mathrm{t}+2 \mid$ "saved" ....... $\mathrm{t}$, lives to $\mathrm{t}+1)=25 \%$

$\operatorname{Pr}($ dying .......................... $\mathrm{t}+3 \mid$ "saved" ....... t, lives to $\mathrm{t}+2)=12.5 \%$

$\operatorname{Pr}($ dying .......................... $\mathrm{t}+4 \mid$ "saved" ....... t, lives to $\mathrm{t}+3)=6.25 \%$
} 
The parameters used in constructing Figure 3 were chosen for illustrative purposes, but the patterns in this figure offer several insights that will help guide the measurement of the effects on mortality. One lesson implied by Figure 3 is that identifying the timing of the effects of the reform is critical. Measuring the effects of reform on mortality in later periods may not accurately capture the effects of the reform. For example, the mortality rate several years after the reform might look similar to the mortality rate before the reform simply because the post-reform population includes sicker individuals previously saved by the reform. In other words, the delayed mortality effect is caused by an unobserved change in the health of the population that is related to the reform, which may introduce a bias when measuring the effects of the reform in periods beyond the immediate post period. This bias is likely to be negatively correlated with the impact of Part D on the mortality rate. Therefore, in order to identify the effects of insurance expansion on mortality in later periods, it may be important to account for the changes in the health of the population caused by the reform. Another lesson learned from Figure 3 is that the changes in the disease-specific mortality rates may be more appropriate than looking at changes in total mortality if Part D had a differential effect on mortality for cardiovascular disease.

\section{Data}

The data for this study are from two main sources. One data source is the MCBS data from 2001 to 2009. The MCBS is an annual survey administered by the Center for Medicare and Medicaid Services (CMS) that randomly surveys about 12,000 individuals from the full Medicare population each year. The second data source is the micro mortality data from the Centers for Disease Control and Prevention (CDC). These two data sources are described below. Additional data sources are also incorporated in our analysis and will be discussed briefly at the end of this section.

The MCBS data contain a variety of demographic and medical-care information on individuals in the survey. The demographics include the age, sex, education, income, and perceived health status of the individuals. The survey also includes questions regarding 26 specific health conditions. In addition to these questions, the survey also covers information about individual insurance enrollment. Although all individuals in the sample are covered by Medicare, the generosity of the drug insurance coverage may vary greatly. For instance, an individual could have a Medicaid plan, a Medicare Advantage plan, or a variety of supplemental insurance plans, such as Medigap or retiree drug coverage. Within each plan category, the level of generosity can also vary by a large amount and the available 
options often changed as a result of the introduction of Part D. For instance, after the introduction of Part D, those individuals who received their prescription drug coverage through Medicaid were automatically enrolled in Part D. The MCBS data also include expenditure information, including total expenditures for all services as well as out-ofpocket expenditures. Expenditure information is also provided by category, including prescription drug expenditures and out-of-pocket drug expenditures.

Table 1 provides some basic descriptive statistics on the Medicare population over the age of 65 around the time of implementation from 2004-07. The first point to note is that a substantial fraction of the $65+$ Medicare population has cardiovascular-related conditions. Around 20 percent of the sample has a serious heart-related condition (including arteriosclerotic heart disease, heart attack, angina, or congestive heart failure) that likely puts them at a high risk of cardiovascular death. In addition, 49 percent report having hypertension and 22 percent have diabetes, which are key risk factors for developing more serious heart conditions. Another feature of this older demographic is that they tend to be afflicted by other serious health conditions. For example, around 9 percent of the population is reported to have some type of cancer. For this older population, these various conditions should be viewed as competing risks that often appear together. For instance, two-thirds of individuals reporting cancer also report having diabetes, hypertension, or some severe heart condition. ${ }^{18}$

The bottom of Table 1 reports some summary information on the observed expenditures in this data both before and after the reform. A particularly noticeable difference pre- and post- reform is the large change in the share of expenditures that is paid out-of-pocket, falling from 31.1 percent prior to the reform to 23.3 percent. Therefore, as expected, Part $\mathrm{D}$ appears to cause an increase in the generosity of drug benefits, but the share of spending for nonprescription drug services paid out-of-pocket barely changes.

In this paper, whether an individual has drug coverage or not is defined using a combination of survey information from the individual that indicates drug insurance coverage and expenditure information. The survey information from individuals includes whether they have drug insurance through Medicaid, Medicare Advantage (the private component of Medicare), or an alternative supplementary drug plan. Benefit structures can vary widely across plans and may also change before and after implementation as the competitive landscape and offerings shift. For this reason, we refine our prescription drug insurance

\footnotetext{
${ }^{18}$ This health information does not represent the actual health of the population, since it is determined by the responses of the survey participants, who may be unaware of health conditions. For instance, until individuals have a cholesterol test they may be unaware of having high cholesterol.
} 


\section{Table 1: Descriptive Statistics for Age 65+ Population}

\begin{tabular}{|c|c|c|c|}
\hline Variable & mean & 90th petl. & 10th pctl. \\
\hline \multicolumn{4}{|l|}{ Health and Demographics } \\
\hline Age & 75.83 & 66 & 87 \\
\hline Male & 0.42 & & \\
\hline Household Income & $\$ 33,937$ & $\$ 8,652$ & $\$ 60,000$ \\
\hline College (Bachelor Degree) & 0.17 & & \\
\hline BMI & 26.90 & 20.98 & 33.47 \\
\hline \multicolumn{4}{|l|}{$\underline{\text { Health }}$} \\
\hline Serious Heart Condition & 0.20 & & \\
\hline Hypertension & 0.49 & & \\
\hline Diabetes & 0.22 & & \\
\hline Cancer & 0.09 & & \\
\hline Cancer and Other Heart-Related Condition & 0.06 & & \\
\hline \multicolumn{4}{|l|}{ Expenditures } \\
\hline \multicolumn{4}{|l|}{$\underline{\text { Pre-Reform (2004-2005) }}$} \\
\hline Average Total Expenditures Drugs & $\$ 1,743$ & & \\
\hline Average Out-of-pocket Expenditures Drugs & $\$ 543$ & & \\
\hline Share of Expenditures Out-of-Pocket - Drugs & $31.1 \%$ & & \\
\hline Average Total Expenditures (Excluding Drugs) & $\$ 7,873$ & & \\
\hline Average Out-of-pocket Expenditures (Excluding Drugs) & $\$ 726$ & & \\
\hline Share of Expenditures Out-of-Pocket (Excluding Drugs) & $9.2 \%$ & & \\
\hline \multicolumn{4}{|l|}{$\underline{\text { Post-Reform (2006-2007) }}$} \\
\hline Average Total Expenditures Drugs & $\$ 2,196$ & & \\
\hline Average Out-of-pocket Expenditures Drugs & $\$ 512$ & & \\
\hline Share of Expenditures Out-of-Pocket - Drugs & $23.3 \%$ & & \\
\hline Average Total Expenditures (Excluding Drugs) & $\$ 8,710$ & & \\
\hline Average Out-of-pocket Expenditures (Excluding Drugs) & $\$ 875$ & & \\
\hline Share of Expenditures Out-of-Pocket (Excluding Drugs) & $10.0 \%$ & & \\
\hline
\end{tabular}


indicator by incorporating reported out-of-pocket and total prescription drug expenditure information into our definition of drug coverage to ensure that the expenditure information does not contradict the coverage variable from the survey. ${ }^{19}$

The MCBS data are used in two aspects of this paper. First, the MCBS data are used to estimate both the pre-reform drug insurance coverage across geographic areas, as well as the predicted change in the insurance rate due to the reform. This is essential for identification of the mortality effect of the reform and will be discussed further in the following subsection. Second, the MCBS data are used to examine how the reform impacts prescription drug utilization and expenditures.

The second data source is mortality data from the CDC. The mortality data include information on every death in the United States from 2000 to 2010. They include the age, sex, specific cause of death, and the county of the death for each individual in the United States who died over the sample period. The cause of death is listed as a precise diagnosis that we aggregate to more broadly defined disease chapters. In this paper we classify "cardiovascular deaths" as all causes of death that fall under the chapter category called "diseases of the circulatory system" in the International Classification of Diseases, Ninth Revision (ICD-9). ${ }^{20}$ These causes of death include atherosclerosis, heart attacks, and various types of heart disease. As discussed previously, the key therapeutic classes mentioned above target the major conditions in this category. Table D1 reports the frequency by disease chapter in the Appendix of this paper, which shows that 40 percent of all deaths are cardiovascular deaths. For simplicity, most of this paper focuses primarily on just two cause-of-death categories, (1) cardiovascular-related deaths and (2) noncardiovascular-related deaths (i.e., all others). After using these categories to demonstrate the main points, later sections will demonstrate some insights from expanding the analysis to incorporate alternative cause-of-death categories. To construct mortality rate estimates for each county, the mortality data are combined with information about the

\footnotetext{
${ }^{19}$ Specifically, for those individuals who have more than $\$ 100$ in total drug expenditures, we indicate people as having drug insurance if they pay less than 20 percent of the total expenditures out-of-pocket and we mark them as not having drug coverage if they pay more than 80 percent of expenditures out-of-pocket. Survey information indicating drug insurance status is used for those individuals who have less than $\$ 100$ in drug expenditures and those individuals who pay less than 80 percent out-of-pocket, but more than 20 percent. We explore alternative drug coverage definitions, but they produce qualitatively similar results.

${ }^{20}$ Specifically, the data provide cause of death by ICD-10 codes. Since ICD-9 codes have been more broadly used in the health literature, we use a disease-crosswalk to map these codes to broadly defined ICD-9 disease chapters (http://www.nber.org/data/icd9-icd-10-cm-and-pcs-crosswalk-generalequivalence-mapping.html).
} 
population in each county taken from the intercessional estimates of the U.S. Census Bureau, which is a population estimate for July 1 of each year. The annual mortality rate is computed by dividing the total deaths from July 1 to June 30 of the following year by the total population estimate for July 1 of the initial year. The broad national trends for these two causes of death are shown in Figure 1, discussed previously. ${ }^{21}$

There are two measurements of mortality assessed in this paper. One measurement is a basic ratio of the number of deaths from period $t$ to $t+1$ divided by the population in period $t$. In these estimates, the mortality rates are constructed by sex and five-year age categories up to the age of 84 . The Census also reports total population for males and females age 85 and older, but there are no five-year age categories. Since age adjustment cannot be performed for those individuals 85 and over, we focus on the age 65 to 84 population. ${ }^{22}$ An overall mortality rate is constructed by weighting the population in each age-sex bin based on the overall population in that category for the year 2000, so that mortality rates are comparable across counties and over time. ${ }^{23}$ One issue with this mortality measure is that it treats the death of a 65-year-old person and an 84-year-old person equally, even though the total years-of-life-lost (YLL) are likely greater when a 65-year-old individual dies than when an 84-year-old individual dies. To better reflect the total YLL, we construct an alternative measure in which deaths are weighted by the expected years of life lost for each age category. ${ }^{24}$ To reduce small-sample bias, we include only those counties with at least 2,000 individuals 65 and over, which implies about 30 to 40 cardiovascular deaths per year in the county.

In addition to the above data, our analysis also incorporates annual unemployment

\footnotetext{
${ }^{21}$ We use CDC data rather than Medicare claims data to study the impact of Part D on mortality for two reasons. First, we are not aware of any available sample of claims for the full Medicare Advantage population. Second, even if claims data were available, it may be challenging to use this information to control for the health of the population, since the observation of diseases in the claims will be biased toward those who seek medical care. In contrast, the death certificates are more likely to be uniformly measured across populations and over time.

${ }^{22}$ Results for the overall $65+$ population (i.e., including those age 85 and above) are included in Appendix Table D5.

${ }^{23}$ Let Share $_{00}^{65-69}$ be the share of the population above 65 that is in the age 65-69 age range in 2000. Let $\operatorname{Mort}_{d, t}^{65-69}$ be the mortality rate in the 65-69 age range with disease $d$ at time $t$ to $t+1$. Then the overall mortality rate is constructed as a weighted average of the population share: $\sum_{a \in\{65-69, \ldots, 80-84, \text { and } 85+\}}$ Mort $_{d, t}^{a} \cdot$ Share $_{00}^{a}$.

${ }^{24}$ Specifically, we use data on the Actuarial Life tables from the Social Security website (http://www.ssa.gov/OACT/STATS/table4c6.html). Let the life expectancy for individuals in age range, $a$, be denoted, $L^{a}$. The mortality rate that values the years of potential life lost is calculated as: $\sum_{a \in\{65-69, \ldots, 80-84, \text { and } 85+\}}$ Mort $_{d, t}^{a} \cdot$ Share $_{00}^{a} \cdot L^{a}$.
} 
data at the county level from the Bureau of Labor Statistics. While much of the analysis in this paper looks over a relatively short time period and uses county-disease fixed effects that lessen the need for detailed controls for population health, the unemployment rate has been shown to be a key determinant of population mortality in several studies, starting with the seminal work of Ruhm (2000). Since unemployment rates can change quickly over short periods of time, this information is included in our analysis. Another more general trend noted in the literature is the relationship between socioeconomic status and mortality trends. Specifically, several papers have documented mortality rates falling more rapidly for populations with higher socioeconomic status, relative to populations with lower socioeconomic status (see Saez and Zucman (2014)). We use the median household income in 2000 as a proxy for the socioeconomic status of the county and interact that income level with a year trend variable. For robustness checks, additional information about the population and demographics are taken from the Area Resource File (ARF) and health information is taken from Behavioral Risk Factor Surveillance System (BRFSS). ${ }^{25}$

\subsection{Measuring the Geographic Variation of the Impact of Medi- care Part D}

One of the challenges in this study is to characterize the population that is most affected by Medicare Part D. Intuitively, those individuals most affected by drug insurance expansion should be those who had no drug coverage before the expansion. The institutional features of the insurance market reveal that geography was likely a major source of variation in drug coverage prior to the reform. In particular, two major sources of prescription drug coverage for those age 65 and over before the reform were enrollment in Medicaid or the Medicare Advantage program-both of which varied by geography.

The determinants of the availability of Medicare Advantage (the private insurance alternative) or Medicaid coverage differ substantially. Medicaid eligibility varies greatly by state, where each state determines the exact rules for eligibility in the Medicaid program. The determinants of Medicare Advantage coverage are influenced primarily by private insurers' potential profitability in a particular geographic area. Profitability will depend on a variety of factors, such as the potential number of covered lives in an area (i.e., scale) or the number of insurers offering commercial insurance (i.e., scope), and regulatory considerations (e.g., CMS reimbursement rate). The Medicare regulator, CMS, reimburses

\footnotetext{
${ }^{25}$ We use county level estimates of smoking, obesity and physical activity estimated and generously supplied by Dwyer-Lindgren et al. (2014) based on the BRFSS data.
} 
Medicare Advantage plans for each covered life. These rates, set by the CMS, vary at the county level, and have been shown to be key determinants of entry across markets. ${ }^{26}$ In addition to these sources of geographic variation that are affected by government policy, the generosity of retiree benefits, including drug benefits, may vary across regions due to differences in labor market conditions and practices. Geography also plays a major role post-reform, since the private Part D prescription drug insurers choose whether or not to enter each of the 34 regulatory defined regions.

The differences in Part D coverage across the United States reveal the importance of geography. Table 2 shows prescription drug coverage information from the MCBS for the five states most affected by the reform and the five states that appear least affected. There is a large amount of variation across states, with a standard deviation of a 7.9 percent change in drug insurance coverage. There is a clear positive correlation between those lacking drug coverage in a state before the reform and the post-reform gains in coverage. ${ }^{27}$

While Table 2 demonstrates the importance of geographic variation at the state level, the features of the Medicare drug insurance market prior to reform suggest that the effect of Part D should be measured at the county level. Additional support for focusing on variation at the county-level is supported by the sample design of the MCBS survey, where the sampling units consist of MSAs and groups of rural counties. This can be seen by looking at a map where the MCBS sample is drawn. Figure 4 shows the geography of the MCBS sample for the 2004-2005 time period, where darker shades represent a higher number of observations. The map shows that many states are not even sampled. ${ }^{28}$ In addition, within states that are sampled, only part of the state is sampled. For example, the sample is drawn from the Seattle area of Washington state, but not eastern Washington.

Based on the sample design of the MCBS and the local determinants of drug coverage, our analysis focuses on those local areas where the MCBS sample is concentrated. In order

\footnotetext{
${ }^{26}$ Regulatory restrictions require that when private insurers enter at the county level they must make plans available to the entire Medicare population in that county. Although Medicare Advantage plans were not required to offer drug benefits before the reform, greater competition in the Medicare Advantage market has been associated with improved generosity of benefits, including drug benefits (Dunn (2011)).

${ }^{27}$ Finkelstein (2007) uses the rate of uninsured prior to Medicare's introduction as a measure of the impact of Medicare's change. Since Medicare led to almost full insurance coverage for the 65 and over population, the fraction of individuals uninsured before the reform was equal to the predicted impact of the change. For the Medicare Part D population, the share of individuals without drug insurance is a strong predictor of the change in the share of those insured, but is not equal to the actual change.

${ }^{28}$ The following states have too few observations to be included in the analysis: Alaska, Maine, Idaho, Mississippi, North Dakota, Utah, Oregon, Delaware, New Hampshire, South Dakota, Rhode Island, Vermont, Hawaii, and Montana.
} 
Table 2: State Level Drug Coverage

\begin{tabular}{|c|c|c|c|c|}
\hline State & $\begin{array}{c}\text { Pre-Part D } \\
(2004-05) \\
\end{array}$ & $\begin{array}{c}\text { Post-Part D } \\
(2006-07)\end{array}$ & Change & Obs \\
\hline Nebraska & $31.9 \%$ & $75.0 \%$ & $43.1 \%$ & 365 \\
\hline Arkansas & $41.3 \%$ & $77.5 \%$ & $36.1 \%$ & 337 \\
\hline Georgia & $46.1 \%$ & $81.4 \%$ & $35.2 \%$ & 1,150 \\
\hline Indiana & $52.8 \%$ & $83.3 \%$ & $30.4 \%$ & 118 \\
\hline West Virginia & $55.6 \%$ & $85.9 \%$ & $30.3 \%$ & 468 \\
\hline Oklahoma & $76.1 \%$ & $88.3 \%$ & $12.2 \%$ & 367 \\
\hline Massachusetts & $77.2 \%$ & $89.0 \%$ & $11.8 \%$ & 638 \\
\hline Illinois & $69.6 \%$ & $81.4 \%$ & $11.8 \%$ & 1,205 \\
\hline Virginia & $71.3 \%$ & $82.4 \%$ & $11.1 \%$ & 443 \\
\hline Arizona & $80.8 \%$ & $90.6 \%$ & $9.8 \%$ & 784 \\
\hline Standard Deviation & $11.4 \%$ & $5.2 \%$ & $7.9 \%$ & \\
\hline p90 & $78.1 \%$ & $91.8 \%$ & $31.9 \%$ & \\
\hline p10 & $50.0 \%$ & $79.4 \%$ & $12.0 \%$ & \\
\hline
\end{tabular}


Figure 4: Number of Observations per County in MCBS

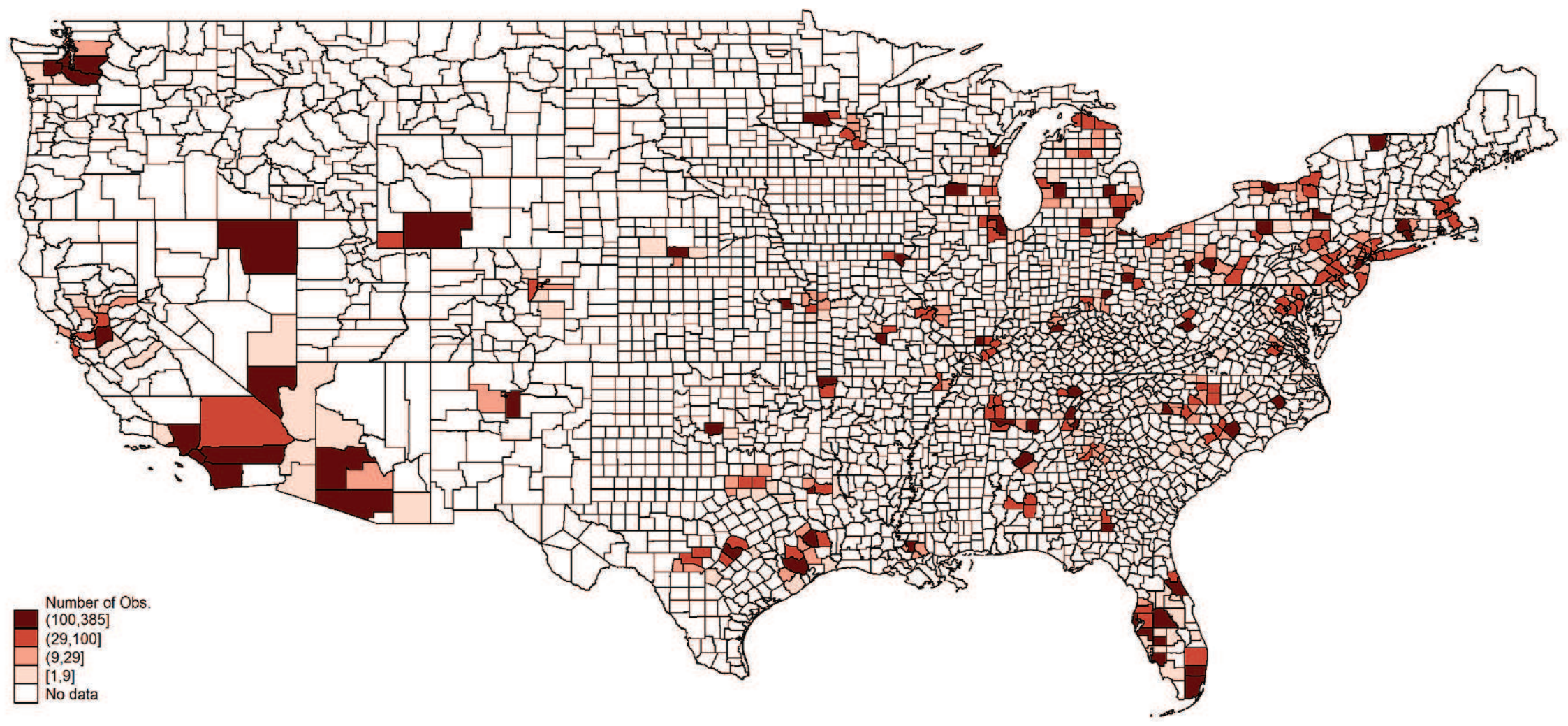


to capture the variation in prescription drug offerings at the county level, and maximize the accuracy of the county-level estimates, we examine two samples: a "core" sample of counties and an "expanded" sample, which includes the core sample. The core sample includes those counties in MCBS where we have sufficient observations in the MCBS to infer the level of prescription drug coverage before Part D was implemented. To expand the number of counties in our analysis, we make predictions of the county-level pre-Part D prescription coverage level using the observable characteristics of those counties where the MCBS data is present.

\subsubsection{Core Sample}

To construct an age-sex adjusted level of prescription drug coverage, we run a probit model on the set of individuals in the MCBS prior to the reform. Specifically, we run the following probit on sample years 2004 and 2005 in the MCBS data:

$$
\operatorname{Pr}\left(\text { Covered }_{i}=1 \mid X, \gamma_{c}\right)=\Phi\left(\beta X+\gamma_{c}\right)
$$

where $\gamma_{c}$ are county-specific fixed effects and $X$ is a vector of covariates representing the individual $i$ 's age and sex as well as a year dummy. ${ }^{29}$ The dependent variable represents an indicator whether individual $i$ has drug coverage. ${ }^{30} \Phi$ represents the normal distribution CDF.

We use the population weights from MCBS to derive the predicted pre-reform insurance rate in each county. Specifically, we calculate $S H A R E_{c}^{p r e}=\frac{\sum_{i} w_{i} \Phi\left(\widehat{\beta} X+\hat{\gamma}_{c}\right)}{\sum_{i} w_{i}}$ where $w_{i}$ is a population weight for individual $i$ from the MCBS data, where the weighted means are taken over the entire 2004 and 2005 sample. Essentially, for county $c$ we are computing a coverage rate for the complete distribution of Medicare enrollees pre-reform. For descriptive purposes, we repeated this exercise for the sample of individuals in the 2006 and 2007 MCBS, creating a variable $S H A R E_{c}^{\text {post }}$. The change in insurance coverage in county $c$ is then simply $\triangle I N S_{c}=S H A R E_{c}^{\text {post }}-S H A R E_{c}^{\text {pre }}$. To maximize the accuracy of each county-level estimate, our core sample includes only those counties in MCBS with at least 30 individual observations over the 2004 to 2005 time period, which results in 169 of the

\footnotetext{
${ }^{29}$ In our main estimates we include only age and sex information in $X$, since they are reflected and controlled for in our mortality estimates. Results of this probit estimation are reported in Appendix Table D3. For robustness, we ran a multitude of variations of (1) to calculate the share of covered individuals (e.g., including additional controls in the vector $X$ ). See Appendix Table D4.

${ }^{30}$ See Section 3 concerning how we created this drug coverage dummy variable from the MCBS.
} 
Figure 5: Share With Drug Insurance Pre-Reform: Core Sample

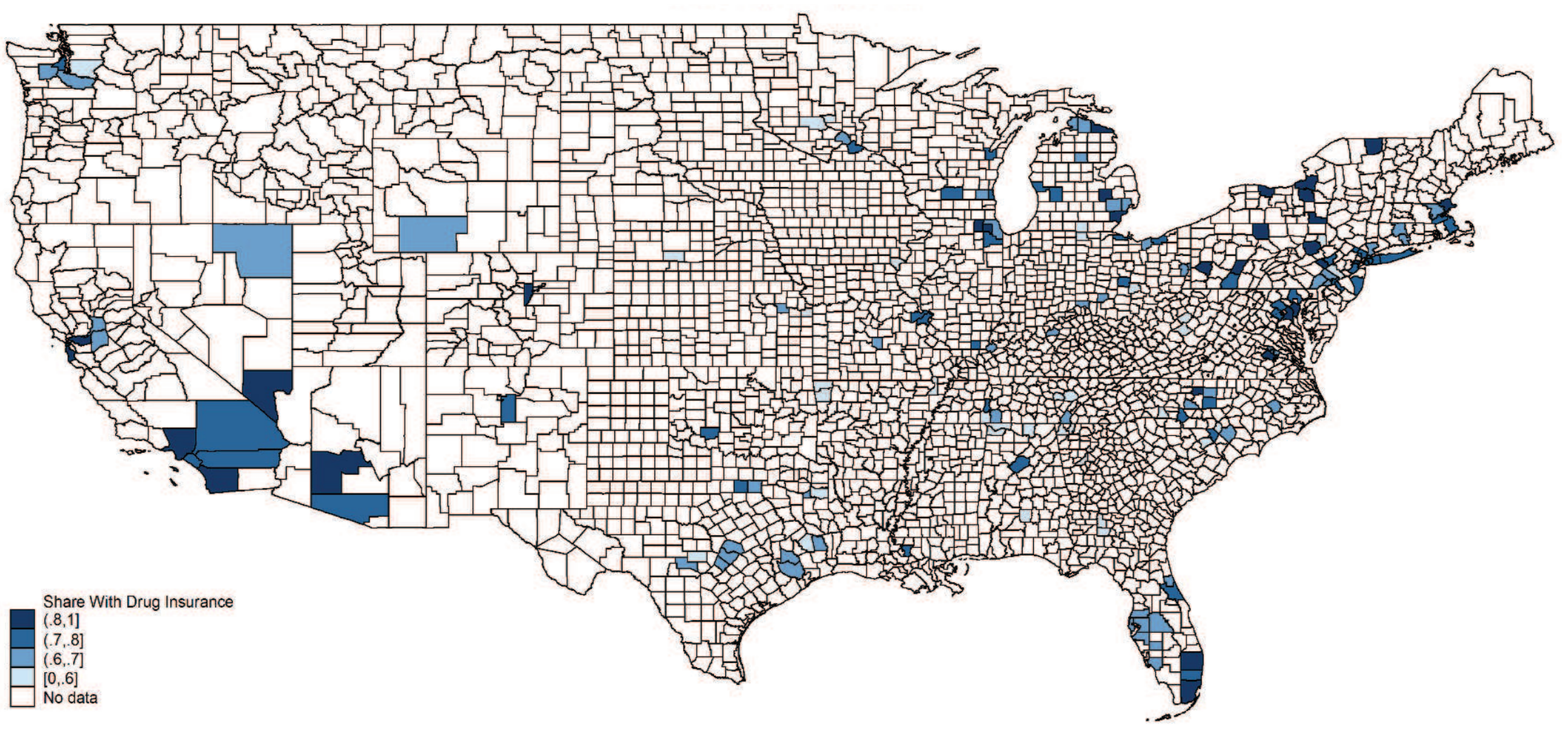


386 counties in the MCBS. ${ }^{31}$ There is a considerable amount of variation in $S H A R E_{c}^{\text {pre }}$. For the 169 counties included in our core sample, the standard deviation of $\Delta I N S_{c}$ is 11.3 percent, considerably larger than the state-level variation. The variation in the drug coverage for this core sample is shown graphically in Figure 5, where areas with a higher level of drug coverage pre-Part D are shaded with a darker color. Graphically it can be seen that the variation in coverage across counties within the same state can be as large as the variation in coverage across states. For instance, for the 12 counties in Florida the $S H A R E_{c}^{p r e}$ variable ranges from 60 to 87 percent. The following section shows that much of this variation can be explained by observable demographic and economic factors.

\subsubsection{Expanded Sample}

The MCBS sample spans a large area of the country and includes a diverse set of rural and urban counties. Our strategy for expanding the county level sample is guided by where in the country the MCBS is conducted. Given the lack of MCBS data in many large geographic areas (e.g., Oregon, Idaho, and North Dakota) we do not attempt to expand the sample across all counties in the U.S. Instead, we focus on predictions in the immediate geographic areas where the MCBS sample is concentrated, typically around MSAs or CSAs.

We estimate a regression model to make predictions of drug coverage rates by county based on the $S H A R E_{c}^{\text {pre }}$ measures constructed as described above. In particular, we regress $S H A R E_{c}^{p r e}$ on 2005 county-level population characteristics, and use the estimated parameters to predict drug coverage rates for certain counties outside of the core sample. ${ }^{32}$ The explanatory variables include the share Medicaid in the county, Medicare Advantage penetration, income, population density, population size, share veteran, share white, and the share of the population over 65 below the poverty level. ${ }^{33}$ Importantly, we include region dummies in the regression to capture unobservable local factors that affect prescription drug insurance coverage. ${ }^{34}$ The regression results are shown in Table 3 . The estimates validate the importance of population characteristics determining differences in coverage

\footnotetext{
${ }^{31}$ This is also based on the threshold that the age $65+$ year 2000 county population was greater than 2,000 individuals.

${ }^{32}$ The county-level explanatory variables in the regression model are from the 2005 Area Resource File

${ }^{33}$ One advantage of using population estimates for predictive purposes is that it eliminates measurement error from having a limited number of observations in the MCBS for any particular county.

${ }^{34} \mathrm{~A}$ region was defined as a CSA. For those counties not in a CSA, region was defined as the MSA. For those counties not in a CSA or MSA, the region was defined as the state. Regions without multiple counties were not included in the regression.
} 
across counties. As expected, the estimates show that both Medicaid and Medicare Advantage programs are important factors that determined drug coverage prior to Part D. In addition, the share of the population that is a veteran is another strong and positive predictor of coverage, likely from veteran health benefits that cover prescription drugs. Finally, we find that the share of the over 65 population below poverty is a strong predictor of lower coverage in an area. The $R^{2}$ is relatively high, 0.74, implying the regression is capturing a large degree of the variation in drug coverage rates across the country. ${ }^{35}$ These same steps are taken in an analogous fashion to predict the level of coverage post reform, $S H A R E_{c}^{\text {post }}$.

Table 3: Predictors of Pre-Part D Insurance Coverage by County

\begin{tabular}{lc}
\hline \hline & Coverage Share \\
\hline \hline Share Medicaid in 2005 & $0.314^{* *}$ \\
& $(0.150)$ \\
Medicare Advantage Penetration in 2005 & $0.002^{* * *}$ \\
& $(0.001)$ \\
Log Income 2005 & 0.031 \\
& $(0.050)$ \\
Log Population Density 2005 & 0.011 \\
& $(0.009)$ \\
Log 65+ Population 2005 & 0.008 \\
& $(0.007)$ \\
Share Veterans 2005 & $1.320^{* * *}$ \\
Share White 2005 & $(0.429)$ \\
Share Below Poverty 2005 & $-0.187^{* * *}$ \\
& $(0.070)$ \\
\hline \hline Observations & $-0.635^{* *}$ \\
$R^{2}$ & $(0.320)$ \\
\hline
\end{tabular}

Notes: The dependent variable is $S H A R E_{c}^{\text {pre }}$. Observations were weighted by the MCBS county sample size. All regressions include region fixed effects (either the CSA, MSA, or state) and rural/urban continuum code dummies. ${ }^{*} p<0.10,{ }^{* *} p<0.05,{ }^{* * *} p<0.01$.

\footnotetext{
${ }^{35}$ While we chose this particular approach for expanding the sample, several alternative approaches produced similar results. For instance, including explanatory variables in the model nonlinearly had no effect on the results. In addition, substituting our "core" sample predictions with the predictions of this model also produced similar results.
} 
Figure 6: Share With Drug Insurance Pre-Reform: Expanded Sample

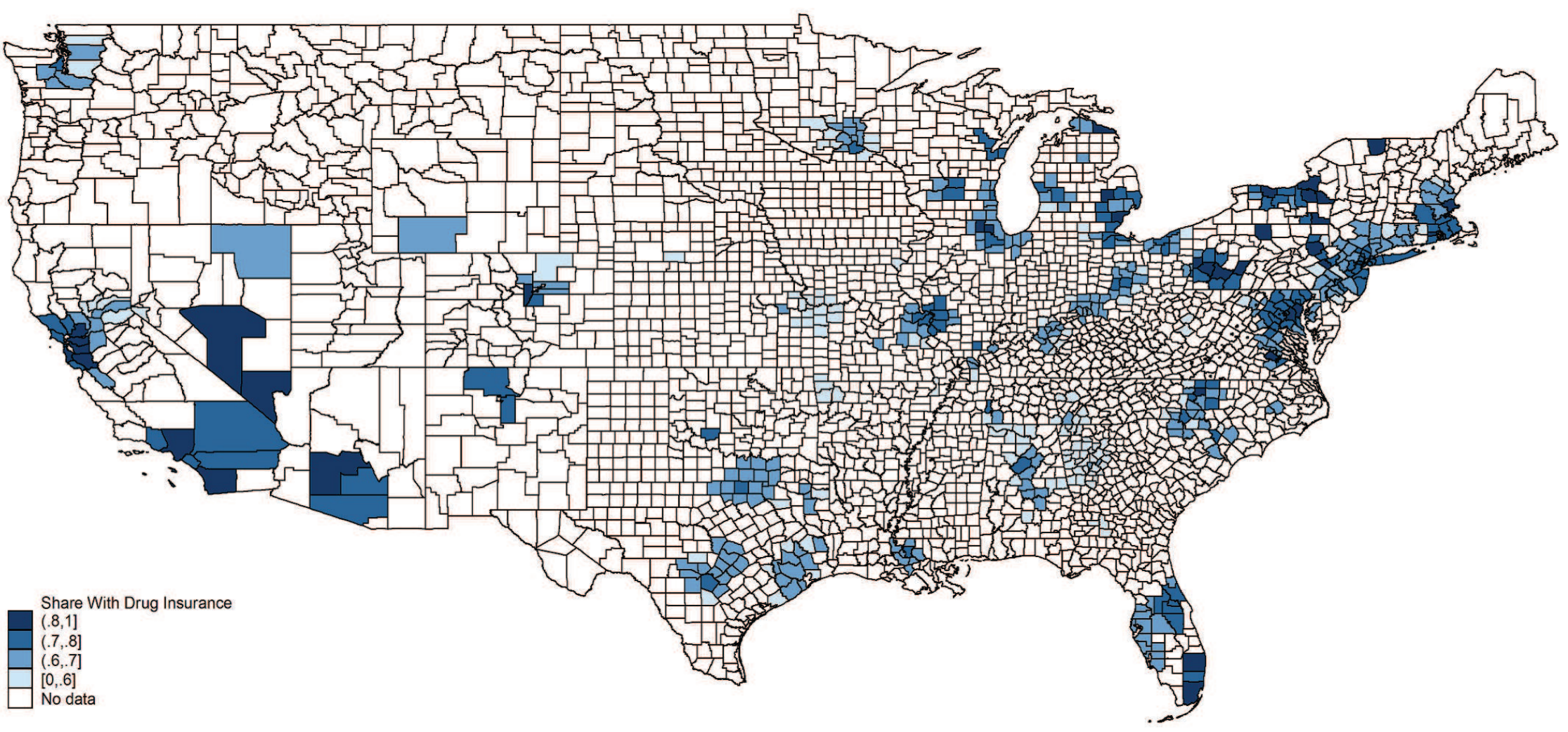


We use the estimates from (3) to make predictions about the levels of coverage for counties outside of the core sample. Specifically, the additional counties included in the expanded sample are those located in areas where we believe to have a reasonable estimate of the region dummy. Our specific criterion is that the region includes 30 or more observations within a selected CSA or MSA area. The map of counties that are included in the expanded sample are shown in Figure 6. The expanded sample includes an extra 361 counties, increasing the total sample size to 530 counties. The core sample counties includes about 38 percent of the over 65 population in 2005, while the expanded sample of counties includes 56 percent of that population. While the sample is not 100 percent, one should note that these areas were selected by the MCBS survey for constructing a nationally representative sample of the United States Medicare population.

The basis of our identification strategy is to identify geographic areas most impacted by the reform and those least impacted. Our prior assumption is that those areas with lower levels of coverage, pre-Part D, will be most impacted by the implementation of Part D and obtain the greatest increase in drug coverage. To test this assumption, we study the relationship between the share of coverage prior to the reform, and the increase in insurance coverage post-reform. Figure 7 below shows a scatter plot showing the relationship between the pre-reform level of drug coverage, $S H A R E_{c}^{p r e}$ and the percentage change in drug coverage $\Delta I N S_{c}$, constructed by simply taking the first difference: $\triangle I N S_{c}=S H A R E_{c}^{\text {post }}-S H A R E_{c}^{\text {pre }}{ }^{36}$ There is a clear and significant negative relationship and the fit is strong. A simple regression of $\triangle I N S_{c}$ on $S H A R E_{c}^{\text {pre }}$ reveals an R-squared of 0.89 and a coefficient of -0.83 with standard error of 0.02 for the core sample, while the expanded sample has an R-squared of 0.87 and a coefficient of -0.79 with standard error 0.01 .

While our analysis exploits geographic differences in drug coverage, demographic factors may also affect levels of coverage before and after the reform. Specifically, individuals are less likely to have drug coverage as they get older, and this difference is especially large for individuals over the age of 85 . There are several reasons that this paper does not focus on demographic variation in insurance coverage. First, the geographic variation appears to offer considerably more variation, relative to the demographic factors. This may be observed in Table D2 of the Appendix, which shows differences in pre- and post- reform drug coverage by age and sex. Second, much of the demographic variation in prescription drug coverage occurs because of the $85+$ population, which is problematic because there is limited information available regarding the age distribution of this population by county.

\footnotetext{
${ }^{36} S H A R E_{c}^{\text {post }}$ was constructed in analogous way as $S H A R E_{c}^{\text {pre }}$.
} 
Figure 7: Pre-Reform Coverage versus Percent Change in Coverage

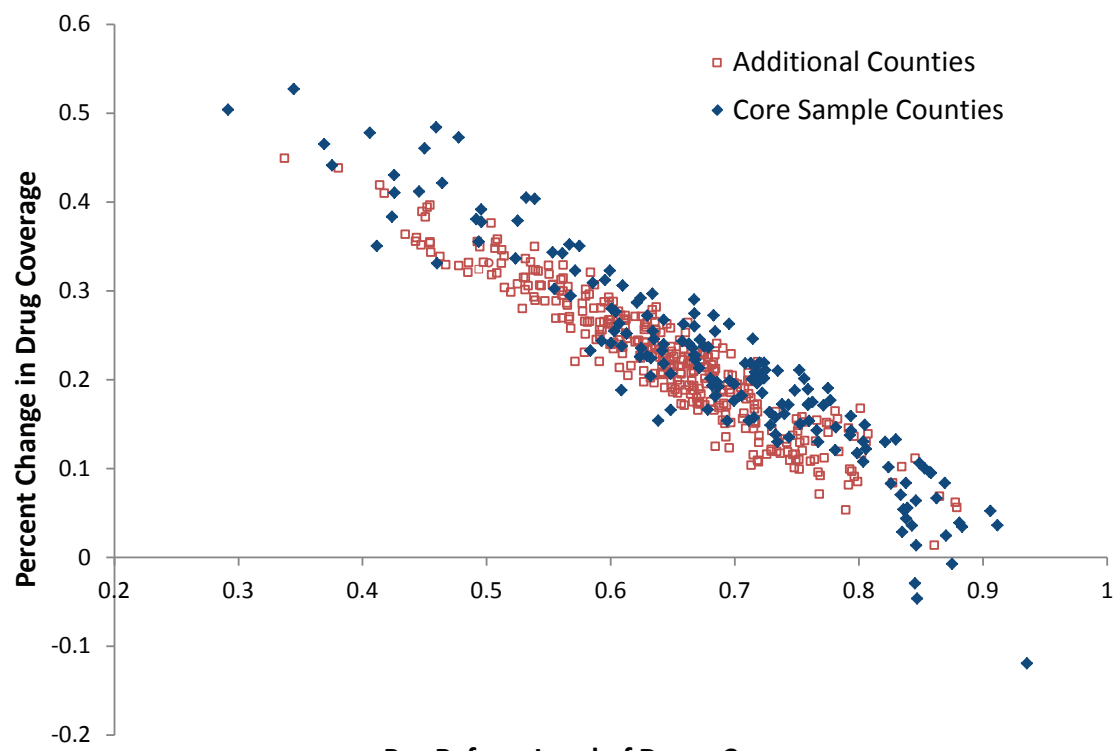

Pre-Reform Level of Druge Coverage

Notes: Figure shows a scatter plot of the share of individuals in the county with prescription drug coverage before the reform $\left(S H A R E_{c}^{\text {pre }}\right)$ against the change in drug coverage over the reform period $\left(\Delta I N S_{c}\right)$. The 169 core counties are marked in blue and were constructed directly from the MCBS sample. The 361 additional counties are marked in red-pre- and post-reform insurance coverage rates were constructed based on a regression model using county-level observable variables.

Finally, focusing on geographic variation in coverage simplifies the analysis.

\section{Timing of the Impact of Medicare Part D}

In this section, we examine the timing of the effect of the reform. In the first subsection, we examine how Part D impacted the out-of-pocket price of prescription drug purchases and we explore the timing of those effects. We also examine whether the timing of the effect on out-of-pocket pricing correspond with changes in the utilization of prescription drug purchases. In the second subsection, we assess the timing of the Part D on mortality. Understanding the pattern of Part D's effect on mortality offers important clues as to the importance of the key dynamic effects of mortality as described previously. 


\subsection{Timing of Part D on Prescription Drug Purchases and Out- of-Pocket Prices}

The most direct effect of the introduction of Part D on health care markets should be its impact on out-of-pocket prices and utilization. Although Figure 7 demonstrates that those areas with less drug coverage pre-reform (years 2004-05), see the greatest increase in coverage post-reform (i.e., 2006-07), it does not show how prescription drug use or the out-of-pocket prices paid by consumers in those counties changed over the reform period. In this section, we show that the timing of the impact of Part D on out-of-pocket prices and utilization may be observed by looking at the change in these key variables in those markets most impacted by Part D, as measured by the share of the population without drug coverage Pre-Reform, $\left(1-S H A R E_{c}^{\text {pre }}\right)$.

To demonstrate the timing of the effect, we apply a difference-in-differences model to show how outcome variables in the MCBS data change in those counties most impacted by Part D. To do this, the outcome variable will be estimated as a function, $f$, of county fixed effects $\left(\gamma_{c}\right)$, time fixed effects $\left(\gamma_{t}\right)$, and individual specific controls $\left(Z_{i, t, c}\right)^{37}$, and the treatment variable, $\left(1-S H A R E_{c}^{p r e}\right)$, interacted with time dummies, $\mathbf{D}_{t}$ :

$$
\text { Outcome }_{i, t, c}=f\left(\tau_{t}\left(1-S H A R E_{c}^{\text {pre }}\right) \cdot \mathbf{D}_{t}+\delta Z_{i, t, c}+\beta X_{c, t}+\gamma_{c}+\gamma_{t}\right) .
$$

The coefficients $\tau_{t}$ will indicate changes in the outcome variable for those counties most impacted by Part D. Note that the specific treatment variable is (1-SHARE $\left.E_{c}^{p r e}\right)$, which is the share of individuals without coverage prior to Part D implementation. We use the share without coverage as the treatment variable since it is positively correlated with the predicted changed in insurance (see Figure 7), making interpretation of our results more straightforward.

To investigate price effects, we estimate equation (2) with two different measures of the out-of-pocket price as left-hand-side outcome variables. One measure of the out-of-pocket

price is the out-of-pocket expenditure share of individual $i$ (i.e., $\left(\frac{\text { out-of-pocket drug spend }{ }_{i, t, c}}{\text { total drug spend } i_{i, t, c}}\right)$ ) and the second measure of price is the log of the average out-of-pocket cost per prescription filled of individual $i$ (i.e., $\left.\log \left(\frac{\text { out-of-pocket drug spend } \mathrm{s}_{i, t, c}}{\text { number of prescriptions filled } i, t, c}\right)\right)$. The model is estimated using a

\footnotetext{
${ }^{37}$ The explanatory controls include age, sex, income, perceived health status, twenty six medical condition categorical variables, race, BMI, and sex. We also include county level controls, $X_{c, t}$, which include the unemployment rate and income trends (i.e. median income in the county in 2000 multiplied by a time trend). Similar results are obtained with a more limited set of controls.
} 
linear specification. ${ }^{38}$ Standard errors were clustered by county.

Figure 8 plots estimates of $\tau_{t}$, along with 95 percent confidence intervals, taken from equation (2) estimated on the expanded sample. ${ }^{39}$ There are a few features worth noting about these graphs. First, across these two distinct methods of measuring out-of-pocket price, the most pronounced drop in price occurred in 2006. Second, there is little evidence of any strong pre-trend or post trend in the data. Those counties most impacted by Part D had relatively stable out-of-pocket prices prior to the reform. In addition, those counties have persistently lower levels of out-of-pocket prices post reform, relative to pre-reform levels.

Figure 8: Impact of Part D on Prescription Drug Out-of-Pocket Price
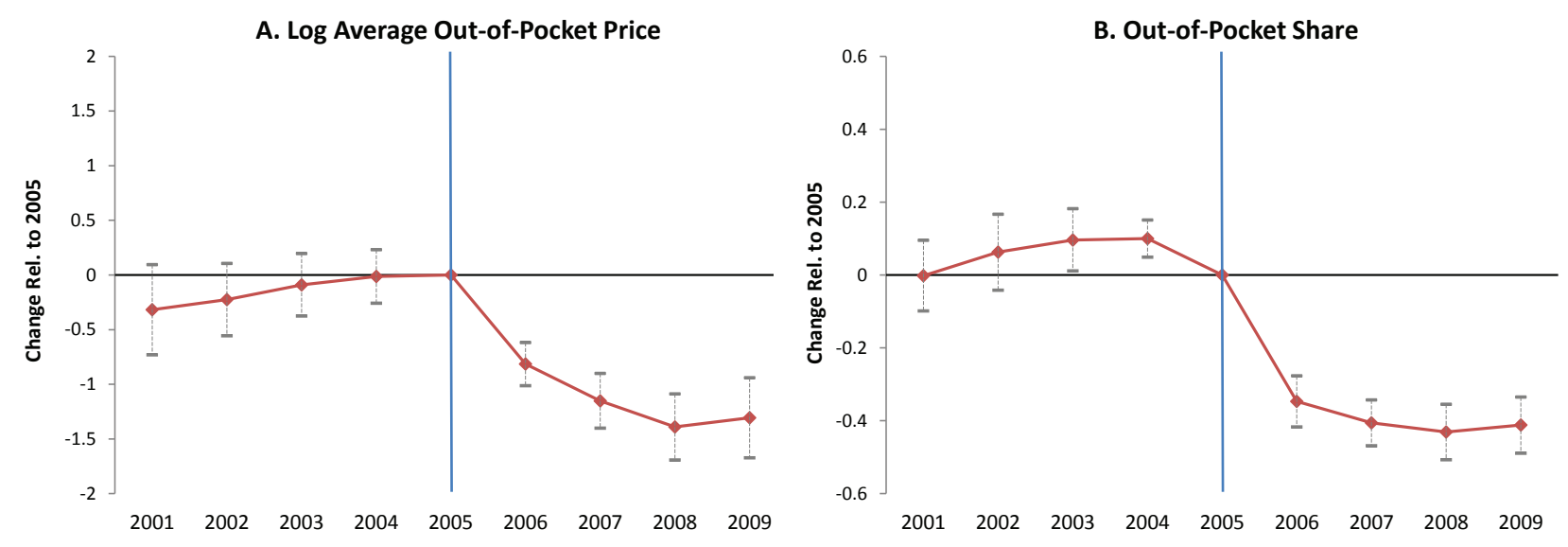

Notes: Panel A shows the coefficients $\tau_{t}$, and their 95 percent confidence intervals, estimated from (2) with the log out-of-pocket price as the dependent variable. Panel B shows the analogous estimates and 95 percent confidence intervals with the out-of-pocket share as the dependent variable. All estimates taken over the expanded sample, which includes 530 counties. Standard errors are clustered by county. Estimates taken over the core sample are shown in Appendix Figure D12.

Next, we show that those counties most impacted by the reform experienced larger than average increases in utilization. To do this, we look at two distinct outcome measures

\footnotetext{
${ }^{38}$ For the out-of-pocket expenditure share, the linear model is $\frac{\text { out-of-pocket drug spend }{ }_{i, t, c}}{\text { total drug } \text { spend }_{i, t, c}}=\tau_{t}(1-$ $\left.S H A R E_{c}^{p r e}\right) \cdot \mathbf{D}_{t}+\delta Z_{i, t, c}+\beta X_{c, t}+\gamma_{c}+\gamma_{t}+w_{i, t, c}$.

${ }^{39}$ The estimate is shown only for the expanded sample, but the figure using the core sample is almost identical and shown in the appendix.
} 
of utilization, total drug spending per individual and the number of prescriptions filled per individual. ${ }^{40}$ To account for the skewness of the data, we estimate a GLM model with a $\log$ link. ${ }^{41}$ The estimates of these models are shown in Figure 9 for the expanded sample. ${ }^{42}$ Corresponding with the drop in out-of-pocket price in 2006, we see a sharp and significant growth in utilization in 2006 using either measure of utilization. Those counties most impacted by the reform experienced a level increase in utilization that is greater than the amount in the pre-reform period. Similar to the change in the out-of-pocket price, there does not appear to be any pre-trend effect in these counties.

Additional and closely related analysis is conducted to obtain a precise effect of the reform on expenditures and out-of-pocket price for the entire Medicare population. We use this analysis at the end of the study to conduct a cost benefit analysis of the reform. ${ }^{43}$ To summarize, we estimate that the average out-of-pocket share falls from 43 percent if no reform occurs, compared to around 31 percent with the reform. We find that the expenditure increases by about 10 percent with the reform, relative to the predicted expenditure level with no reform. Together, based on the estimates of the predicted expenditure change and out-of-pocket share change, we find an arc price elasticity of demand of -0.29 . Using the number of prescriptions as the utilization variable, we find a 7 percent increase in prescriptions filled and an implied arc price elasticity of -0.25. A more direct demand estimation approach applying IV techniques and using the Part D change in coverage variable as an instrument, we obtain similar elasticity estimates of around -0.2 to -0.4. These price elasticity estimates are comparable to those found in the health literature (see Chandra et al. (2010) and the RAND study (Newhouse (1993))).

\footnotetext{
${ }^{40}$ The price of the underlying drugs are not likely to play an important role when using expenditures as a left hand side variable because drugs are often negotiated on a national level, so the average effect on negotiated prices will be captured by $\gamma_{t}$. To the extent that those with insurance pay a lower price than those without, the expenditure effect will include those price differences, so the expenditure change will understate the full quantity response (see Duggan and Morton (2010) for additional details relating to Part D's effect on prices). However, to address the potential issues with changing prices, we also show that using the count of the number of prescriptions purchased shows similar effects.

${ }^{41}$ Specifically, the GLM model is estimated with a log-link and a gamma family distribution. The following is the functional form of the GLM model: $E_{i, t, c}=\exp \left(\tau_{t}\left(1-S H A R E_{c}^{p r e}\right) \cdot \mathbf{D}_{t}+\beta Z_{i, t, c}+\gamma_{c}+\right.$ $\left.\gamma_{t}\right)+v_{i, t, c}$. The term $v_{i, t, c}$ represents a random error term. We explore the impact of alternative functional forms, and obtain similar estimates across alternative specifications.

${ }^{42}$ The estimate is shown only for the expanded sample, but the figure using the core sample is almost identical and shown in the appendix.

${ }^{43}$ See Appendix A for details.
} 
Figure 9: Impact of Part D on Prescription Drug Use and Spending
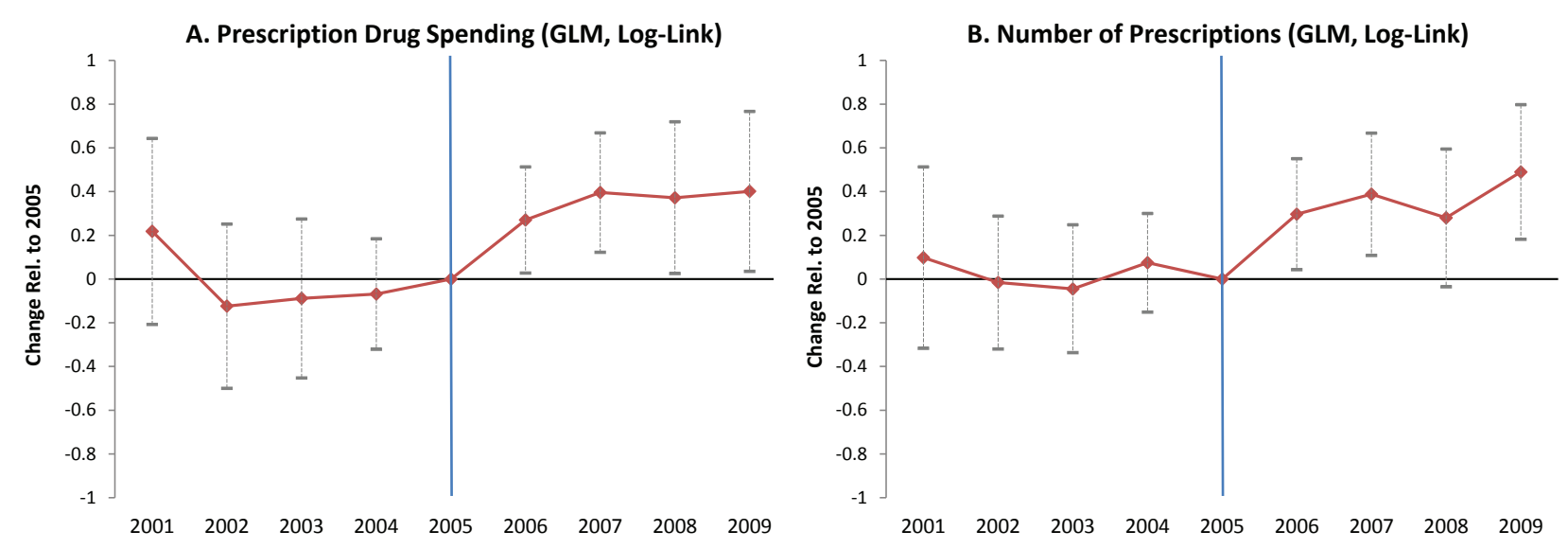

Notes: Panel A shows the coefficients $\tau_{t}$, and their 95 percent confidence intervals, estimated from (2) with prescription drug spending as the dependent variable. Panel B shows the analogous estimates and 95 percent confidence intervals with number of prescriptions as the dependent variable. All estimates taken over the expanded sample, which includes 530 counties. Standard errors are clustered by county. Estimates taken over the core sample are shown in Appendix Figure D13.

\subsection{Timing of Part D on Mortality}

To assess the timing of Part D drug insurance expansion on mortality, we apply a similar difference-in-differences (DD) regression model. Again, the focus will be measuring the impact of Part D on post-reform mortality using the prescription coverage share, $S H A R E_{c}^{p r e}$, as a treatment variable. The mortality regression takes the following form:

$$
M_{d, t, c}=\tau_{d, t}\left(1-S H A R E_{c}^{p r e}\right) \cdot \gamma_{d, t}+\beta X_{c, t}+\gamma_{d, c}+\gamma_{d, t}+\epsilon_{d, t, c},
$$

where $M_{d, t, c}$ is the mortality rate from disease $d$ in year $t$ in county $c$ and $\gamma_{d, t}$ represent time-disease dummies. Note that the time variable in the mortality analysis spans two half years, so for example, time $t=2006$ is calculated based on the deaths from mid-2006 to mid-2007, divided by the population in mid-2006. Our time dummies are also based on this definition of $t$. The main parameter to be estimated in this model is $\tau_{d, t}$, which captures the effect of the reform on the mortality rate in year $t$, relative to the omitted year which is 2004 (i.e. July 2004 to June 2005). The county-disease fixed effects are $\gamma_{d, c}$, the year-disease fixed effects are, $\gamma_{d, t}$. We assess two disease-types: $d=\{$ cardiovascular, noncardiovascular $\}$ 
where all deaths fall into one of these two exhaustive categories. The county disease-specific dummies in this analysis are critical because they capture aspects of the population's health in a particular county that are constant both before and after reform. The time dummies are disease specific and account for factors affecting mortality that are the same across all counties, such as common technological progress or information that impacts the treatment of health conditions in all counties. The disease categories in this model are viewed as independent and estimates for each may be computed using two separate regressions: one regression where the dependent variable is the cardiovascular mortality rate and a second regression where the dependent variable is the noncardiovascular mortality rate. The vector $X_{c, t}$ includes county level controls. ${ }^{44}$

The estimates of this model for both the core and expanded sample are reported in Figure 10, where each year on the $\mathrm{x}$-axis represents the mortality rate from July 1 of the listed year to June 30 of the following year. The omitted year is is 2004 (i.e., July 2004 to June 2005), thus (3) measures the relative impact of Part D in year $t$ relative to 2004. There are several points to note about Figure 10. First, there are no strong pre-reform trends for cardiovascular mortality, although we do observe a slight upward trend for noncardiovascular-related mortality. We do observe a slight downward trend for cardiovascular deaths in 2005, which could potentially represent an initial impact of Part D. ${ }^{45}$ Second, one of the striking features in Figure 10 is the effect on cardiovascular-related mortality in the July 1, 2006, to June 30, 2007 period. This sharp and significant drop in cardiovascular-related mortality corresponds precisely to the expected impact of expanding drug coverage. The coefficient for the year 2006 is -0.0023 for the expanded sample and -0.0025 for the core sample. This implies a decline in mortality of 0.2 to 0.3 percentage points (or about a 12 percent decline in the mortality rate) for a county that goes from no drug coverage to full drug coverage.

In line with the simulation in Figure 3 we observe an increase in both cardiovascular

\footnotetext{
${ }^{44}$ This includes a county-specific income trend (i.e., the median income of the county in the year 2000 multiplied by a year trend) and the county-level unemployment rate. Numerous studies have shown that income is an important determinant of the mortality rate (e.g., Cutler, Deaton, and Lleras-Muney (2006), Saez and Zucman (2014)). Ruhm (2000) shows that the business cycle may be in an important determinant of mortality. The income trend captures long-run socioeconomic trends, while the unemployment rate captures short-run changes in health.

${ }^{45}$ Recall that the year 2005 will include the first six months of Part D, which could also be impacted by individuals visiting physicians and purchasing drugs in anticipation of the reform. These trends could also be attributable to the Medicare Discount Drug Card Program (also created by the Medicare Modernization Act) which came into effect in mid-2004. This program was meant to subsidize Medicare recipients for prescription drugs during the two-year period before Part D was fully implemented.
} 
Figure 10: Impact of Part D on Mortality
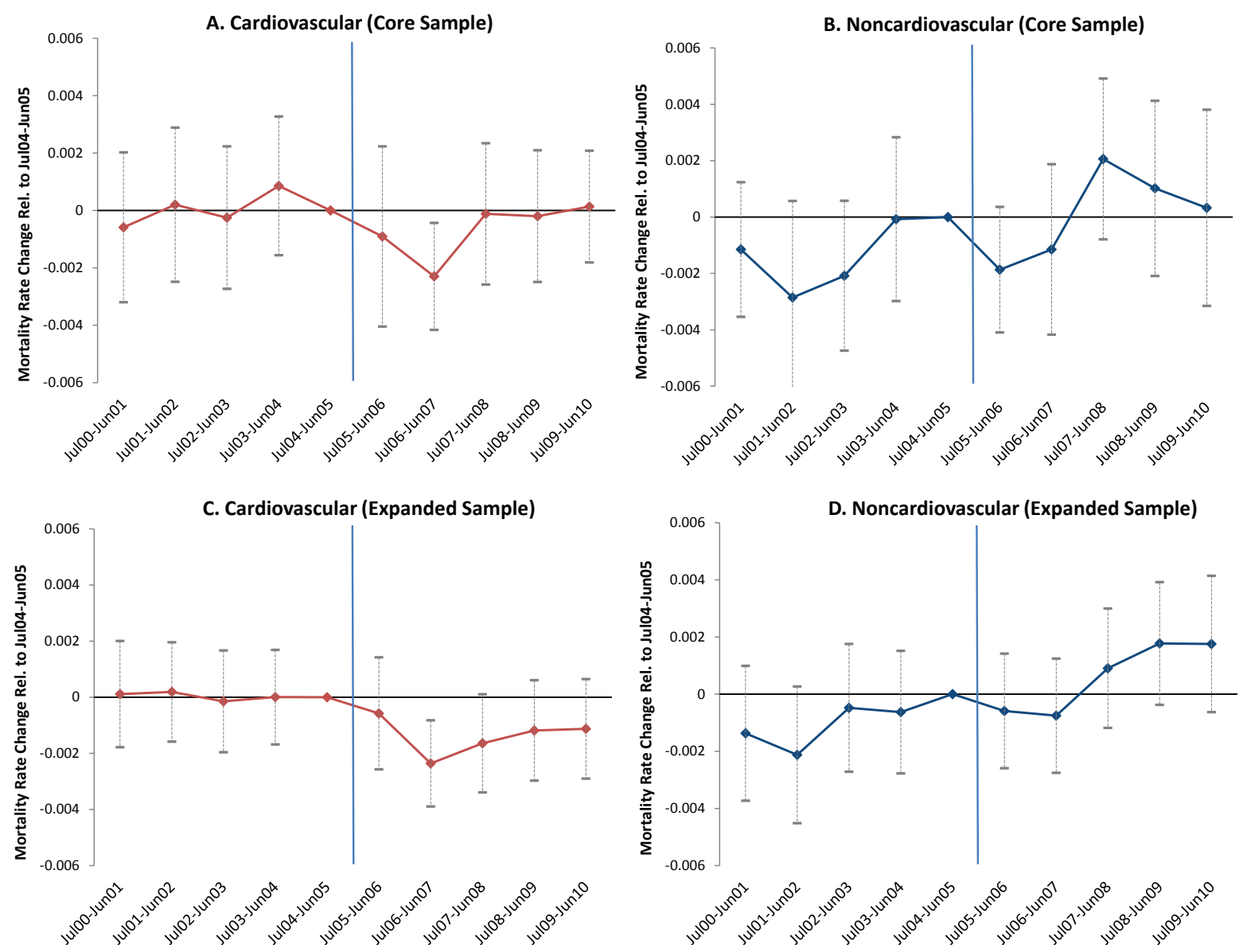

Notes: Graphs show the coefficient $\tau_{d, t}$ from equation (3) - the interaction of pre-Part D share of individuals without prescription drug coverage (i.e., $\left.\left(1-S H A R E_{c}^{p r e}\right)\right)$ with year fixed effects. The outcome is the age-sex adjusted mortality rate for the 65 to 84 population. Red diamonds indicate estimates where the outcome is cardiovascular mortality rate, blue squares indicate estimates using the noncardiovascular mortality rate as the dependent variable. Panels A and B show estimates taken over the core sample, which includes 169 counties. Panels B and C show estimates taken over the expanded sample, which includes 530 counties. The omitted year in the regression is 2004 (that is, July 2004 to June 2005). Dotted lines show 95 percent confidence bands. Vertical line approximately indicates implementation of Part D (January 2006). 
and noncardiovascular mortality in periods beyond the immediate post period. While the effects on cardiovascular mortality show no pre-trend patterns, this is less clear for noncardiovascular mortality. In particular, the counties most impacted by Part D experienced lower mortality rates for noncardiovascular conditions early in the period (i.e., 2000 and 2001), compared to the period immediately before the reform (i.e., 2003 and 2004). Several additional analysis were conducted to explore the robustness of these patterns by attempting to control for pre-trend effects. For one exercise, we include numerous additional control variables that may be related to mortality trends. ${ }^{46}$ These additional controls have no effect on the cardiovascular pattern; however, they do mitigate the upward trend observed in the noncardiovascular category. ${ }^{47}$ As a more conservative approach, we included county-disease specific trends in the analysis. ${ }^{48}$ We found similar declines in the cardiovascular mortality rate. For noncardiovascular conditions, all trends appear to be eliminated with the coefficient $\tau_{\text {noncardio,t }}$ not rising above zero. (see Appendix Figure D14).

These graphs provide information about the time-series patterns of the effect of Part D on mortality, which supports the main patterns outlined in Figure 3. As suggested in Figure 3, we see the immediate decline in cardiovascular mortality for those counties most impacted by the reform. This mortality decline is followed by, what appears to be, a delayed mortality effect that shows an upward rise in mortality in those same counties. Recall that if this upward rise is due to a delayed mortality effect, then estimates of $\tau_{d, t}$ in later periods may be inappropriate for measuring the causal effect of the reform on mortality. This is because counties most affected by Part are likely to have sicker populations in periods beyond the immediate post period, creating a positive bias on $\tau_{d, t}$ in future periods. More explicit evidence of this delayed mortality effect is presented in Section 5.

\footnotetext{
${ }^{46}$ These variables include the share of county under the poverty rate, education levels, smoking rates, obesity rates, and physical activity interacted with time trends.

${ }^{47}$ We still observe a post-2006 rise in mortality for noncardiovascular conditions, although it is not significant different from the 2004 mortality rate. One potentially reason that controlling for trends may matter may be related to smoking. Those counties most affected by Part D have higher rates of smoking and the decline in smoking has been lower for those counties, relative to others. Therefore, those counties most impacted by the reform may have noncardiovascular conditions related to smoking, such as cancer and COPD, rise relative to other counties.

${ }^{48}$ To do this, we remove the year 2000 interaction with variable $\left(1-S H A R E_{c}^{\text {pre }}\right)$, and instead include disease-county specific trend variables.
} 


\subsubsection{Triple Difference Specification and the Impact of Part D on the Near Elderly}

The plots in Figure 10 offer strong evidence that Part D led to a sharp reduction in cardiovascular-related deaths of the elderly population. However, one may be concerned that these patterns could be caused by other unobserved health, economic or environmental factors that happen to affect those counties where Part D expansion had the greatest effect. To address this concern one could implement an exercise using the population ages 55-64 (the "near elderly") as an additional control group. In this subsection, we discuss the results of this type of "triple difference" (DDD) exercise, which computes the relative effect of Part D on the elderly relative to the near elderly. We show that a DDD estimate will result in an understatement of the effects of Part D because the near elderly were also impacted by Part D. This is not entirely surprising given that approximately 17 percent of Medicare enrollees are below the age of 65 and are relatively sick since one must be disabled, have end-stage renal disease, or Amyotrophic Lateral Sclerosis (ALS) to qualify for Medicare. ${ }^{49}$

To undertake this exercise, we append mortality data for the near elderly (ages 55 to 64) to our original data set and run the following DDD regression:

$$
\begin{aligned}
M_{g, d, t, c}= & \alpha_{d, t} \cdot \mathbf{D}_{A g e \geq 65} \cdot\left(1-S H A R E_{c}^{p r e}\right) \cdot \gamma_{d, t}+\tau_{d, t}\left(1-S H A R E_{c}^{p r e}\right) \cdot \gamma_{d, t} \\
& +\beta X_{c, t}+\mathbf{D}_{A g e \geq 65} \cdot \gamma_{d, t}+\gamma_{d, t}+\gamma_{d, c} \epsilon_{d, t, c},
\end{aligned}
$$

where $M_{g, d, t, c}$ is the mortality rate of the elderly ( $g=$ ages 65 to 84 ) or the near elderly ( $g=$ ages 55 to 64 ), and $\mathbf{D}_{A g e \geq 65}$ is a dummy variable equal to one if the dependent variable is the mortality rate for elderly and equal to zero if dependent variable is the mortality rate for the near elderly. The coefficients $\alpha_{d, t}$ quantify the relative effect of pre-Part D drug insurance coverage on the elderly mortality rate relative to the near elderly mortality rate in year $t$ relative to 2004. Similar to the analysis above, we run this regression twice: once where the dependent variable is the cardiovascular mortality rate and another regression where dependent variable is the noncardiovascular mortality rate. To differentiate between this model and the previous model, we will refer to the estimates taken from (4) as the DDD estimates and the estimates taken from (3) as DD estimates.

\footnotetext{
${ }^{49}$ As mentioned previously, the mortality rate for near elderly Medicare beneficiaries is much higher than the broader population in that age range. In addition, recall that Part D expansion substantially increased coverage for the near elderly Medicare beneficiaries.
} 
Figure 11: Impact of Part D on Mortality: Elderly versus Near Elderly
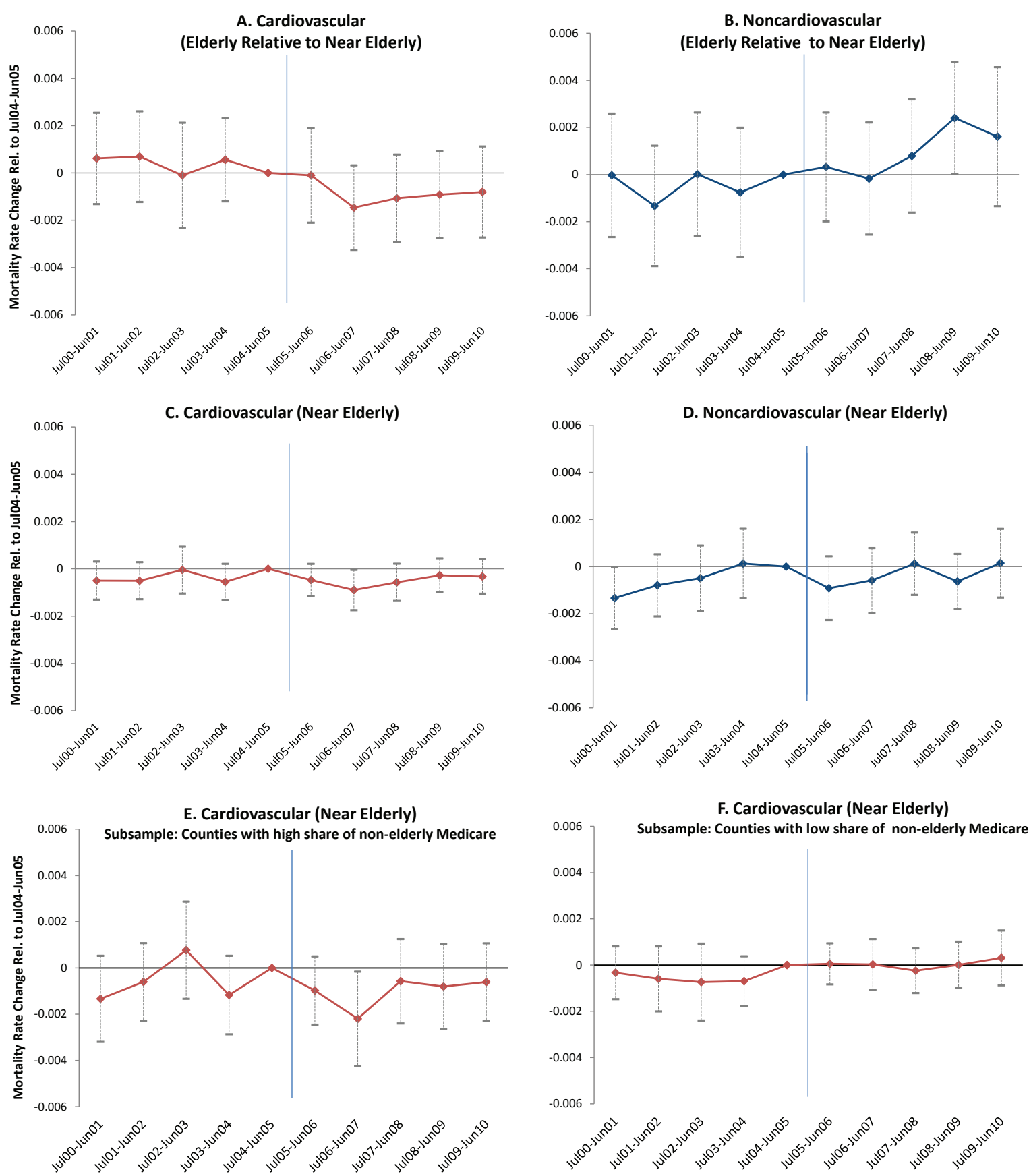

Notes: Panels A and B plot the the point estimate and $95 \%$ confidence bands of the coefficient $\alpha_{d, t}$ from equation (4) the interaction of pre-Part D share of individuals without prescription drug coverage, $\left(1-S H A R E_{c}^{p r e}\right)$, an elderly dummy variable, and year fixed effects. The dependent variable is the age-sex adjusted mortality rate for either the elderly population (ages 65 to 84 ) or the near elderly population (ages 55 to 64 ). Panels $\mathrm{C}$ and D show the estimates and confidence bands of $\tau_{d, t}$ of equation (3) where the dependent variable is the mortality rate of the near elderly population. Panels $\mathrm{E}$ and $\mathrm{F}$ show the same interaction for two mutually exclusive subsamples: counties where the share of medicare enrollees who are non-elderly (under 65) is in the upper tercile (Panel E) and the lower tercile (Panel F). Red diamonds indicate estimates where the outcome is cardiovascular mortality rate, blue sq 8 es indicate estimates using the noncardiovascular mortality rate as the dependent variable. The omitted year in the regression is 2004 (that is, July 2004 to June 2005). All estimates taken over the expanded sample. Vertical line approximately indicates implementation of Part D (January 2006). 
We report estimates of $\alpha_{d, t}$ from the DDD estimation in panels $\mathrm{A}$ and $\mathrm{B}$ of Figure 11. ${ }^{50}$ Generally, the DDD estimates show a similar pattern to those in Figure 10, however, there are some differences. For instance, the impact on noncardiovascular mortality shows no pre-reform upward trend, providing some evidence of a competing-risk and delayed mortality effect in the subsequent reform periods. Cardiovascular mortality shows a very similar pattern to the DD estimates, however, the magnitude of the decline is smaller. To be clear, the estimate is not statistically significant relative to 2004, however, is statistically significant when testing significance relative to multiple years in the pre-period (rather than just 2004). ${ }^{51}$ The DDD decline (Panel A of Figure 11) is about 60 percent of the size of the DD decline (Panel C of Figure 10).

The lower magnitude in the DDD estimates is attributable to the fact that Part D also affected the mortality rate of the near-elderly, which can be explained by describing the results in Panels $\mathrm{C}$ through $\mathrm{F}$ of Figure 11. Panel $\mathrm{C}$ of Figure 11 shows estimates of $\tau_{d, t}$ running the DD specification (3) using the near-elderly mortality rate as the dependent variable. The pattern of the coefficients of $\tau$ show a clear impact of the reform on the nearelderly population, as $\tau$ falls to -0.0009 in 2006-about 40 percent of the size of the effect on the elderly population. To be sure this was attributable to the reform, we repeated this exercise a few times. First, we used the near-elderly noncardiovascular mortality rate as the dependent variable in the DD specification, which shows no such effect for noncardiovascular mortality (Panel D). Next, we divided the sample into two mutually exclusive categories and ran the DD specification using the near-elderly cardiovascular mortality as the dependent variable. The first subsample (Panel E) includes counties where the share of medicare enrollees in 2005 who are non-elderly is in the upper tercile, and the second subsample (Panel F) includes those counties where the share is in the lower tercile (Panel F). ${ }^{52}$ The results imply a relatively large effect of Part D on the nearelderly cardiovascular mortality rate in counties with a high share of non-elderly Medicare enrollees, however, no discernable effect in those counties with a low share. That is, the effect of Part D on the near elderly cardiovascular rate is stemming entirely from those counties with a high proportion of Medicare enrollees under the age of 65 - exactly in those counties we would expect. Overall, this exercise demonstrates that caution should be used when quantifying the effects of Part D off of the relative difference between the elderly and

\footnotetext{
${ }^{50}$ These estimates were taken over the expanded sample.

${ }^{51}$ That is, relative to the entire pre-2006 period, cardiovascular mortality for the over 65 population significantly declines in 2006 relative to the near elderly mortality rate.

${ }^{52} \mathrm{CMS}$ provides information by county for the share of enrollees who are aged versus disabled. The upper tercile cutoff is 0.174 and the lower tercile is 0.140 .
} 
near elderly. In other words, the near-elderly are not an ideal control group to assess the impact of the reform and will result in estimates that understate the actual effects of the reform.

To summarize, the analysis in this section highlights some of the challenges of measuring the effects of Part D on mortality. First, identification over the entire post-reform period (i.e., periods after 2006) is problematic since Figure 10 highlights that there may be delayed-mortality effects in later periods. County fixed effects, aimed at controlling for the health of the population, will not capture harvesting effects (discussed in Figure 3) as a result of Part D. Indeed, later in this paper we will show that if dynamic considerations are incorporated into the analysis, then stronger mortality effects of Part D may be identified beyond 2006. Second, it is possible that a decline in mortality of one type may be related to an increase in mortality from other causes. This pattern suggests that a model that explicitly addresses these alternatives in a single competing-risks framework may be useful. Finally, using the near elderly population as a control group is problematic since this group seems to have been affected by Part D, albeit to a smaller degree than the elderly population.

\section{Competing-Risks Model}

In this section, we consider a complete system for measuring the effects of Part D on mortality. We use a competing-risks model which allows alternative causes of death to be interrelated. That is, the model takes into account that an increase in mortality from cancer necessarily implies a reduction in cardiovascular-related deaths. The model assumes three different health states: (1) cardiovascular death, (2) noncardiovascular death, and (3) alive. First, we introduce the baseline model. We then incorporate dynamic effects into the model which control for delayed-mortality effects - that is, the impact of the reform on the health of the population in subsequent periods.

\subsection{Baseline Model}

Since the goal is to quantify the entire post-period effect of the reform, we include a post-period dummy in place of the flexible time dummies used in the previous analysis. Following much of the notation of (3), the health state of an individual, $i, h_{d, t, c, i}$, takes the following functional form: 


$$
h_{d, t, c, i}=\tau_{d}\left(1-S H A R E_{c}^{p r e}\right) \cdot \text { Post }_{t}+\beta X_{d, t, c}+\gamma_{d, c}+\gamma_{d, t}+\xi_{d, t, c}+\epsilon_{d, t, c, i},
$$

where the additional variable contained in $(5), \epsilon_{d, t, c, i}$ includes random factors that determine an individual's cause of death that is not shared by the entire county in time period $t$. We normalize the health state of being alive to zero. Therefore, the higher the value of the health state variable for cardiovascular-related and noncardiovascular-related conditions, the greater the probability that an individual dies of those respective causes. The main difference under equation (5), relative to previous model, is that all three options are explicitly viewed as substitutes. For example, if $h_{\text {noncardio }, t, c, i}>h_{\text {cardio,t,c,i}}>0$ then a person will die of a noncardiovascular cause, rather than a cardiovascular condition. To provide some structure on the substitution patterns among states, we assume that $\epsilon_{d, t, c, i}$ is independently and identically distributed as type 1 extreme value. Also, let the average health of the population in the county for disease $d$ be denoted:

$$
\delta_{d, t, c}=\tau_{d}\left(1-S H A R E_{c}^{p r e}\right) \cdot \text { Post }_{t}+\beta X_{d, t, c}+\gamma_{d, c}+\gamma_{d, t}+\xi_{d, t, c} .
$$

The usual logit functional form for the shares of individuals dying of disease $d$ in period $t$ is then:

$$
s_{d, t, c}=\frac{\exp \left(\delta_{d, t, c}\right)}{1+\sum_{d \in\{\text { cardio,noncardio }\}} \exp \left(\delta_{d, t, c}\right)} .
$$

Berry (1994) shows that the above model may be estimated with the following linear regression:

$$
\begin{aligned}
\log \left(s_{d, t, c}\right)-\log \left(s_{\text {alive }, t, c}\right) & =\delta_{d, t, c} \\
& =\tau_{d}\left(1-S H A R E_{c}^{\text {pre }}\right) \cdot \text { Post }_{t}+\beta X_{d, t, c}+\gamma_{d, t}+\xi_{d, t, c} .
\end{aligned}
$$

Equation 6 provides a simple empirical model, which contains all the potential states of the individual. The model implicitly incorporates the substitution among conditions, where the logit functional form assumes that individuals substitute in proportion to the shares of each health state. One advantage of this approach is it accounts for all health states when measuring the impact on total mortality and it also allows for a clear relationship across alternative causes of death.

There are two types of mortality rates studied in the competing-risks model. The simple mortality share, $s_{d, t, c}$, considers the share of the population that falls into each of the three health states in each time period. The YLL mortality share, $s_{d, t, c}^{Y L L}$, considers the 
total potential life years in each state at the end of each period. Essentially, this approach weights the population in each age group by the expected years of life for the average individual in that age group. Rather than normalize each county to the 2000 population, this analysis controls for the demographics by including the share of the population in each age-sex category interacted with each condition category as independent variables. ${ }^{53}$

\subsection{Incorporating Dynamic Effects}

Measuring the effects of Part D in future periods must also take into account the impact of the reform on the health of the population in subsequent periods. Specifically, as argued in Figure 3, the cardiovascular health of the population in previous periods may influence the health and the mortality rate of the population in subsequent periods. ${ }^{54}$ We address this issue by explicitly controlling for dynamic mortality effects in the model. Importantly, the lag of the dependent variable contains information regarding the changing health of the population. If a relatively small fraction of individuals die from cardiovascular-related diseases in a previous period, relative to the average amount for that county, this likely implies a relatively large stock of individuals in the population who may suffer or die from this illness in a subsequent period. The lag of the dependent variable may be incorporated into the empirical model to capture changes in the health of the population, as well as changes in the health of the population related to the reform. Let the lag of the dependent variable be denoted $\delta_{d, t-1, c}$. The model that incorporates these dynamic considerations is the following:

$$
\begin{aligned}
\delta_{d, t, c}= & \tau_{d}\left(1-S H A R E_{c}^{\text {pre }}\right) \cdot \text { Post }_{t}+\beta X_{d, t, c} \\
& +\left[\kappa_{d, 1} \delta_{d, t-1, c}+\kappa_{d, 2} \delta_{d, t-1, c}\left(1-S H A R E_{c}^{\text {pre }}\right) \cdot \text { Post }_{t-1}\right. \\
& \left.+\kappa_{d, 3} \delta_{d, t-1, c}\left(1-S H A R E_{c}^{p r e}\right)+\kappa_{d, 4} \delta_{d, t-1, c} \cdot \text { Post }_{t-1}\right] \\
& +\gamma_{d, c}+\gamma_{d, t}+\xi_{d, t, c},
\end{aligned}
$$

\footnotetext{
${ }^{53}$ Specifically, the share variables are calculated as: $s_{d, t, c}=\frac{\operatorname{Died}_{t}^{d} t o t+1}{\text { Total Population in Period } t}$ and $s_{d, t, c}^{Y L L}=$ $\operatorname{Died}_{t \quad \text { to } t+1}^{d}$ Weighted by Expected Life Years Lost Total Expected Life Years Lost for Population in Period $t$.

${ }^{54}$ For example, suppose the reform acts to increase the life expectancy for those with an illness for about one year. In this case, those areas where the reform has a large impact will receive a large reduction in mortality in the amount of $\tau_{d}\left(1-S H A R E_{c}^{\text {pre }}\right) \cdot$ Post $_{t}$. However, in the following year the population saved by the reform in the previous year, $\tau_{d}\left(1-S H A R E_{c}^{\text {pre }}\right) \cdot$ Post $_{t}$, will include less-healthy individuals who are more likely to die, thereby reducing the health of the population by an amount proportional to $\left(1-S H A R E_{c}^{\text {pre }}\right) \cdot$ Post $_{t}$.
} 
where the dynamic terms are included in the bracketed expression. The term $\delta_{d, t-1, c}$ captures the health of the population in the previous period for disease $d$, and its systematic relationship to current period mortality. The model also allows for the lagged dependent variable to have a unique effect one period after the reform, which is proportional to the magnitude of the reform's effect, through the expression $\delta_{d, t-1, c}\left(1-S H A R E_{c}^{\text {pre }}\right)$ Post $_{t-1}$ where the term Post P $_{-1}$ is an indicator if the year is 2007 or later. ${ }^{55}$ This second expression is crucial, since it is likely that many individuals changed treatment as a result of the reform, resulting in a change in survival in subsequent periods in proportion to those affected by the Part D introduction. In addition to being an important control, this variable also offers a test for the presence of the delayed mortality effect. A negative coefficient of $\kappa_{d, 2}$ would imply that those counties most impacted by the reform (i.e. a larger decrease in mortality due to the reform) would have a larger increase in mortality in the subsequent period. For completeness, two additional terms are added. The term $\delta_{d, t-1, c}\left(1-S H A R E_{c}^{p r e}\right)$ allows for the dynamic relationship to be different over the entire sample period for those counties predicted to be most impacted by the reform. Another term, $\delta_{d, t-1, c}$ Post $_{t-1}$, captures the change in this dynamic relationship across all counties one year after the reform.

\subsection{Competing-Risk Model Results}

In this section, we report results using both the baseline competing-risk model (6) and competing-risk model incorporating dynamic effects (7). We report two sets of results. First, we report results of the baseline model estimated on years 2000 to 2006 in Table 4this shows the immediate post period, 2006 (i.e., July 2006 to June 2007) where we know that there are no delayed-mortality effects. ${ }^{56}$ Second, we report results of both the baseline model and the baseline model with dynamic effects estimated on the full sample - that is, years 2000 through 2009.

Columns (1) through (6) of Table 4 reports results of the logit model estimated on 2000 to 2006 data $^{57}$ using either the core (columns (1), (3), (5)) or expanded (columns (2), (4),

\footnotetext{
${ }^{55}$ Specifically July 2007 or later - one year after the immediate post reform period (July 2006 to June 2007)

${ }^{56}$ As additional controls we include county-specific trends.

${ }^{57}$ The results in Table 4 are estimated on the sample from July 2000 to June 2007, but do not include 2005 (i.e., July 2005 to June 2006) since this includes months where Part D was implemented (i.e., January to June 2006). Please see Appendix Table D6 for results that include 2005 (i.e., July 2005 to June 2006) as a pre-reform observation.
} 
(6)) samples. For robustness purposes we include results based on regressions that include county trends (columns (3) and (4)) and county-disease trends (columns (5) and (6)), as well as results where we use population weights (Panels B and C). Panels A and B show results using mortality shares as the dependent variable, while panels $\mathrm{C}$ and $\mathrm{D}$ show results using years-of-life-lost shares, both measures for the 65 to 84 population. ${ }^{58}$

The results across all estimates in Table 4 show a drop in cardiovascular-related deaths in the immediate post period. The effect on noncardiovascular deaths is small and statistically insignificant. The estimates from Panel A, column (4), for example, imply that a county with a 1 percentage point increase in the share of individuals without drug insurance prior to the reform, leads to an average 0.003 percent increase in lives saved from the reform. ${ }^{59}$ That is, for a population of 100,000 individuals, 3 additional individuals would be saved, on average. For all estimates, we find that mortality rates for cardiovascularrelated conditions significantly decline and so does overall mortality, tested by applying a Wald test of the joint significance of $\tau_{\text {cardio }}+\tau_{\text {noncardio }}$.

Table 5 reports the results of the analysis where the full sample from 2001-2009 is studied using mortality shares as the dependent variable. ${ }^{60}$ Excluding the lagged terms, shown in columns (1) and (2), imply there is no effect of Part D on cardiovascular-related deaths, and the results show a significant increase in noncardiovascular-related deaths. The model in columns (3) and (4) include the lagged dependent-variable terms. The change in the results is striking, with the effect of Part D having a negative and statistically significant effect on cardiovascular mortality post-reform, while the effect on noncardiovascular mortality becomes insignificant.

\footnotetext{
${ }^{58}$ See Appendix Table D5 for results using the entire $65+$ population (i.e., including individuals 85 and above). Appendix Table D4 shows estimates under alternative specifications to construct SHARE pre. Additional robustness checks have also been conducted, such as removing states that may be impacted by Hurricane Katrina.

${ }^{59}$ To calculate how a 1 percentage point change in the share of the population without drug insurance prereform would impact mortality, we first calculate the number of individuals in each health state using the logit equation and assuming no change in pre-reform drug insurance. Next, we calculate a counterfactual estimate of $\delta_{d, t, c}$ with a 1 percentage point increase in $\left(1-S H A R E_{c}^{\text {pre }}\right)$ by adding the term $\tau_{d} * 0.01 *$ Post $_{t}$ to the expected value of $\delta_{d, t, c}$ for cardiovascular and noncardiovascular causes of death and then recalculate the number of individuals in each health state. The percentage change in lives saved is then computed as the increase in number of individuals in the "alive" state divided by the total population.

${ }^{60}$ See Appendix Table D7 for results using years-of-life-lost shares as the dependent variable. Results using population weights are reported in Appendix Table D8. The year 2000 is dropped since equation 7 contains a lag. Unlike estimates from Table 4, these results include the year July 2005 to June 2006 because the specification includes one-year lagged values.
} 
Table 4: Competing-Risks Model: 2000 to 2007

\begin{tabular}{|c|c|c|c|c|c|c|}
\hline & $(1)$ & $(2)$ & $(3)$ & (4) & (5) & (6) \\
\hline \multicolumn{7}{|l|}{ A. Mortality } \\
\hline \multirow[t]{2}{*}{ (1-CoverageShare)*Post*Cardio } & $-0.176^{* * *}$ & $-0.112^{* *}$ & $-0.231^{* * *}$ & $-0.171^{* * *}$ & $-0.231^{* *}$ & $-0.154^{* *}$ \\
\hline & $(0.060)$ & $(0.052)$ & $(0.066)$ & $(0.061)$ & $(0.090)$ & $(0.077)$ \\
\hline \multirow[t]{2}{*}{ (1-CoverageShare)*Post*NonCardio } & 0.004 & 0.019 & -0.051 & -0.040 & -0.051 & -0.057 \\
\hline & $(0.048)$ & $(0.038)$ & $(0.079)$ & $(0.052)$ & $(0.072)$ & $(0.060)$ \\
\hline \multicolumn{7}{|l|}{ B. Mortality (Weighted) } \\
\hline \multirow[t]{2}{*}{ (1-CoverageShare)*Post*Cardio } & $-0.104^{* *}$ & $-0.098 * * *$ & $-0.096 * *$ & $-0.111^{* * *}$ & -0.071 & $-0.086^{*}$ \\
\hline & $(0.042)$ & $(0.034)$ & $(0.048)$ & $(0.038)$ & $(0.056)$ & $(0.045)$ \\
\hline \multirow[t]{2}{*}{ (1-CoverageShare)*Post*NonCardio } & 0.014 & 0.006 & 0.022 & -0.007 & -0.004 & -0.032 \\
\hline & $(0.037)$ & $(0.026)$ & $(0.043)$ & $(0.031)$ & $(0.045)$ & $(0.033)$ \\
\hline \multicolumn{7}{|l|}{ C. Years of Life Lost } \\
\hline \multirow[t]{2}{*}{ (1-CoverageShare)*Post*Cardio } & $-0.203^{* * *}$ & $-0.108^{*}$ & $-0.247^{* * *}$ & $-0.162^{* *}$ & $-0.243^{* *}$ & $-0.145^{*}$ \\
\hline & $(0.065)$ & $(0.056)$ & $(0.072)$ & $(0.064)$ & $(0.095)$ & $(0.079)$ \\
\hline \multirow[t]{2}{*}{ (1-CoverageShare)*Post*NonCardio } & -0.013 & 0.001 & -0.057 & -0.053 & -0.060 & -0.069 \\
\hline & $(0.045)$ & $(0.038)$ & $(0.077)$ & $(0.052)$ & $(0.070)$ & $(0.061)$ \\
\hline \multicolumn{7}{|l|}{ D. Years of Life Lost (Weighted) } \\
\hline \multirow[t]{2}{*}{ (1-CoverageShare)*Post*Cardio } & $-0.128^{* * *}$ & $-0.097^{* * *}$ & $-0.157^{* * *}$ & $-0.133^{* * *}$ & $-0.143^{* *}$ & $-0.102^{*}$ \\
\hline & $(0.043)$ & $(0.037)$ & $(0.047)$ & $(0.043)$ & $(0.060)$ & $(0.052)$ \\
\hline \multirow[t]{2}{*}{ (1-CoverageShare)*Post*NonCardio } & 0.007 & -0.007 & -0.022 & -0.043 & -0.036 & $-0.074^{*}$ \\
\hline & $(0.037)$ & $(0.027)$ & $(0.053)$ & $(0.038)$ & $(0.050)$ & $(0.041)$ \\
\hline Observations & 2028 & 6360 & 2028 & 6360 & 2028 & 6360 \\
\hline Sample & Core & Expanded & Core & Expanded & Core & Expanded \\
\hline County Trend & No & No & Yes & Yes & No & No \\
\hline County-Disease Trend & No & No & No & No & Yes & Yes \\
\hline
\end{tabular}

Notes: This tables shows the estimates of $\tau_{d}$ in equation (6) under 24 different specifications. The mortality share measures used in the above estimates are based on mortality (Panels A and B) or years-of-life lost (Panels C and D) for the 65 to 84 population. See Appendix Table D5 for results where mortality measures were constructed for the entire $65+$ population. The estimation is taken over the sample period July 2000 to June 2007. The post period is July 2006 to June 2007. The July 2005 to June 2006 period was removed, see Appendix Table D6 for results that include this period as a pre-reform observation. The core sample includes 169 counties, and the expanded sample includes 530 counties. "Weighted" regressions use the square root of the age $65+$ county population from the year 2000 as weights. All regressions include county-disease fixed effects, year-disease fixed effects, the unemployment rate, and county income trends. Standard errors clustered by county. ${ }^{*} p<0.10,{ }^{* *} p<0.05,{ }^{* * *} p<0.01$. 
Table 5: Competing-Risks Model Incorporating Dynamic Effects: 2000 to 2009

\begin{tabular}{|c|c|c|c|c|}
\hline & $(1)$ & $(2)$ & $(3)$ & $(4)$ \\
\hline 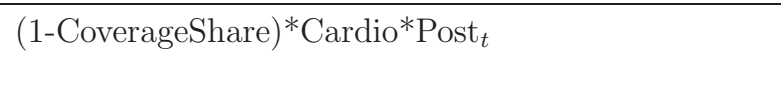 & $\begin{array}{c}0.029 \\
(0.050)\end{array}$ & $\begin{array}{l}-0.028 \\
(0.043)\end{array}$ & $\begin{array}{c}-0.203^{* * *} \\
(0.061)\end{array}$ & $\begin{array}{c}-0.117^{* *} \\
(0.057)\end{array}$ \\
\hline$(1 \text {-CoverageShare })^{*}$ NonCardio* Post $_{t}$ & $\begin{array}{c}0.079^{* *} \\
(0.035)\end{array}$ & $\begin{array}{c}0.086^{* * *} \\
(0.028)\end{array}$ & $\begin{array}{l}-0.008 \\
(0.049)\end{array}$ & $\begin{array}{c}0.013 \\
(0.036)\end{array}$ \\
\hline$\left(1\right.$-CoverageShare) ${ }^{*}$ Cardio*Post $_{t-1} * \delta_{\text {cardio }, t-1}$ & & & $\begin{array}{c}-0.046^{* * *} \\
(0.015)\end{array}$ & $\begin{array}{c}-0.023^{*} \\
(0.012)\end{array}$ \\
\hline$(1$-CoverageShare $) *$ NonCardio ${ }^{*}$ Post $_{t-1} * \delta_{\text {noncardio }, t-1}$ & & & $\begin{array}{c}-0.027^{* *} \\
(0.011)\end{array}$ & $\begin{array}{c}-0.026^{* * *} \\
(0.010)\end{array}$ \\
\hline Cardio Post $_{t-1} * \delta_{\text {cardio, } t-1}$ & & & $\begin{array}{c}0.010 \\
(0.037)\end{array}$ & $\begin{array}{l}0.039^{*} \\
(0.021)\end{array}$ \\
\hline NonCardio $*$ Post $_{t-1} * \delta_{\text {noncardio }, t-1}$ & & & $\begin{array}{c}0.015 \\
(0.035)\end{array}$ & $\begin{array}{c}0.019 \\
(0.023)\end{array}$ \\
\hline$(1$-CoverageShare $) *$ Cardio $* \delta_{\text {cardio }, t-1}$ & & & $\begin{array}{c}-0.350^{* *} \\
(0.166)\end{array}$ & $\begin{array}{l}-0.040 \\
(0.173)\end{array}$ \\
\hline$(1 \text {-CoverageShare })^{*}$ NonCardio* $\delta_{\text {noncardio }, t-1}$ & & & $\begin{array}{l}-0.420 \\
(0.257)\end{array}$ & $\begin{array}{l}-0.059 \\
(0.193)\end{array}$ \\
\hline Cardio* $\delta_{\text {cardio }, t-1}$ & & & $\begin{array}{c}0.072 \\
(0.072)\end{array}$ & $\begin{array}{c}0.011 \\
(0.070)\end{array}$ \\
\hline NonCardio $* \delta_{\text {noncardio }, t-1}$ & & & $\begin{array}{c}0.015 \\
(0.122) \\
\end{array}$ & $\begin{array}{l}-0.030 \\
(0.075) \\
\end{array}$ \\
\hline Observations & 3042 & 9540 & 3042 & 9540 \\
\hline Sample & Core & Expanded & Core & Expanded \\
\hline
\end{tabular}

Notes: The share measures used in the above estimates are based on mortality for the 65 to 84 population. The estimation is taken over the entire sample period 2001 to 2009, although includes lags from the year 2000. The post period is July 2006 to June 2010. The core sample includes 169 counties, and the expanded sample includes 530 counties. Post $t_{t-1}$ is an indicator if the period is later than July 2007. All regressions include county-disease fixed effects, year-disease fixed effects and the unemployment rate. We report estimates using years-of-life lost in Appendix Table D7 and estimates using county population weights in Appendix Table D8. Standard errors clustered by county. ${ }^{*} p<0.10,{ }^{* *} p<0.05,{ }^{* * *} p<0.01$. 
The coefficient on the lagged-dependent variable interacted with the Part D change, $\kappa_{d, 2}$, shows that for those counties most impacted by the reform, a larger decline in mortality in those counties had a larger increase in the mortality rate in the following period. That is, this term provides evidence of delayed-mortality effects.

One issue with applying equation (7) is that it incorporates both fixed effects and lagged dependent variables in the model. When the number of time periods is small, this estimation strategy potentially leads to inconsistent estimates (see Nickell (1981)). The concern arises because the change in the lagged-dependent variable is necessarily related to the change in the error term, $\xi_{d, t, c}$. However, we tested the model for serial correlation in the error term using the Wooldridge test (Drukker (2003)) and found strong evidence that this was not impacting our results. ${ }^{61}$

The results of Table 5 indicate that the mortality effects of Part D continue through our entire sample and confirm the intuition described in Figure 3. Specifically, once the change in the health of the population post-reform is accounted for, through $\kappa_{d, 2}$, the effects on mortality hold throughout the entire sample. While this result supports the previous results, as with all studies of policy effects, there are more factors that could explain the effects of reform on mortality as one moves farther away from the event, leading to less precise estimates.

\subsection{Robustness Analysis}

Several additional models and specifications have been estimated to explore the robostness of the results presented in this paper. Many of these robustness checks have been noted throughout the text and in footnotes. This section highlights these robustness checks, which may be found in Appendices C and D.

The baseline competing risk model suffers from the "independence of irrelevant alternatives" problem that is caused by assuming that individuals substitute among alternatives in proportion to the share of each health state. In Appendix C and Table C3, we allow for more flexible substitution patterns by applying a nested-logit model, which is commonly applied in the industrial organization literature (Berry (1994)). Consistent to the results in the text, the nested logit model shows significant declines in cardiovascular mortality.

Table 1 presents estimates based on alternative constructions of the variable $S H A R E_{c}^{p r e}$.

\footnotetext{
${ }^{61}$ Specifically, the p-value on the F-statistic testing the null-hypothesis of no serial correlation on equation (6) under the 2000 to 2009 sample was 0.80 . We also performed a robustness exercise in which we removed the county-disease fixed effects and included the year 2000 value of the dependent variable as a control. No results changed.
} 
For instance, using raw estimates from MCBS without demographic controls, using an alternative time period from MCBS (2000 to 2003), or including additional individual demographic controls from the MCBS (e.g., education, race and health factors). Across a variety of alternative specifications, we obtain results consistent with those found in the text.

Table D5 includes the same estimates as in Table 4 of the text, but includes the full $65+$ population, rather than 65 to 84. Table D6 includes the period July 2005 to June 2006 as a pre-reform period, which we view as partially impacted by the reform. Table D7 includes the dynamic results from Table 5, but using the years-of-life-lost mortality calculation. Table D8 includes the dynamic results from Table 5, but weighted for the county population size. The results from all of these robustness checks are similar to those presented in the text.

\section{Measuring the Value of Medicare Part D Expansion}

As a final exercise, we incorporate the results on expenditures with the results on mortality to perform a type of cost-benefit analysis of the reform. To simplify the analysis, we focus on the lives saved in 2007. The results are included in Table 6, which are scaled to the overall impact on the $65+$ Medicare population. ${ }^{62}$

The top half of Table 6 reports estimates of the reform's effect related to expenditures. The MCBS population weights are applied to arrive at a total expenditure estimate on prescription drugs for 2007 of around $\$ 79$ billion. The estimated impact of the reform on expenditures, based on estimates similar to specification (2) detailed in Appendix A, is 10 percent, which amounts to an expenditure increase caused by the reform of $\$ 7.9$ billion. ${ }^{63}$ A back-of-the-envelope calculation is conducted to arrive at expenditure figures for cardiovascular-related conditions. Since about 48 percent of total drug expenditures are on cardiovascular-related drugs, we estimate that the share of additional spending on cardiovascular-related drugs is $\$ 3.8$ billion (i.e., $\$ 7.9 .48$ percent). Second, to arrive at a figure of out-of-pocket expenditures for prescription drugs, we use the average share of outof-pocket post-reform spending of 23 percent, to arrive at the total increase in out-of-pocket

\footnotetext{
${ }^{62}$ Another important point to note is that the geographic coverage is limited by the fact that the MCBS does not cover all states and many counties had too few observations to accurately measure the impact of Part D. However, the estimates from the counties used in the analysis are scaled to the 2007 figures for the entire U.S.

${ }^{63} \mathrm{We}$ arrive at this figure by comparing expected expenditures with the reform, to counterfactual expenditures without the reform. See the Appendix A for details.
} 
spending on cardiovascular drugs of $\$ 800$ million.

Next, we calculate the effects of the reform on lives saved in 2007 and then monetize this amount by assigning $\$ 200,000$ per statistical life year. ${ }^{64}$ To compute the lives saved, we compare the number of observed deaths in 2007 with the reform, to the counterfactual number of deaths assuming the reform did not occur. ${ }^{65}$

We report a range of estimated lives saved based on the different models studied in this paper, including both static and dynamic estimates. Our preferred estimates satisfy several key criteria. First, we focus on specifications with a simple mortality rate, rather than years-of-life lost, as it is easier to translate the estimates into lives saved in 2007 and estimates from both approaches imply a similar number of lives saved. Also, we selected unweighted specifications in order to maximize the geographic diversity of the counties contributing to the estimates and to insure that populous urban areas do not dominate the results. Finally, we view that accounting for dynamics or county-specific trends as important. For this reason, all the static specifications that we include in this section incorporate a county-specific trend variable.

While we view some specification features as preferable to others, there are many cases where the trade-offs across specifications are less certain. ${ }^{66}$ Therefore, we select and report the effects on mortality using a variety estimates that satisfy the key criteria discussed above. These estimates are reported at the bottom of Table 6 . The number of lives saved ranges from 7,000 to 26,000 . In dollar terms this amounts to between $\$ 1.5$ and $\$ 4.8$ billion

${ }^{64}$ This is the amount applied in Eggleston et al. (2011).

${ }^{65}$ This is computed in analogous manner to how we compute the counterfactual expenditures in Appendix A. To obtain the mortality rate without the reform, we subtract the term, $\tau_{d} \cdot \frac{\Delta \widehat{I N S}_{c}}{\widehat{\alpha}_{1}}$, from the expected mortality rate, where $\tau_{d}$ is the coefficient on $\left(1-S H A R E_{c}^{\text {pre }}\right)$ in the mortality rate regression, $\triangle \widehat{I N S}_{c}$ is the expected change in insurance from the reform obtained from the linear regression $\triangle \widehat{I N S}_{c}=\widehat{\alpha}_{0}+$ $\widehat{\alpha}_{1}\left(1-S H A R E_{c}^{p r e}\right)$, and $\widehat{\alpha}_{1}$ is the coefficient in this regression.

${ }^{66}$ For instance, there is a trade-off between using the core and expanded samples. The expanded sample is able to include a much larger number of counties, potentially increasing precision and the representativeness of the estimates. On the other hand, the core sample has the desirable feature of using the individuals observed in each county to measure the likely impact of Part D, while the expanded sample is based on predictions. For this reason, we present estimates using both the core and expanded samples. Another case where the trade-off is unclear is between using county-specific trends or county-disease-specific trends. The county-disease specific trends are able to account for disease-specific trends in each county, but also greatly reduce the degrees of freedom. We present a third estimate that includes county-disease-specific trends. Finally, in addition to these trade-offs, it is unclear whether a static or dynamic specification is preferred. The dynamic specification estimates the effects of the reform over the entire sample, but includes periods that are more distant from the reform. The dynamic specification is also more reliant on the functional form. 


\section{Table 6: Cost-Benefit Analysis of Part D Expansion in 2007}

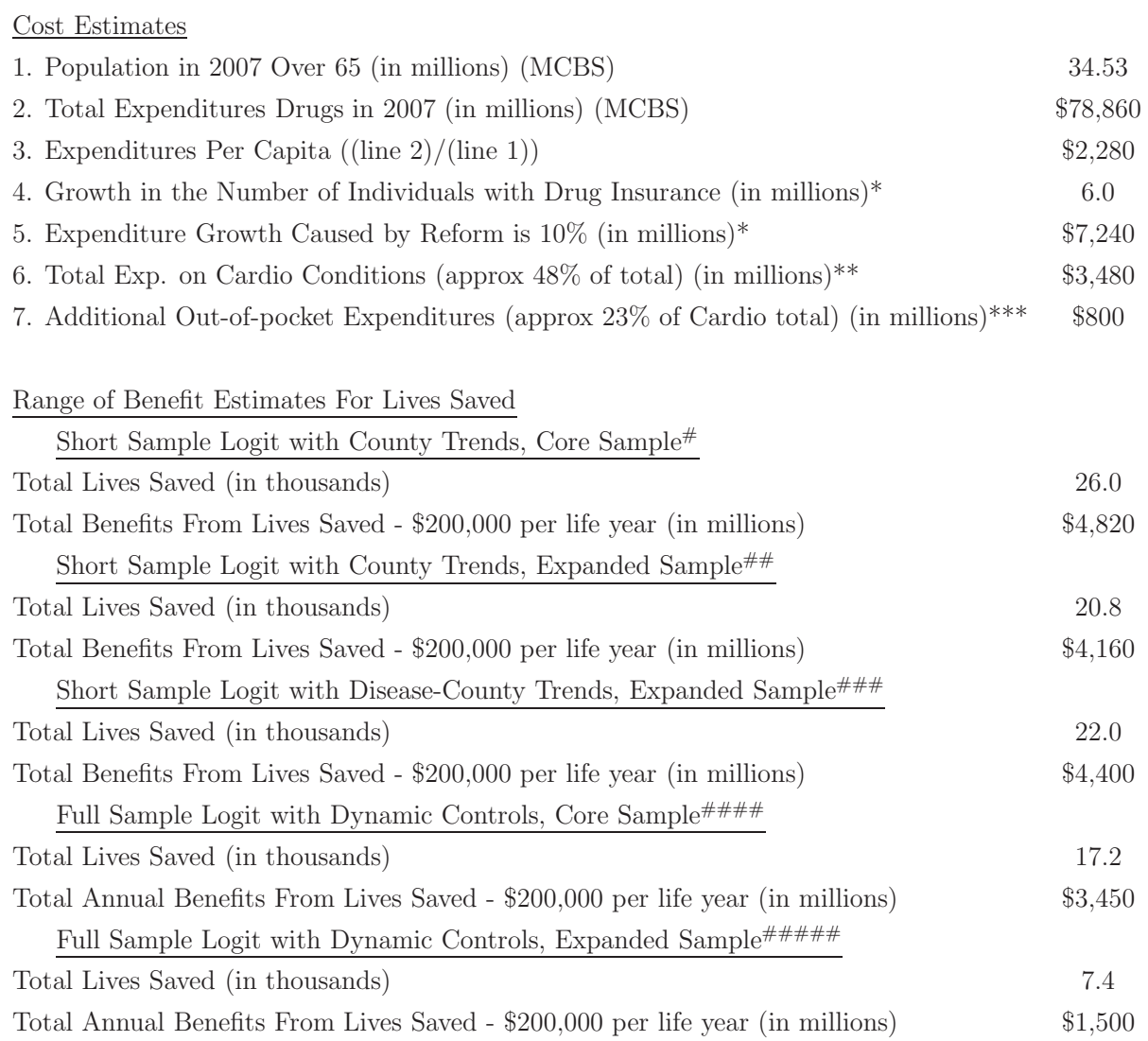

Notes:

*Amount is computed based on predicted change from Part D for those counties with 30 or more observations, but applying the amount to the full population. The drug insurance definition includes additional individuals receiving drug insurance, where the definition of drug insurance depends on the generosity of the plan. Predicted expenditure growth is based on the Poisson estimates in Tabletable: expenditure.

${ }^{* *}$ Calculated as a share of cardiovascular drug expenditures over the period 2003-09 from the underlying MEPS data.

${ }^{* * *}$ Applying the observed ratio of out-of-pocket expenditures for drugs to total drug expenditures from Table 1.

\#Constructed using estimate from Table 4, Panel A, Column 3

\#\#Constructed using estimate from Table 4, Panel A, Column 4

\#\#\# Constructed using estimate from Table 4, Panel, Column 6

\#\#\#\# Constructed using estimate from Table 5, Column 3

\#\#\#\#\#Constructed using estimate from Table 5, Column 4 
in the value of lives saved. The estimated value of lives saved exceeds the out-of-pocket expenditures of individuals on cardiovascular drugs, which is consistent with individuals purchasing prescription drugs whose benefit exceeds the out-of-pocket costs. The value of the additional drugs purchased for our preferred specifications ( $\$ 1.5$ to $\$ 4.8$ billion) lies in the range of the total cost of the drugs ( $\$ 3.5$ billion). In fact, based on four out of five of these estimates, the benefit generated from lives saved are equal to or above the total additional expenditures on cardiovascular drugs.

The analysis here does not consider the welfare benefits of reducing the financial risk of the population. The work of Engelhardt and Gruber (2011) examine this issue and find that the welfare benefits of financial protection are about $\$ 455$ per beneficiary, on average, or $\$ 15.7$ billion in total. ${ }^{67}$ This amount is slightly larger than the deadweight loss that they estimate of $\$ 430$ per recipient, or $\$ 14.8$ billion. Incorporating the health benefits of cardiovascular treatments into the calculation adds between $\$ 43-\$ 140$ in welfare benefits per Medicare beneficiary, suggesting an overall welfare gain from Part D's introduction of between $\$ 68$ and $\$ 165$ per beneficiary or between $\$ 2.3$ and $\$ 5.7$ billion per year.

\section{Conclusion}

This study provides evidence of the impact of the Medicare Part D prescription drug insurance expansion on mortality for the above-65 population. Applying a differencein-differences framework that exploits the geographic differences in drug coverage across markets prior to reform, we find a statistically significant reduction in cardiovascularrelated deaths, saving between 7,000 and 26,000 lives in its first year. While the exact magnitude of the number of lives saved depends on the particular specification, the basic result of a decline in cardiovascular-related deaths is shown to hold up across a multitude of robustness tests.

We find three features of the analysis that are critical for identifying the effects from the Part D program. First, we recognize that the Part D reform may transform the health of the population in future periods. Consequently, much of our analysis focuses on the impact of the reform immediately after implementation. Second, we study the impact of mortality on the condition that is most likely to be impacted by the reform, cardiovascular-related conditions. Third, we find that Part D had a small but statistically significant effect on the under 65 population. Thus, researchers should be aware that the under 65 population

\footnotetext{
${ }^{67}$ We are scaling up the Engelhardt and Gruber estimate to the number of Medicare individuals over 65 in 2007 .
} 
may not be a proper control group when studying the impact of the Part D reform.

It is unclear whether the insights applied in this paper to measure the effects of Part D reform would be effective in measuring the impact of policy changes on mortality in other settings. Indeed, it may be that the unique features of the Part D insurance expansion led to identifiable effects on mortality (e.g., proven and effective drugs for treating cardiovascular conditions). However, we hope that the basic lessons learned in this study may lead to new insights for studying the effects of reforms on mortality across other settings. 


\section{References}

[1] Antithrombotic Trialists' Collaboration, (2002), "Collaborative meta-analysis of randomized trials of antiplatelet therapy for prevention of death, myocardial infarction, and stroke in high risk patients," BMJ, 324(7329) pgs 71-86.

[2] Berry, Steven, (1994), "Estimating Discrete-Choice Models of Product Differentiation," Rand Journal of Economics, 25, pgs 242-262.

[3] Berry, Steven, James Levinsohn, and Ariel Pakes, (2004), "Differentiated Products Demand Systems from a Combination of Micro and Macro Data: The New Car Market," Journal of Political Economy, 112(1), pgs 68-105.

[4] Baicker, Katherine, Sarah Taubman, Heidi Allen, Mira Bernstein, Jonathan Gruber, Joseph Newhouse, Eric Schneider, Bill Wright, Alan Zaslavsky, and Amy Finkelstein, (2013), "The Oregon Experiment - Effects of Medicaid on Clinical Outcomes," New England Journal of Medicine.

[5] Blood Pressure Lowering Treatment Trialists' Collaboration. 2003. "Effects of different blood-pressure-lowering regimens on major cardiovascular events: results of prospectively-designed overviews of randomised trials." Lancet Vol. 362. pgs 1527-35.

[6] Card, David, Carlos Dobkin, Nicole Maestas, (2009), "Does Medicare Save Lives?," Quarterly Journal of Economics, 124(2) pgs 597-636.

[7] Chandra, Amitabh, Jonathan Gruber, and Robin McKnight, (2010), "Patient Cost Sharing and Hospitalization Offsets in the Elderly," American Economic Review, 100(1) pgs 193-213.

[8] Cholesterol Treatment Trialists' Collaborators (2005) "Efficacy and safety of cholesterol-lowering treatment: prospective meta-analysis of data from 90,056 participants in 14 randomised trials of statins." Lancet. Vol. 366 Pages 1267-1278.

[9] Cholesterol Treatment Trialists' Collaborators (2008) "Efficacy of cholesterol-lowering therapy in 18,686 people with diabetes in 14 randomised trials of statins: a metaanalysis." Lancet. Vol. 371 Pages 117-25.

[10] Cholesterol Treatment Trialists' Collaborators (2010) "Efficacy and safety of more intensive lowering of LDL cholesterol: a meta-analysis of data from 170,000 participants in 26 randomised trials" Lancet. Vol. 376 Pages 1670-1681. 
[11] Cholesterol Treatment Trialists' Collaborators (2012) "The effects of lowering LDL cholesterol with statin therapy in people at low risk of vascular disease: meta-analysis of individual data from 27 randomised trials." Lancet. Vol. 380 Pages 581-590.

[12] Congressional Budget Office. (2014). "Competition and the Cost of Medicare's Prescription Drug Program."

[13] Cutler, David, (2004), Your Money or Your Life: Strong Medicine for America's Healthcare System, Oxford University Press.

[14] Cutler, David and Wendy Everett, (2010), "Thinking outside the pillbox - medication adherence as a priority for health care reform," New England Journal of Medicine, Perspective, 362, pgs 17.

[15] Cutler, David, Angus Deaton, and Adriana Lleras-Muney. (2006) "The Determinants of Mortality." Journal of Economic Perspectives. Vol. 20(3) Pages 97-120

[16] Cutler, David, Genia Long, Ernst Berndt, Jimmy Royer, Andree-Anne Fournier, Alicia Sasser and Pierre Cremieux, (2007), "The Value of Antihypertensive Drugs: A Perspective on Medical Innovation," Health Affairs, 26(1) pgs 97-110.

[17] Dahlof, Bjorn, Lars H. Lindholm, Lennart Hansson, Bengt Schersten, Tord Ekbom, P.O. Wester. (1991). "Morbidity and mortality in teh Swedish Trial in Old Patients with Hypertension." Lancet Vol. 338. No. 8778.

[18] Deschenes, Olivier and Enrico Moretti. (2009). "Extreme weather events, mortality, and migration." The Review of Economics and Statistics. Vol. 91(4). 659-681.

[19] Drukker, David M. (2003) "Testing for serial correlation in linear panel-data models." The Stata Journal 3, Number 2, pp. 168-177.

[20] Duggan, Mark and Fiona Scott-Morton, (2010), "The Effect of Medicare Part D on Pharmaceutical Prices and Utilization," American Economic Review, 100(1) pgs 590607.

[21] Dunn, Abe, (2011), "The Effect of Health Insurance Competition when Private Insurers Compete with a Public Option", BEA Working Paper.

[22] Dunn, Abe, (2012), "Drug Innovations and Welfare Measured Computed from Market Demand: The Case of Anticholesterol Drugs," American Economic Journal: Applied Economics, 4(3) pgs 167-89. 
[23] Dunn, Abe and Adam Hale Shapiro (2015), "Physician Payments Under Health Care Reform," Journal of Health Economics, Vol. 39. pgs. 89-105.

[24] Dwyer-Lindgren, Laura, Ali Mokdad, Tanja Srebotnjak, Abraham Flaxman, Gillian Hansen, and Christopher Murray, (2014), "Cigarette Smoking Prevalence in US Counties: 1996-2012," Population Health Metrics, 12(5)

[25] Eaddy, Michael, Christopher Cook, Ken O’Day, Steven Burch, Ron Cantrell, (2012), "How Patient Cost-Sharing Trends Affect Adherence and Outcomes: A Literature Review," Pharmacy and Therapeutics, 37(1), pgs 45-55.

[26] Eggleston, Karen, Nilay Shah, Steven Smith, Ernst Berndt, and Joseph Newhouse, (2011), "Quality Adjustment for Health Care Spending on Chronic Disease: Evidence from Diabetes Treatment, 1999-2009," American Economic Review, Papers and Proceedings, 101(3), pgs 206-211.

[27] Engelhardt, Gary V., and Jonathan Gruber. 2011. "Medicare Part D and the Financial Protection of the Elderly." American Economic Journal: Economic Policy, 3(4): 77 102.

[28] Finkelstein, Amy and Robin McKnight, (2008), "What did Medicare do? The initial impact of Medicare on mortality and out of pocket medical spending," Journal of Public Economics, pgs 1644-1668.

[29] Finkelstein, Amy, (2007), "The Aggregate Effects of Health Insurance: Evidence from the Introduction of Medicare," Quarterly Journal of Economics, 122(1), pgs 1-37.

[30] Hajat, S., R. Kovats, R. Atkinson, and A. Haines, 2002. "Impact of Hot Temperatures on Death in London: A Time Series Approach,' Journal of Epidemiology and Community Health 56 (2002), 367-372.

[31] Khan, Nasreen and Robert Kaestner. 2009. "Effect of Prescription Drug Coverage on the Elderly's Use of Prescription Drugs." Inquiry.

[32] Ketcham, Jonathan and Kosali Simon, (2008), "Medicare Part D's Effects on Elderly Drug Costs and Utilization," American Journal of Managed Care, November pgs 1422.

[33] Lakdawalla, Darius and Wesley Yin, (2014), "Insurers' negotiating Leverage and the External Effects of Medicare Part D," The Review of Economics and Statistics, forthcoming. 
[34] LaRosa, John, Jiang He, and Suma Vupputuri, (1999), "Effects of Statins on Risk of Coronary Disease. A Meta-Analysis of Randomized Controlled Trials," Journal of the American Medical Association, 282 pgs 2340-6.

[35] Law, M.R., N.J. Wald, and A.R. Rudnicka, (2003), "Quantifying Effects of Statins on Low Density Lipoprotein Cholesterol, Ischemic Heart Disease, and Stroke: Systematic Review and Meta-Analysis," BMJ, 326(28), pgs 1-7.

[36] Lee, R., "Short-Term Variation: Vital Rates, Prices, and Weather", in E. A. Wrigley and R. S. Schofield (Eds.) 1981, The Population History of England 1541-1871

[37] Levy, Helen, Meltzer, David, 2004. "What do we really know about whether health insurance affects health?" In: McLaughlin, Catherine (Ed.), Health Policy on the Uninsured: Setting the Agenda. Urban Institute Press.

[38] Lichtenberg, Frank R. and Shawn X. Sun. 2007. "The Impact of Medicare Part D on Prescription Drug Use by the Elderly." Health Affairs.

[39] Newhouse, J. P. and the Insurance Experiment Group (1993). "Free for all? Lessons from the RAND Health Insurance Experiment," Cambridge, MA: Harvard University Press.

[40] Nickell, Stephen, (1981), "Biases in Dynamic Models with Fixed Effects," Econometrica, 49, pgs 1417-26.

[41] Ruhm, Christopher, (2000), "Are recessions good for your health?" Quarterly Journal of Economics, 115(2) pgs 618-650.

[42] Saez,Emmanuel, and Gabriel Zucman. (2014). "Wealth Inequality in the United States since 1913: Evidence from Capitilized Income Tax Data.” NBER Working Paper.

[43] Schwartz, Joel. (2001), "Is there harvesting in the association of airborne particles with daily deaths and hospital admissions?" Epidemiology. Vol 12(1). pgs.55-61.

[44] SHEP Cooperative Research Group, (1991), "Prevention of stroke by antihypertensive drug treatment in older persons with isolated systolic hypertension." Journal of the American Medical Association, 265(24) pgs 3255-3264.

[45] Solomon, Matthew, Dana Goldman, Geoffrey Joyce, Jose Escarce, (2009), "Costsharing and the initiation of drug therapy for the chronically ill," Archive of Internal Medicine, 169(8). 
[46] Veterans Administration Cooperative Study Group on Antihypertension Agents, (1967), "Effects of Morbidity on Treatment for Hypertension: Results in Patients with Diastolic Blood Pressures Averaging 115 Through 129 mm Hg," Journal of the American Medical Association,

[47] Veterans Administration Cooperative Study Group on Antihypertension Agents, (1970), "Effects of Morbidity on Treatment for Hypertension II. Results in Patients with Diastolic Blood Pressure Average 90 Through 114 mm Hg," Journal of the American Medical Association. 


\section{Appendix}

\section{A Implied Impact of Reform on Spending, Utiliza- tion, and Out-of-Pocket Price}

This section outlines how we measured the overall impact of the reform on out-of-pocket share and expenditures shown in Table 6. The steps taken here are very similar to those applied in Figure 8 and Figure 9, however, rather than including a different coefficient for each year, we include a single post-2006 treatment variable to capture the full impact on expenditures. Specifically, we estimate the coefficient $\tau$ in the specification:

$$
\text { Outcome }_{i, t, c}=f\left(\tau \cdot\left(1-S H A R E_{c}^{p r e}\right) P O S T_{t}+\delta Z_{i, t, c}+\beta X_{c, t}+\gamma_{c}+\gamma_{t}\right) .
$$

Table A1 shows estimates of $\tau$ taken from estimating (8) on different dependent variables. We limit the sample to three years pre-reform (2003-2005) and three years post reform (2006-2008). For the estimates to be comparable to the mortality analysis, we use only a limited set of demographic controls, including age, sex, unemployment rate, and median county income in 2000 interacted with a trend. Similar results are found when including additional control variables or looking at different years or samples.

As stated in the text, the value $\left(1-S H A R E_{c}^{\text {pre }}\right)$ is not equivalent to the full effect of the reform, since only a percentage of the those without drug insurance receive drug insurance because of the reform. Let the expected effect of the reform be determined by the simple regression model (as depicted in Figure 7):

$$
\Delta I N S_{c}=\alpha_{0}+\alpha_{1}\left(1-S H A R E_{c}^{\text {pre }}\right),
$$

then the expected change in coverage from the reform is:

$$
\Delta \widehat{I N S}_{c}=\widehat{\alpha}_{0}+\widehat{\alpha}_{1}\left(1-S H A R E_{c}^{\text {pre }}\right)
$$

and it follows that $\left(1-S H A R E_{c}^{p r e}\right)=\frac{\Delta \widehat{I N S}_{c}-\widehat{\alpha}_{0}}{\widehat{\alpha}_{1}}$. Substituting this value into (8), it follows:

$$
\widehat{\text { Outcome }_{i, t, c}^{\text {WithReform }}}=f\left(\widehat{\tau} \cdot\left(\frac{\widehat{\Delta} \widehat{I N S}_{c}-\widehat{\alpha}_{0}}{\widehat{\alpha}_{1}}\right) P O S T_{t}+\widehat{\delta} Z_{i, t, c}+\widehat{\beta} X_{c, t}+\widehat{\gamma}_{c}+\widehat{\gamma}_{t}\right)
$$


Table A1: Impact of Medicare Part D on Prescription Drug Spending and Utilization

\begin{tabular}{lcccccc}
\hline \hline & $(1)$ & $(2)$ & $(3)$ & $(4)$ & $(5)$ & $(6)$ \\
\hline \hline (1-CoverageShare)*Post & $0.368^{* * *}$ & $0.364^{* * *}$ & $0.266^{* * *}$ & $-0.460^{* * *}$ & $-0.466^{* * *}$ & $-1.066^{* * *}$ \\
& $(0.131)$ & $(0.135)$ & $(0.098)$ & $(0.033)$ & $(0.033)$ & $(0.138)$ \\
\hline \hline Observations & 51011 & 46366 & 51011 & 50667 & 46054 & 42484 \\
Dependant Variable & Expenditures & Expenditures & Num. of Prescriptions & OOP Share & OOP Share & log(average OOP spend) \\
& & & & & \\
Functional Form & Gamma, Log Link & Gamma, Log-Link & Gamma, Log-Link & Linear & Linear & Linear \\
Sample & Expanded & Core & Expanded & Expanded & Core & Expanded
\end{tabular}

Notes: We estimate equation (8) using a GLM model with a log link and Gamma distribution for expenditures, and a linear model for out of pocket spending. We limit the sample to three years pre-reform (2003-2005) and three years post reform (2006-2008). For the estimates to be comparable to the mortality analysis, we use only a limited set of demographic controls, including age, sex, unemployment rate, and median county income in 2000 interacted with a trend. Similar results are found when including additional control variables or looking at different years or samples. The core sample includes 169 counties, and the expanded sample includes 530 counties (see map in Figure 6). Standard errors clustered by county. ${ }^{*} p<0.10,{ }^{* *} p<0.05,{ }^{* * *} p<0.01$.

To obtain the expected effect of no reform we set $\Delta \widehat{I N S}_{c}$ equal to zero, by subtracting the term $\tau \cdot \frac{\Delta \widehat{I N S}_{c}}{\widehat{\alpha}_{1}}$, inside the function $f$. That is, to construct the no-reform counterfactual, we calculate: ${ }^{68}$

$\widehat{\text { Outcome }}_{i, t, c}^{\text {NoReform }}=f\left(\widehat{\tau} \cdot\left(\frac{\widehat{\Delta} \widehat{I N S_{c}}-\widehat{\alpha}_{0}}{\widehat{\alpha}_{1}}\right) P O S T_{t}+\widehat{\delta} Z_{i, t, c}+\widehat{\beta} X_{c, t}+\widehat{\gamma}_{c}+\widehat{\gamma}_{t}-\widehat{\tau} \cdot \frac{\Delta \widehat{I N S}_{c}}{\widehat{\alpha}_{1}}\right)$

After computing the predicted outcomes for each individual, we then compute the overall effect by summing across all individuals, weighted by the individual population weights. The predicted growth in expenditures due to the reform is then computed as total expenditures with reform divided by total expenditures without the reform. The estimates of the impact of the reform on expenditures (i.e., columns (1) and (2)), imply a 10.1 percent increase in expenditures caused by the reform. The third specification measures the impact of the reform on the number of prescriptions filled, which was predicted to increase by 7.4

\footnotetext{
${ }^{68}$ Alternatively one could run the regression with $\Delta \widehat{I N S}_{c}=\widehat{\alpha}_{0}+\widehat{\alpha}_{1}\left(1-S H A R E_{c}^{p r e}\right)$ as the covariate, rather than $\left(1-S H A R E_{c}^{p r e}\right)$, and then running the counterfactual by setting $\triangle \widehat{I N S}_{c}=0$. The results using either calculation are equivalent. Similar steps are taken to estimate counterfactual mortality effects from the reform.
} 
percent. The implied decline in out-of-pocket cost (i.e., columns (4) and (5)) was around 28 percent and around 25 percent for column (6).

This paper is the first to use geographic differences in Part D effects to measure the impact on drug expenditures, while other work in the literature primarily focuses on the differential expenditures for those above and below 65. Despite the difference in the approach taken here, the magnitude of the estimates fall in similar range to previous estimates in the literature. While some estimates on the effect of utilization are larger than ours (e.g., Lichtenberg and Sun (2007) find Part D increased utilization by 13 percent), others find more modest increases in expenditures (e.g., Ketcham and Simon (2008) find an increase of 8 percent in total prescription-drug spending while Khan and Kaestner (2009) find an increase of 4-10 percent in utilization). As for the impact on out-of-pocket costs, Ketcham and Simon find a more modest decline in out-of-pocket costs of around 17 percent. As noted in our paper and also in Ketcham and Simon, these previous studies that use the under 65 population as the comparison group to the over 65 population are likely to underestimate the effect of the reform due to the under-65 Medicare population.

\section{B Implied Demand Elasticity}

As an alternative method for understanding the impact of the reform, we use the reform to estimate a model of demand. Specifically, we estimate the following GLM demand model with a log link:

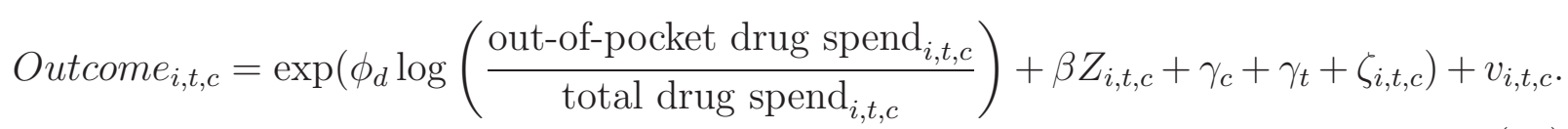

where Outcome $e_{i, t, c}$ is either an expenditure measure or a count of the number of prescriptions. The term $\zeta_{i, t, c}$ represent the unobserved health conditions of an individual. In

this model, the generosity of the insurance, as captured by $\log \left(\frac{\text { out-of-pocket drug spend }}{i, t, c}\right)$, is endogenous, since those with the greatest health problems will purchase more insurance. Specifically, there may be a correlation between $\log \left(\frac{\text { out-of-pocket drug spend }{ }_{i, t, c}}{\text { total drug } \operatorname{spend}_{i, t, c}}\right)$ and the unobserved factors expressed by the error term $\zeta_{i, t, c}$. To address this endogeneity problem we use $\left(1-S H A R E_{c}^{\text {pre }}\right) \cdot$ Post $_{t}$ as an instrument in a two-stage residual inclusion model following Terza, Basu and Rathouz (2008).

Specifically, in a first stage we estimate: 


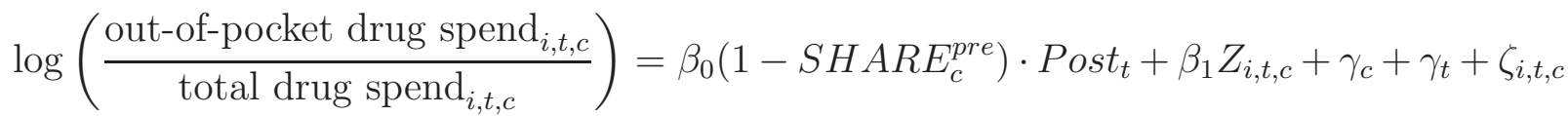

in order to provide a consistent estimate of unobserved factors that may be related to out-of-pocket expenditure share, $\widehat{\zeta}_{i, t, c}=\log \left(\frac{\text { out-of-pocket drug spend }}{i, t, c}\right)-\widehat{\alpha}_{c}+\widehat{\gamma}_{t}+\widehat{\tau}_{d} \Delta I N S_{c}$. Post $_{t}+\widehat{\beta} Z_{i, t, c}$. Including $\widehat{\zeta}_{i, t, c}$ in (13) controls for the unobserved factors that could bias the estimate of $\phi_{d}$. This offers an alternative and more direct estimate of consumer demand that can be compared with well-known studies in the literature as well as our estimated arc elasticity of demand implied by the reform. ${ }^{69}$

\section{Table B2: Prescription Drug Demand Elasticity}

\begin{tabular}{|c|c|c|c|c|c|c|c|c|c|c|}
\hline & (1) & $(2)$ & (3) & (4) & $(5)$ & (6) & (7) & (8) & (9) & $(10)$ \\
\hline \multirow[t]{2}{*}{$\begin{array}{l}\text { Log Exp. Share } \\
\text { E }\end{array}$} & $-0.417^{* * *}$ & $-0.417^{* * *}$ & $-0.296^{* * *}$ & $-0.312^{* * *}$ & $-0.311^{* * *}$ & $-0.349 * * *$ & $-0.247^{* *}$ & $-0.264^{* *}$ & $-0.278^{* *}$ & $-0.296^{* *}$ \\
\hline & 0.009 & 0.009 & 0.104 & 0.104 & 0.125 & 0.125 & 0.115 & 0.115 & 0.117 & 0.116 \\
\hline Observations & 45658 & 50235 & 45658 & 50235 & $4 \quad 45333$ & 499890 & 45658 & 50235 & $4 \quad 45333$ & 49980 \\
\hline Residual Inclusion & No & No & Yes & Yes & Yes & Yes & Yes & Yes & Yes & Yes \\
\hline Additional Controls & No & No & No & No & Yes & Yes & No & No & Yes & Yes \\
\hline Sample & Core & Expanded & Core & Expanded & Core & Expanded & Core & Expanded & Core & Expanded \\
\hline Functional Form & \multicolumn{6}{|c|}{ Gamma } & \multicolumn{4}{|c|}{ Poisson } \\
\hline
\end{tabular}

Notes: We estimate equation (13) using a GLM model with a log link. We apply the residual inclusion model to adjust for endogeneity. We limit the sample to three years pre-reform (2003-2005) and three years post reform (2006-2008). All specifications include a limited set of controls, including age, sex, unemployment rate, and median county income in 2000 interacted with a trend. The additional individual control variables include income, BMI, education, race, self-reported health, an indicator of death in that year, and indicators for 26 disease conditions. The core sample includes 169 counties, and the expanded sample includes 530 counties. Standard errors clustered by county

The estimates of the demand model are included in Table B2. Columns (1) and (2) show the GLM estimates without instrumenting using the core and expanded samples, respectively. The estimates show a highly significant and negative relationship between expenditures and the out-of-pocket price, which is likely biased downward because of selection. The following columns (3) and (4) estimate the model using the residual inclusion

${ }^{69}$ Although expenditure is a left-hand side variable, it should be noted that the demand estimation is likely capturing a quantity effect, since the county and time fixed effects likely account for any drug price differences across markets and over time. 
approach to account for endogeneity, again using the core and expanded samples. As expected, one can see that this greatly reduces the elasticity and the significance of the estimates compared to the first two columns. The elasticities are both around -0.3 . The estimates in columns (5) and (6) are similar to those in columns (3) and (4), but include additional health and demographic information. This additional demographic information has a limited effect on the estimates. The estimates in columns (7) through (10) correspond to those in columns (3) through (6), but use a Poisson distribution rather than a Gamma distribution. The absolute value of the elasticities fall by only a small amount. Overall, the individual demand elasticity estimates correspond well with the implied elasticity of the reform as well as elasticity estimates fromt he literature.

\section{Nested Logit}

A limitation of the baseline competing-risks model (6) is that it has restrictive substitution patterns. In particular, the model suffers from the "independence of irrelevant alternatives" problem that is caused by assuming that individuals substitute among alternatives in proportion to the share of each health state. Specifically, the logit functional form assumes that substitution between causes of death is in proportion to shares. This assumption may be problematic since those who die in period $t$ may have worse health and a greater chance of dying from an alternative cause, compared with the typical individual. For instance, in a logit model if health is poor in a population and many people suffer from multiple comorbidities, then substitution away from cardiovascular deaths toward noncardiovascular deaths is likely understated and the substitution to the health state of "alive" is likely overstated.

The nested logit specification allows for more flexibility in the substitution among alternative causes of death. For our nested logit model, we add a third type of mortality category that includes individuals who die of a noncardiovascular illness, who are recorded as having a cardiovascular comorbidity at the time of their death. The model allows for a distinct correlation pattern among those individuals who die from a cardiovascular illness or have a cardiovascular comorbidity at the time of death.

To estimate a nested logit model, we must add a third mortality category. This third mortality category draws upon additional medical condition information from the CDC mortality data, which lists all of an individual's major conditions at the time of death. Thus, the three different causes of death considered in the analysis are cardiovascular death, noncardiovascular death with cardiovascular comorbidity, and noncardiovascular 
death without cardiovascular comorbidity. The share of individuals dying in each of these categories is 40 percent, 23 percent, and 37 percent, respectively. Column (1) of Table C3 presents the results of the estimates with the three mortality categories included. The estimates show a significant decline in cardiovascular-related mortality, as in the previous results. However, we see an increase in noncardiovascular-related deaths with a cardiovascular comorbidity, although this estimate is not statistically significant. However, the positive sign is consistent with individuals surviving their cardiovascular illness, but dying of other causes.

The nested logit model follows from the fact that the error term, $\epsilon_{d, t, c, i}$, then has two components, including an i.i.d. shock and another group-specific component. In our analysis we select a nesting structure that includes those who die of a cardiovascular illness and those who die of a noncardiovascular illness with a cardiovascular comorbidity within the same nest. That is, one can think of the group-specific shock as capturing the prevalence of cardiovascular comorbidities in the population. Berry (1994) shows that this type of nesting structure may be incorporated into linear estimation of equation (6) by adding the nesting term, $\log \left(\frac{s_{d}}{s_{\text {cardio }}+s_{\text {noncardio } w / \text { cardio comorbidity }}}\right)$.

The inclusion of this additional term creates two complications. First, the term is endogenous, since the share term is contained within the dependent variable, so we will need to estimate the model using instrumental variables. Second, the inclusion of diseasecounty fixed effects removes much of the variation from the model, which complicates trying to find appropriate instruments for the nesting term. To address these issues we first specify a model similar to column (1) that allows for more degrees of freedom. Rather than including disease-county fixed effects, the estimate in column (2) includes only county fixed effects along with disease fixed effects that are common across counties. To capture county-specific health, the estimate in column (2) includes the value of the dependent variable in 2000 as an additional covariate. ${ }^{70}$ Although many more degrees of freedom are added by the exclusion of the disease-specific fixed effects, the estimate in column (2) is quite similar to those of column (1). A likely reason for this is that mortality rates by disease are specific to each county and persistent, so the mortality in 2000 is a strong predictor of mortality in future periods.

With the additional nesting term included, the nested logit regression model becomes:

\footnotetext{
${ }^{70}$ Since the mortality in 2000 is added to the specification, we limit the pre-period sample to $2002-04$. We could include 2001 in the Model 2 specification with similar results. However, for the model that includes a nest, Model 3, we use the two-period lag of the nesting term as an instrument, implying 2001 must be dropped from Model 3. To keep the estimates comparable, 2001 is also dropped from Model 2.
} 
Table C3: Nested Logit Model

\begin{tabular}{|c|c|c|c|c|c|c|}
\hline & $(1)$ & $(2)$ & $(3)$ & $(4)$ & $(5)$ & $(6)$ \\
\hline \multirow[t]{2}{*}{ (1- CoverageShare)*Cardio*Post } & $-0.209^{* * *}$ & $-0.247^{* * *}$ & $-0.198^{* * *}$ & $-0.134^{* *}$ & $-0.151^{* * *}$ & $-0.135^{* * *}$ \\
\hline & $(0.065)$ & $(0.070)$ & $(0.057)$ & $(0.056)$ & $(0.055)$ & $(0.047)$ \\
\hline \multirow[t]{2}{*}{ (1- CoverageShare)*NonCardio w/CardioCom*Post } & 0.040 & 0.056 & -0.058 & -0.043 & -0.052 & $-0.117^{* *}$ \\
\hline & $(0.081)$ & $(0.082)$ & $(0.060)$ & $(0.076)$ & $(0.077)$ & $(0.053)$ \\
\hline \multirow[t]{2}{*}{ (1- CoverageShare)*NonCardio w/o CardioCom*Post } & -0.016 & 0.006 & 0.056 & 0.005 & 0.033 & 0.062 \\
\hline & $(0.064)$ & $(0.068)$ & $(0.067)$ & $(0.052)$ & $(0.055)$ & $(0.056)$ \\
\hline \multirow[t]{2}{*}{ Cardio* $\delta_{\text {cardio }, 0}$} & & $0.681^{* * *}$ & $0.457^{* * *}$ & & $0.575^{* * *}$ & $0.364^{* * *}$ \\
\hline & & $(0.079)$ & $(0.099)$ & & $(0.032)$ & $(0.037)$ \\
\hline \multirow[t]{2}{*}{ NonCardio w/ Cardiocom* $\delta_{\text {cardio }, 0}$} & & $0.854^{* * *}$ & $0.577^{* * *}$ & & $0.691^{* * *}$ & $0.410^{* * *}$ \\
\hline & & $(0.049)$ & $(0.058)$ & & $(0.028)$ & $(0.034)$ \\
\hline \multirow{2}{*}{ NonCardio w/o Cardiocom* $\delta_{\text {cardio }, 0}$} & & $0.927^{* * *}$ & $0.933^{* * *}$ & & $0.788^{* * *}$ & $0.750^{* * *}$ \\
\hline & & $(0.039)$ & $(0.047)$ & & $(0.039)$ & $(0.049)$ \\
\hline \multirow[t]{2}{*}{ Nesting Parameter } & & & $0.484^{* * *}$ & & & $0.592^{* * *}$ \\
\hline & & & $(0.066)$ & & & $(0.047)$ \\
\hline Observations & 3006 & 3006 & 2505 & 9360 & 9360 & 7800 \\
\hline Sample Years & 2000-04, 2006 & 2001-04, 2006 & 2001-04, 2006 & 2000-04, 2006 & 2001-04, 2006 & 2001-04, 2006 \\
\hline Sample & Core & Core & Core & Expanded & Expanded & Expanded \\
\hline County-Disease FE & Yes & No & No & Yes & No & No \\
\hline County FE & No & Yes & Yes & No & Yes & Yes \\
\hline Instrumental Variables & No & Yes & Yes & No & Yes & Yes \\
\hline
\end{tabular}

Notes: The share measures used in the above estimates are based on the years-of-life lost for the 65 to 84 population. All regressions include county-disease fixed effects, year-disease fixed effects, countyspecific income trends, the age distribution of the population and the unemployment rate. Standard errors clustered by county. ${ }^{*} p<0.10,{ }^{* *} p<0.05,{ }^{* * *} p<0.01$.

$$
\begin{aligned}
\delta_{d, t, c} & =\delta_{0, t, c}+\tau_{d} \cdot\left(1-S H A R E_{c}^{\text {pre }}\right) \cdot \text { Post }_{t} \\
& +\beta X_{d, t, c}+\sigma \ln \left(\frac{s_{d \in\{\text { cardio, noncardio } w / \text { cardio comorb. }\}}}{s_{\text {cardio }}+s_{\text {noncardio } w / \text { cardio comorb. }}}\right) \\
& +\gamma_{c}+\gamma_{d, t}+\xi_{d, t, c}
\end{aligned}
$$

where $\delta_{0, t, c}$ is the value of the dependent variable in 2000. With the additional degrees of freedom, we then choose two specific instruments to address the endogeneity concerns. One instrument is the value of the nesting term for the population that is 55-64 years old. The nesting term of this younger population within the same county may be correlated through common health factors affecting the entire population, but should also be exogenous, since the population is distinct and should be less directly affected by Part D than those over 65. The two-period lag value of the nesting term is also used as an instrument for the current period nest. The two-period lag is used since it covers the mortality rate of the same disease category within the same county and the instrument is derived from data 
prior to the Part D implementation. ${ }^{71}$

The results of the nested logit model are reported in column (3). The nesting parameter is shown to be large and statistically significant, implying strong substitution between cardiovascular-related deaths and noncardiovascular-related deaths where a cardiovascular comorbidity is present, as might be expected. Similar to the previous estimates, column (3) also shows a significant reduction in cardiovascular-related deaths. However, distinct from columns (1) and (2) we see no increase in noncardiovascular death with a cardiovascular comorbidity. That is, it appears that the increase in this type of mortality, reflected in columns (1) and (2), may be caused by substitution patterns that were not accounted for in previous models. The effects on cardiovascular-related mortality is negative and significant in column (3). The estimates in column (4) through (6) repeat the analysis in columns (1) through (3) using the expanded sample. The results are qualitatively similar.

As one might expect, when we do not account for the correlation among alternative causes of death we tend to find a more positive effect of the reform on those that die of an alternative cause, but have a cardiovascular comorbidity. This effect diminishes when we allow for correlations among individuals that die with some type of cardiovascular comorbidity.

The nested-logit model presents its own unique challenges, such as requiring instruments and the exclusion of county-disease fixed effects. For this reason, we do not present the nested logit as one of our key specifications. However, it is important to highlight that our results are robust to this alternative specification.

\section{Additional Tables and Figures}

\footnotetext{
${ }^{71}$ We use a two-period lag, rather than a one-period lag, so that the transition period, 2005, is not included as an instrument. This assumption is not critical: using a single lag, rather than a two-period lag, produces qualitatively similar results.
} 
Table D1: Cause of Death by ICD-9 Disease Chapter for 65 and Over Population

\begin{tabular}{cc}
\hline Cause of Death Chapter & Share of Deaths \\
\hline \hline Diseases of the circulatory system & $40.4 \%$ \\
Neoplasms & $21.1 \%$ \\
Diseases of the respiratory system & $11.3 \%$ \\
Mental Illness & $7.8 \%$ \\
Endocrine; nutritional; and metabolism & $4.0 \%$ \\
Diseases of the genitourinary system & $2.8 \%$ \\
Diseases of the digestive system & $2.7 \%$ \\
Diseases of the nervous system & $1.9 \%$ \\
Infectious and parasitic diseases & $1.8 \%$ \\
Other & $6.1 \%$
\end{tabular}

Table D2: Demographic Differences in Drug Coverage

\begin{tabular}{|c|c|c|c|c|c|}
\hline Age-Sex Category & $\begin{array}{c}\text { Pre-Part D } \\
(2004-05)\end{array}$ & $\begin{array}{c}\text { Post Part D } \\
(2006-07)\end{array}$ & Change & & $\begin{array}{l}\text { Avg. Annual Pop. } \\
\text { (Thousands) }\end{array}$ \\
\hline \multicolumn{6}{|l|}{ Male } \\
\hline $65-69$ & $68.3 \%$ & $84.1 \%$ & $15.8 \%$ & 16,089 & 4,022 \\
\hline $70-74$ & $69.1 \%$ & $86.2 \%$ & $17.1 \%$ & 13,892 & 3,473 \\
\hline $75-79$ & $68.8 \%$ & $87.5 \%$ & $18.6 \%$ & 12,502 & 3,125 \\
\hline $80-84$ & $66.3 \%$ & $87.0 \%$ & $20.8 \%$ & 8,708 & 2,177 \\
\hline $85+$ & $61.0 \%$ & $84.3 \%$ & $23.2 \%$ & 6,167 & 1,542 \\
\hline \multicolumn{6}{|l|}{ Female } \\
\hline $65-69$ & $73.4 \%$ & $86.8 \%$ & $13.4 \%$ & 18,660 & 4,665 \\
\hline $70-74$ & $73.6 \%$ & $91.0 \%$ & $17.4 \%$ & 17,308 & 4,327 \\
\hline $75-79$ & $70.0 \%$ & $89.7 \%$ & $19.7 \%$ & 15,193 & 3,798 \\
\hline $80-84$ & $67.2 \%$ & $88.3 \%$ & $21.1 \%$ & 13,303 & 3,326 \\
\hline $85+$ & $54.6 \%$ & $86.2 \%$ & $31.5 \%$ & 14,094 & 3,523 \\
\hline s.d. by age-sex category & $5.7 \%$ & $2.2 \%$ & $5.0 \%$ & & \\
\hline s.d. by age-sex category (Under 85 ) & $2.7 \%$ & $2.1 \%$ & $2.6 \%$ & & \\
\hline
\end{tabular}


Table D3: Probit: Predicted Drug Coverage by County

\begin{tabular}{|c|c|c|}
\hline & Pre Reform & Post Reform \\
\hline Age 65 to 69 & $\begin{array}{c}0.513^{* * *} \\
(0.075)\end{array}$ & $\begin{array}{l}0.172^{*} \\
(0.093)\end{array}$ \\
\hline Age 70 to 74 & $\begin{array}{c}0.497^{* * *} \\
(0.075)\end{array}$ & $\begin{array}{c}0.185^{* *} \\
(0.093)\end{array}$ \\
\hline Age 75 to 79 & $\begin{array}{c}0.463^{* * *} \\
(0.075)\end{array}$ & $\begin{array}{c}0.290 * * * \\
(0.094)\end{array}$ \\
\hline Age 80 to 84 & $\begin{array}{c}0.351^{* * *} \\
(0.076)\end{array}$ & $\begin{array}{c}0.237^{* *} \\
(0.094)\end{array}$ \\
\hline Age 85 to 90 & $\begin{array}{c}0.285^{* * *} \\
(0.082)\end{array}$ & $\begin{array}{c}0.138 \\
(0.101)\end{array}$ \\
\hline Male*(Age 65 to 69$)$ & $\begin{array}{c}0.118^{* * *} \\
(0.045)\end{array}$ & $\begin{array}{c}0.159 * * * \\
(0.055)\end{array}$ \\
\hline Male*(Age 70 to 74$)$ & $\begin{array}{c}0.130^{* * *} \\
(0.045)\end{array}$ & $\begin{array}{c}0.314^{* * *} \\
(0.057)\end{array}$ \\
\hline Male*(Age 75 to 79$)$ & $\begin{array}{c}0.008 \\
(0.045)\end{array}$ & $\begin{array}{c}0.117^{* *} \\
(0.059)\end{array}$ \\
\hline Male*(Age 80 to 84$)$ & $\begin{array}{c}0.038 \\
(0.045)\end{array}$ & $\begin{array}{l}0.104^{*} \\
(0.056)\end{array}$ \\
\hline Male*(Age 85 to 89 ) & $\begin{array}{c}-0.126^{* *} \\
(0.057)\end{array}$ & $\begin{array}{c}0.153^{* *} \\
(0.069)\end{array}$ \\
\hline Male*(Age $90+$ ) & $\begin{array}{c}-0.231^{* * *} \\
(0.077)\end{array}$ & $\begin{array}{c}0.103 \\
(0.097) \\
\end{array}$ \\
\hline Observations & 18651 & 18409 \\
\hline
\end{tabular}

Notes: This table shows estimates from estimating the probit model, equation (1) in the text, on sample years 2004 and 2005 in the MCBS data. 
Figure D12: Impact of Part D on Prescription Drug Out-of-Pocket Price: Core Sample
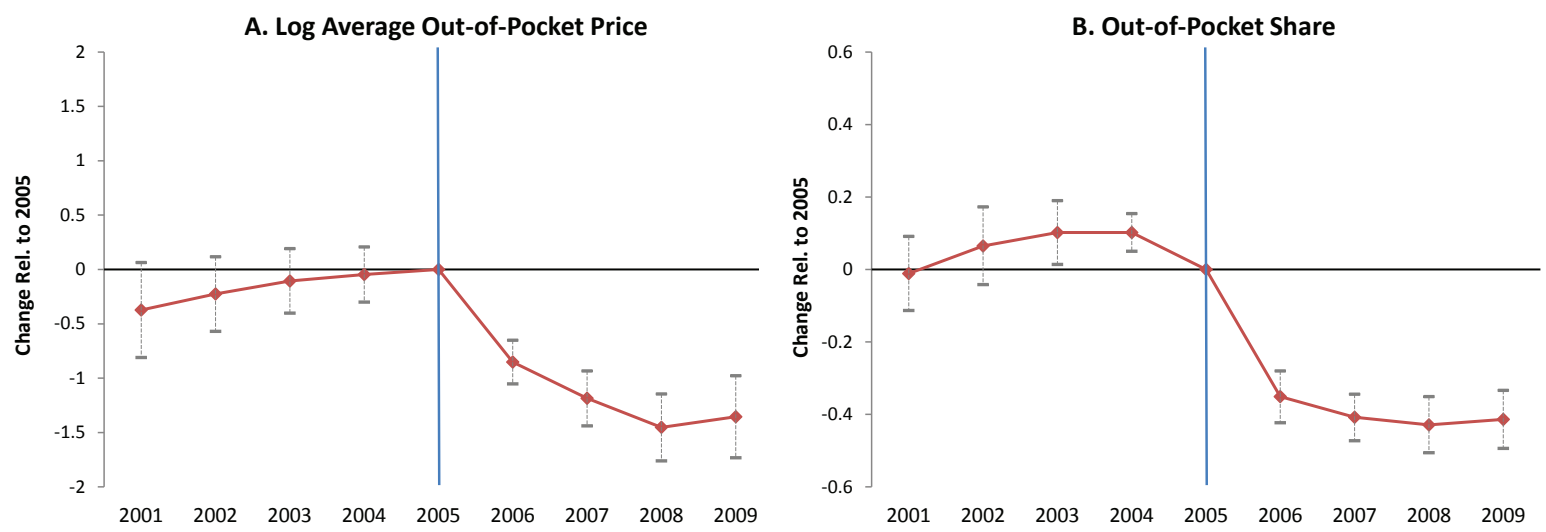

Notes: Panel A shows the coefficients $\tau_{t}$, and their 95 percent confidence intervals, estimated from (2) with the log out-of-pocket price as the dependent variable. Panel B shows the analogous estimates and 95 percent confidence intervals with the log out-of-pocket share as the dependent variable. All estimates taken over the core sample, which includes 169 counties.

Figure D13: Impact of Part D on Prescription Drug Use and Spending: Core Sample
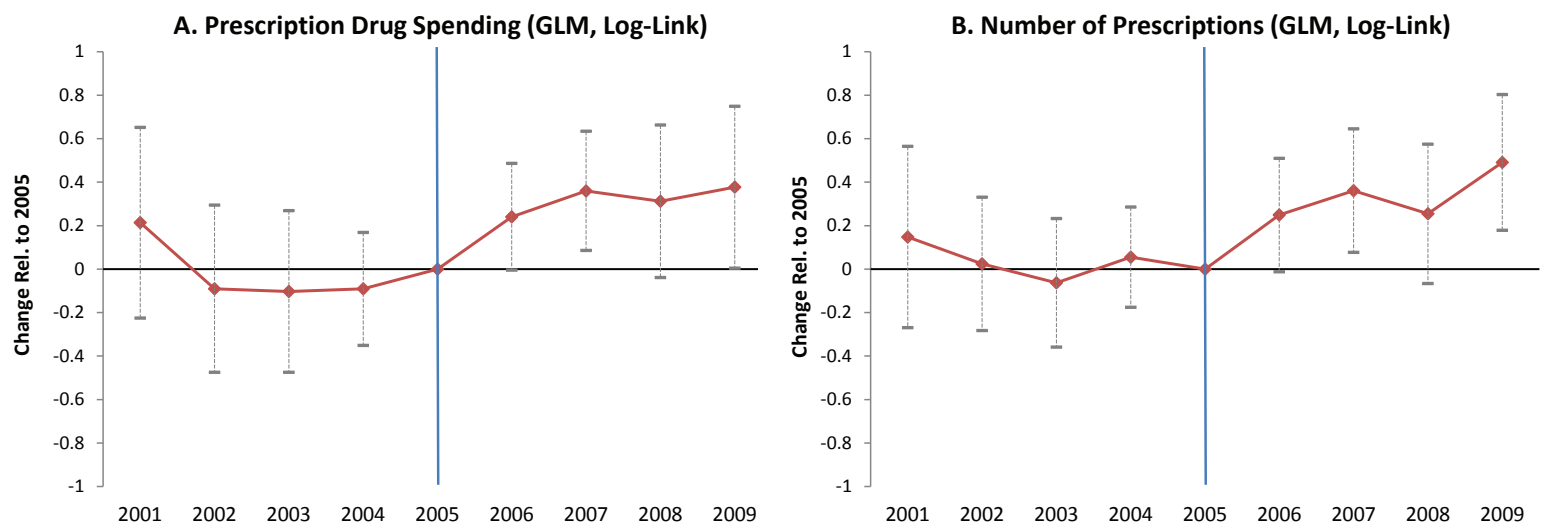

Notes: Panel A shows the coefficients $\tau_{t}$, and their 95 percent confidence intervals, estimated from (2) with prescription drug spending as the dependent variable. Panel B shows the analogous estimates and 95 percent confidence intervals with number of prescriptions as the dependent variable. All estimates taken over the core sample, which includes 169 counties. 
Figure D14: Impact of Part D on Mortality: Detrended Estimates
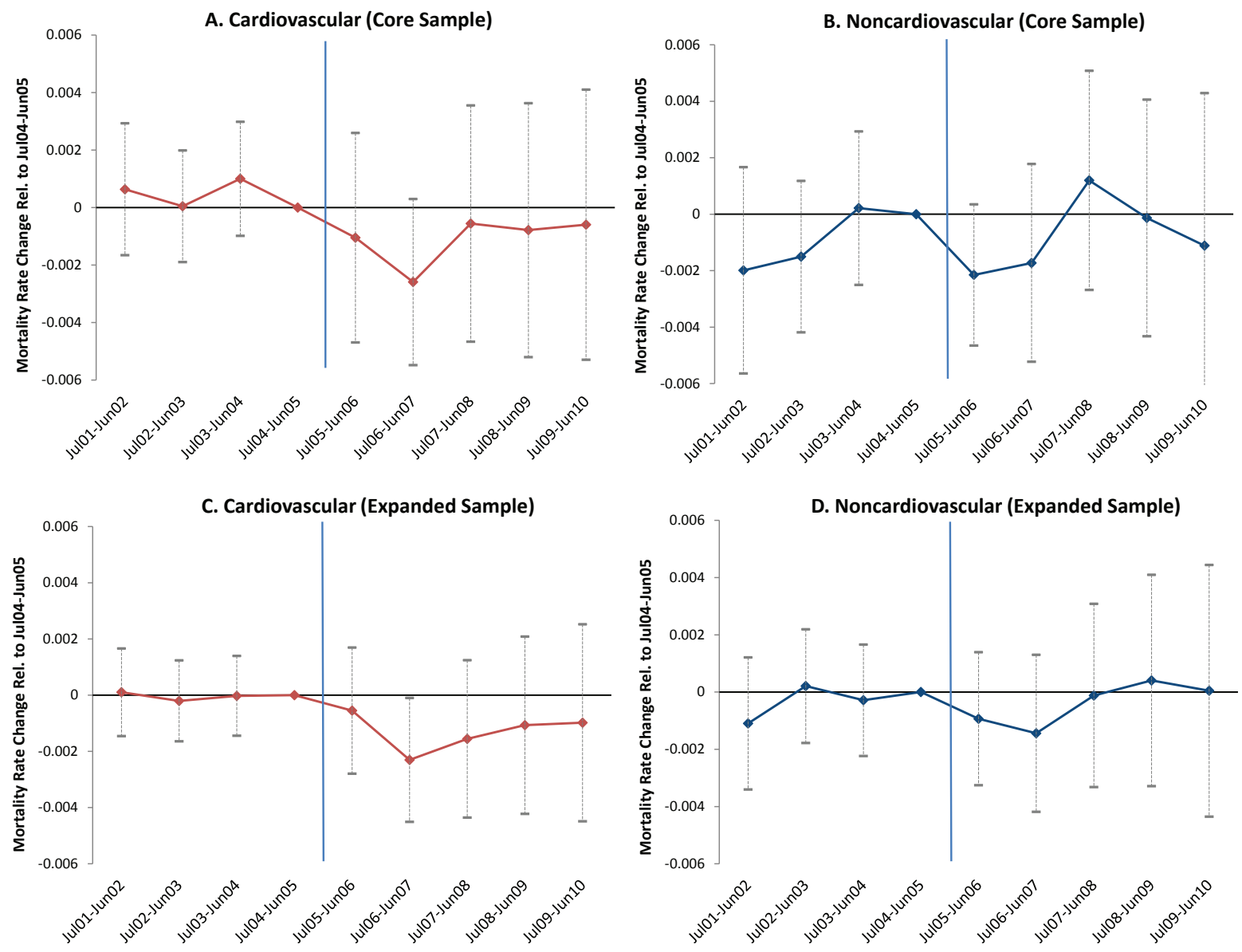

Notes: Graphs show the coefficient $\tau_{d, t}$ from equation (3- the interaction of pre-Part D share of individuals without prescription drug coverage (i.e., $\left.\left(1-S H A R E_{c}^{p r e}\right)\right)$ with year fixed effects-including county-disease trends. The omitted years in the regression is 2004 (that is, July 2004 to June 2005) and 2000 (that is, July 2000 to June 2001), which means the trends were estimated on the pre-reform years. The outcome is the age-sex adjusted mortality rate for the 65 to 84 population. Red diamonds indicate estimates where the outcome is cardiovascular mortality rate, blue squares indicate estimates using the noncardiovascular mortality rate as the dependent variable. Panels A and B show estimates taken over the core sample, which includes 169 counties. Panels B and C show estimates taken over the expanded sample, which includes 530 counties. Dotted lines show 95 percent confidence bands. Vertical line approximately indicates implementation of Part D (January 2006). 
Table D4: Logit Competing-Risks Model: Robustness to Alternative Construction of County-Specific Pre-Reform Insurance Coverage

\begin{tabular}{lcccc}
\hline \hline & $(1)$ & $(2)$ & $(3)$ & $(4)$ \\
\hline \hline (1- CoverageShare)*Cardio*Post & $-0.231^{* * *}$ & $-0.204^{* * *}$ & $-0.241^{* * *}$ & $-0.231^{* * *}$ \\
& $(0.066)$ & $(0.063)$ & $(0.074)$ & $(0.068)$ \\
(1- CoverageShare)*NonCardio*Post & -0.051 & -0.068 & -0.101 & -0.050 \\
& $(0.079)$ & $(0.069)$ & $(0.080)$ & $(0.080)$ \\
\hline \hline Observations & 2028 & 2028 & 2028 & 2028 \\
Probit Used to Construct Shares & Yes & No & Yes & Yes \\
Probit Control Variables & Age, Sex & None & Age, Sex & Age, Sex, \\
& & & & Health, Educ., Race \\
MCBS Pre Years & $2004-2005$ & $2004-2005$ & $2000-2003$ & $2004-2005$
\end{tabular}

Notes: The mortality measure used in the above estimates is based on mortality for the 65 to 84 population. The estimation is taken over the 169 core counties, the sample period is July 2000 to June 2007. The post period is July 2006 to June 2007. The July 2005 to June 2006 period was removed. All regressions include county-disease fixed effects, year-disease fixed effects, county trends, county-specific income trends, and the age distribution of the population and the unemployment rate. "MCBS Pre Years" indicates the years used to calculate $S H A R E_{c}^{\text {pre }}$. "Probit used to construct shares" indicates whether a probit model or simple raw counts of the MCBS data were used to calculate $S H A R E_{c}^{p r e}$. "Probit control variables" indicate the covariates included in the probit regression used to calculate $S H A R E_{c}^{\text {pre }}$ and $S H A R E_{c}^{\text {post }}$. Standard errors clustered by county. ${ }^{*} p<0.10,{ }^{* *} p<0.05,{ }^{* * *} p<0.01$. 
Table D5: Competing-Risks Model, Age 65+: 2000 to 2007

\begin{tabular}{|c|c|c|c|c|c|c|}
\hline & $(1)$ & $(2)$ & $(3)$ & (4) & $(5)$ & (6) \\
\hline \multicolumn{7}{|l|}{ Mortality } \\
\hline \multirow[t]{2}{*}{ (1-CoverageShare)*Post*Cardio } & $-0.129^{* * *}$ & $-0.139 * * *$ & $-0.150 * *$ & $-0.107^{*}$ & $-0.152^{*}$ & -0.070 \\
\hline & $(0.049)$ & $(0.045)$ & $(0.059)$ & $(0.055)$ & $(0.083)$ & $(0.071)$ \\
\hline \multirow[t]{2}{*}{ (1-CoverageShare)*Post*NonCardio } & -0.009 & 0.013 & -0.030 & 0.045 & -0.028 & 0.008 \\
\hline & $(0.049)$ & $(0.039)$ & $(0.071)$ & $(0.051)$ & $(0.066)$ & $(0.053)$ \\
\hline \multicolumn{7}{|l|}{ Mortality (Weighted) } \\
\hline \multirow[t]{2}{*}{ (1-CoverageShare)*Post*Cardio } & $-0.104^{* * *}$ & $-0.122^{* * *}$ & $-0.121^{* * *}$ & $-0.105^{* * *}$ & $-0.097^{*}$ & -0.062 \\
\hline & $(0.033)$ & $(0.030)$ & $(0.036)$ & $(0.035)$ & $(0.050)$ & $(0.045)$ \\
\hline \multirow[t]{2}{*}{ (1-CoverageShare)*Post*NonCardio } & 0.002 & -0.008 & -0.015 & 0.009 & -0.039 & -0.034 \\
\hline & $(0.036)$ & $(0.027)$ & $(0.047)$ & $(0.036)$ & $(0.046)$ & $(0.037)$ \\
\hline \multicolumn{7}{|l|}{ Years of Life Lost } \\
\hline \multirow[t]{2}{*}{ (1-CoverageShare)*Post*Cardio } & $-0.163^{* * *}$ & $-0.127^{* * *}$ & $-0.192^{* * *}$ & $-0.128^{* *}$ & $-0.193^{* *}$ & -0.098 \\
\hline & $(0.047)$ & $(0.046)$ & $(0.058)$ & $(0.054)$ & $(0.084)$ & $(0.070)$ \\
\hline \multirow[t]{2}{*}{ (1-CoverageShare)*Post*NonCardio } & -0.017 & -0.003 & -0.046 & -0.004 & -0.045 & -0.035 \\
\hline & $(0.045)$ & $(0.036)$ & $(0.071)$ & $(0.048)$ & $(0.064)$ & $(0.053)$ \\
\hline \multicolumn{7}{|l|}{ Years of Life Lost (Weighted) } \\
\hline \multirow[t]{2}{*}{ (1-CoverageShare)*Post*Cardio } & $-0.118^{* * *}$ & $-0.114^{* * *}$ & $-0.138 * * *$ & $-0.116^{* * *}$ & $-0.119^{* *}$ & $-0.076^{*}$ \\
\hline & $(0.033)$ & $(0.030)$ & $(0.037)$ & $(0.036)$ & $(0.050)$ & $(0.045)$ \\
\hline \multirow[t]{2}{*}{ (1-CoverageShare)*Post*NonCardio } & 0.003 & -0.013 & -0.017 & -0.016 & -0.035 & -0.056 \\
\hline & $(0.035)$ & $(0.026)$ & $(0.048)$ & $(0.035)$ & $(0.046)$ & $(0.037)$ \\
\hline Observations & 2028 & 6360 & 2028 & 6360 & 2028 & 6360 \\
\hline Sample & Core & Expanded & Core & Expanded & Core & Expanded \\
\hline County Trend & No & No & Yes & Yes & No & No \\
\hline County-Disease Trend & No & No & No & No & Yes & Yes \\
\hline
\end{tabular}

Notes: The mortality share measures used in the above estimates are based on mortality or years-of-life lost for the $65+$ population (i.e., no cutoff at age 84 ). The estimation is taken over the sample period July 2000 to June 2007. The post period is July 2006 to June 2007. The July 2005 to June 2006 period was removed. The core sample includes 169 counties, and the expanded sample includes 530 counties (see map in Figure 6). All regressions include county-disease fixed effects, year-disease fixed effects, the unemployment rate, and county trends. Standard errors clustered by county. ${ }^{*} p<0.10,{ }^{* *} p<0.05$, ${ }^{* * *} p<0.01$. 
Table D6: Competing-Risks Model: 2000 to 2007 (Including July 2005 to June 2006)

\begin{tabular}{|c|c|c|c|c|c|c|}
\hline & (1) & $(2)$ & $(3)$ & (4) & $(5)$ & (6) \\
\hline \multicolumn{7}{|l|}{ Mortality } \\
\hline \multirow[t]{2}{*}{ (1-CoverageShare)*Post*Cardio } & $-0.163^{* *}$ & $-0.115^{* *}$ & $-0.144^{* *}$ & $-0.147 * * *$ & -0.120 & $-0.129 *$ \\
\hline & $(0.067)$ & $(0.051)$ & $(0.073)$ & $(0.056)$ & $(0.086)$ & $(0.068)$ \\
\hline \multirow[t]{2}{*}{ (1-CoverageShare)*Post*NonCardio } & 0.013 & 0.025 & 0.032 & -0.007 & 0.007 & -0.025 \\
\hline & $(0.049)$ & $(0.035)$ & $(0.058)$ & $(0.041)$ & $(0.068)$ & $(0.046)$ \\
\hline \multicolumn{7}{|l|}{ Mortality (Weighted) } \\
\hline \multirow[t]{2}{*}{ (1-CoverageShare)*Post*Cardio } & $-0.104^{* *}$ & $-0.098^{* * *}$ & $-0.096^{* *}$ & $-0.111^{* * *}$ & -0.071 & $-0.086^{*}$ \\
\hline & $(0.042)$ & $(0.034)$ & $(0.048)$ & $(0.038)$ & $(0.056)$ & $(0.045)$ \\
\hline \multirow[t]{2}{*}{ (1-CoverageShare)*Post*NonCardio } & 0.014 & 0.006 & 0.022 & -0.007 & -0.004 & -0.032 \\
\hline & $(0.037)$ & $(0.026)$ & $(0.043)$ & $(0.031)$ & $(0.045)$ & $(0.033)$ \\
\hline \multicolumn{7}{|l|}{ Years of Life Lost } \\
\hline \multirow[t]{2}{*}{ (1-CoverageShare) ${ }^{*}$ Post* Cardio } & $-0.194^{* *}$ & $-0.114^{* *}$ & $-0.164^{*}$ & $-0.142^{* *}$ & -0.141 & $-0.127^{*}$ \\
\hline & $(0.075)$ & $(0.055)$ & $(0.085)$ & $(0.060)$ & $(0.097)$ & $(0.072)$ \\
\hline \multirow[t]{2}{*}{ (1-CoverageShare) ${ }^{*}$ Post*NonCardio } & 0.007 & 0.012 & 0.037 & -0.016 & 0.015 & -0.030 \\
\hline & $(0.043)$ & $(0.035)$ & $(0.053)$ & $(0.041)$ & $(0.060)$ & $(0.046)$ \\
\hline \multicolumn{7}{|l|}{ Years of Life Lost (Weighted) } \\
\hline \multirow[t]{2}{*}{ (1-CoverageShare) ${ }^{*}$ Post* Cardio } & $-0.119^{* *}$ & $-0.093^{* *}$ & $-0.103^{*}$ & $-0.100^{* *}$ & -0.080 & -0.075 \\
\hline & $(0.046)$ & $(0.036)$ & $(0.052)$ & $(0.041)$ & $(0.062)$ & $(0.047)$ \\
\hline \multirow[t]{2}{*}{ (1-CoverageShare)*Post*NonCardio } & 0.014 & 0.001 & 0.030 & -0.005 & 0.007 & -0.030 \\
\hline & $(0.035)$ & $(0.026)$ & $(0.043)$ & $(0.032)$ & $(0.041)$ & $(0.033)$ \\
\hline Observations & 2028 & 6360 & 2028 & 6360 & 2028 & 6360 \\
\hline Sample & Core & Expanded & Core & Expanded & Core & Expanded \\
\hline County Trend & No & No & Yes & Yes & No & No \\
\hline County-Disease Trend & No & No & No & No & Yes & Yes \\
\hline
\end{tabular}

Notes: The mortality share measures used in the above estimates are based on mortality or years-of-life lost for the $65+$ population (i.e., no cutoff at age 84 ). The estimation is taken over the sample period July 2000 to June 2007. The post period is July 2006 to June 2007. The core sample includes 169 counties, and the expanded sample includes 530 counties. All regressions include county-disease fixed effects, yeardisease fixed effects, the unemployment rate, and county trends. Standard errors clustered by county. ${ }^{*} p<0.10,{ }^{* *} p<0.05,{ }^{* * *} p<0.01$. 
Table D7: Competing-Risks Model Incorporating Dynamic Effects (Years-of-Life Lost)

\begin{tabular}{|c|c|c|c|c|}
\hline & $(1)$ & $(2)$ & $(3)$ & $(4)$ \\
\hline \multirow[t]{2}{*}{ 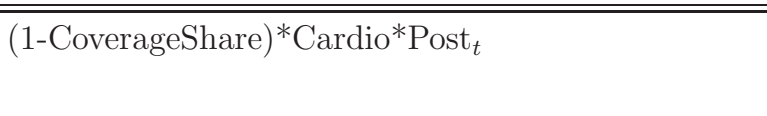 } & 0.029 & -0.022 & $-0.250^{* * *}$ & $-0.112^{*}$ \\
\hline & $(0.051)$ & $(0.044)$ & $(0.066)$ & $(0.061)$ \\
\hline \multirow[t]{2}{*}{ (1-CoverageShare)*NonCardio* Post $_{t}$} & $0.069^{* *}$ & $0.076^{* * *}$ & -0.019 & 0.000 \\
\hline & $(0.033)$ & $(0.027)$ & $(0.046)$ & $(0.035)$ \\
\hline \multirow[t]{2}{*}{$(1$-CoverageShare $) *$ Cardio $^{*}$ Post $_{t-1} * \delta_{\text {cardio }, t-1}$} & & & $-0.048^{* * *}$ & $-0.022^{*}$ \\
\hline & & & $(0.015)$ & $(0.012)$ \\
\hline \multirow[t]{2}{*}{$(1-$ CoverageShare $) *{ }^{*}$ NonCardio ${ }^{*}$ Post $_{t-1} * \delta_{\text {noncardio }, t-1}$} & & & $-0.025^{* *}$ & $-0.026^{* * *}$ \\
\hline & & & $(0.011)$ & $(0.010)$ \\
\hline \multirow[t]{2}{*}{ Cardio $^{*}$ Post $_{t-1} * \delta_{\text {cardio }, t-1}$} & & & 0.014 & $0.037^{*}$ \\
\hline & & & $(0.035)$ & $(0.020)$ \\
\hline \multirow[t]{2}{*}{ NonCardio $^{*}$ Post $_{t-1} * \delta_{\text {noncardio }, t-1}$} & & & 0.028 & 0.019 \\
\hline & & & $(0.035)$ & $(0.023)$ \\
\hline \multirow[t]{2}{*}{$(1$-CoverageShare $) *$ Cardio $* \delta_{\text {cardio }, t-1}$} & & & $-0.493^{* * *}$ & -0.051 \\
\hline & & & $(0.149)$ & $(0.179)$ \\
\hline \multirow[t]{2}{*}{ (1-CoverageShare) $)^{*}$ NonCardio* $\delta_{\text {noncardio }, t-1}$} & & & -0.296 & -0.061 \\
\hline & & & $(0.264)$ & $(0.199)$ \\
\hline \multirow[t]{2}{*}{ Cardio* $\delta_{\text {cardio }, t-1}$} & & & $0.116^{*}$ & 0.003 \\
\hline & & & $(0.070)$ & $(0.073)$ \\
\hline \multirow[t]{2}{*}{ NonCardio $* \delta_{\text {noncardio }, t-1}$} & & & -0.023 & -0.035 \\
\hline & & & $(0.120)$ & $(0.079)$ \\
\hline Observations & 3042 & 9540 & 3042 & 9540 \\
\hline Sample & Core & Expanded & Core & Expanded \\
\hline
\end{tabular}

Notes: The share measures used in the above estimates are based on years-of-life lost for the 65 to 84 population. The estimation is taken over the sample period 2000 to 2009, the post period, Post $_{t}$ is 20062009 (that is, July 2006 to June 2010). The core sample includes 169 counties, and the expanded sample includes 530 counties. All regressions include county-disease fixed effects, year-disease fixed effects and the unemployment rate. Standard errors clustered by county. ${ }^{*} p<0.10,{ }^{* *} p<0.05,{ }^{* * *} p<0.01$. 
Table D8: Logit Competing-Risks Model with Dynamic Considerations (Weighted Regressions)

\begin{tabular}{|c|c|c|c|c|}
\hline & $(1)$ & $(2)$ & $(3)$ & $(4)$ \\
\hline \multirow[t]{2}{*}{ (1-CoverageShare) ${ }^{*}$ Cardio $^{*}$ Post $_{t}$} & 0.041 & -0.008 & $-0.160^{* * *}$ & $-0.109^{* * *}$ \\
\hline & $(0.034)$ & $(0.029)$ & $(0.043)$ & $(0.039)$ \\
\hline \multirow[t]{2}{*}{ (1-CoverageShare) ${ }^{*}$ NonCardio* $^{*}$ Post $_{t}$} & $0.073^{* *}$ & $0.063^{* * *}$ & -0.005 & -0.004 \\
\hline & $(0.032)$ & $(0.023)$ & $(0.039)$ & $(0.027)$ \\
\hline \multirow[t]{2}{*}{$(1$-CoverageShare $) *$ Cardio $^{*}$ Post $_{t-1} * \delta_{\text {cardio }, t-1}$} & & & $-0.028^{* * *}$ & $-0.019^{* *}$ \\
\hline & & & $(0.011)$ & $(0.008)$ \\
\hline \multirow[t]{2}{*}{$(1$-CoverageShare $) *$ NonCardio $*$ Post $_{t-1} * \delta_{\text {noncardio }, t-1}$} & & & $-0.018^{* *}$ & $-0.020^{* * *}$ \\
\hline & & & $(0.008)$ & $(0.006)$ \\
\hline \multirow[t]{2}{*}{ Cardio $^{*}$ Post $_{t-1} * \delta_{\text {cardio }, t-1}$} & & & $0.047^{*}$ & $0.052^{* * *}$ \\
\hline & & & $(0.025)$ & $(0.016)$ \\
\hline \multirow[t]{2}{*}{ NonCardio $*$ Post $_{t-1} * \delta_{\text {noncardio }, t-1}$} & & & 0.017 & $0.026^{*}$ \\
\hline & & & $(0.019)$ & $(0.014)$ \\
\hline \multirow[t]{2}{*}{$(1$-CoverageShare $) *$ Cardio $* \delta_{\text {cardio }, t-1}$} & & & $-0.442^{* * *}$ & -0.150 \\
\hline & & & $(0.153)$ & $(0.132)$ \\
\hline \multirow[t]{2}{*}{$(1-\text { CoverageShare })^{*}$ NonCardio $* \delta_{\text {noncardio }, t-1}$} & & & $-0.547 * *$ & -0.159 \\
\hline & & & $(0.223)$ & $(0.165)$ \\
\hline \multirow[t]{2}{*}{$\operatorname{Cardio}^{*} \delta_{\text {cardio }, t-1}$} & & & $0.130 * *$ & 0.051 \\
\hline & & & $(0.060)$ & $(0.051)$ \\
\hline \multirow[t]{2}{*}{ NonCardio $* \delta_{\text {noncardio }, t-1}$} & & & 0.142 & 0.027 \\
\hline & & & $(0.089)$ & $(0.061)$ \\
\hline Observations & 3042 & 9540 & 3042 & 9540 \\
\hline Sample & Core & Expanded & Core & Expanded \\
\hline
\end{tabular}

Notes: The share measures used in the above estimates are based on mortality for the 65 to 84 population. All regressions are weighted by the square root of the year $200065+$ population. The estimation is taken over the sample period 2001 to 2009, although includes lags from the year 2000. The post period is July 2006 to June 2010. The core sample includes 169 counties, and the expanded sample includes 530 counties. All regressions include county-disease fixed effects, year-disease fixed effects and the unemployment rate. Standard errors clustered by county. ${ }^{*} p<0.10,{ }^{* *} p<0.05,{ }^{* * *} p<0.01$. 